
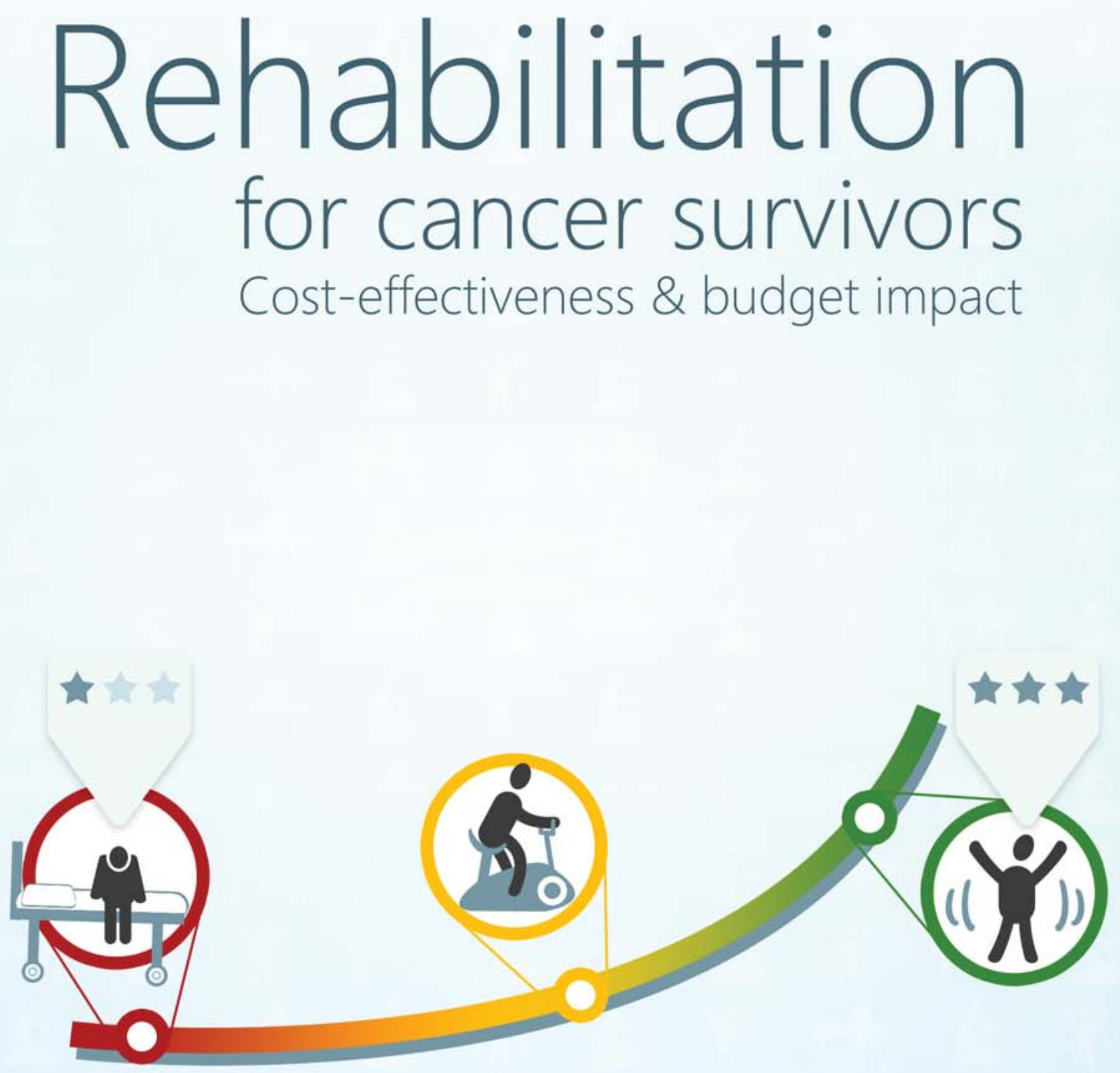

Janne Charlotte Mewes 


\title{
Rehabilitation for cancer survivors Cost-effectiveness and budget impact
}

\author{
Janne Charlotte Mewes
}


Cover design: Sietse Visser, zietze.nl

Printed by: Gildeprint

This thesis is part of the Health Sciences Series of the department Health Technology and Services Research, University of Twente, Enschede, the Netherlands: HSS 16-010. ISSN: 1878-4968 


\title{
REHABILITATION FOR CANCER SURVIVORS
}

\author{
COST-EFFECTIVENESS AND BUDGET IMPACT
}

\section{DISSERTATION}

to obtain

the degree of doctor at the University of Twente, on the authority of the rector magnificus,

Prof. dr. H. Brinksma,

on account of the decision of the graduation committee, to be publicly defended

on Friday 26 February 2016 at 14.45

by

Janne Charlotte Mewes 
This dissertation has been approved by:

Prof. Dr. W.H. van Harten (supervisor)

Prof Dr. M.J. IJzerman (2 ${ }^{\text {nd }}$ supervisor)

Dr. L.M.G. Steuten (co-supervisor)

ISBN: 978-90-365-4028-5

(c) Copyright 2016: Janne Charlotte Mewes, Kiel, Germany

All rights reserved. No parts of this publication may be reproduced, stored in a retrieval system of any nature, or transmitted in any form or by any means, electronic, mechanical, photocopying, recording or otherwise, without written permission by the holder of the copyright. 


\section{Graduation committee:}

Chairman/secretary:

Prof. Dr. T.A.J. Toonen, University of Twente

Supervisors:

Prof. Dr. W.H. van Harten, University of Twente

Prof Dr. M.J. IJzerman, University of Twente

Co-supervisor:

Dr. L.M.G. Steuten, Fred Hutchinson Cancer Research Center and University of Washington

Members:

Prof. Dr. M.M.R. Vollenbroek-Hutten, University of Twente

Prof. Dr. S. Siesling, University of Twente

Dr. N.P.B. Ottevanger, Radboud UMC

Dr. S. Oksbjerg-Dalton, Danish Cancer Society Research Center 


\section{Table of Contents}

$\begin{array}{lll}\text { Chapter } 1 & \text { Introduction } & 9\end{array}$

Chapter 2 Effectiveness of multidimensional cancer survivor rehabilitation 23 and cost-effectiveness of cancer rehabilitation in general: a systematic review

Chapter 3 Cost-effectiveness of cognitive behavioral therapy and physical exercise for alleviating treatment-induced menopausal symptoms in breast cancer patients

Chapter 4 A systematic approach for assessing, in the absence of full evidence, whether multicomponent interventions - "doing more" - can be more cost-effective than single component interventions

Chapter 5 Return-to-work intervention for cancer survivors: budget impact and allocation of costs and returns in the Netherlands and in six major EU-countries

Chapter $6 \quad$ Value of implementation analysis of strategies to increase the adherence of health professionals and patients to (the guidelines for) physical exercise for cancer survivors

Chapter 7 Discussion

Chapter 8 Summary 161

Chapter 9 Samenvatting 



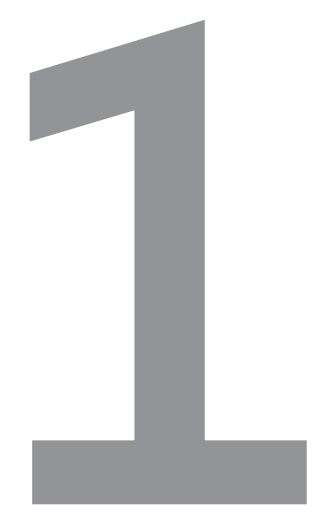

Introduction 



\section{Introduction}

The number of people who are diagnosed with cancer is increasing. In the Netherlands, 57,000 people were diagnosed in 1990. In 2013, this was 102,000', and the projected incidence for 2020 is $123,000^{2}$. During the last decades, the treatment methods for cancer improved and screening was intensified. Tumours are detected in an earlier stage in which the treatment more often is successful ${ }^{3}$. Therefore, more people have a survival of at least five years, which is seen as the critical period after which it can be said that someone is cured ${ }^{4}$. While in the Netherlands the overall 5 -year survival rate was 47\% in the period of 1989 to 1993, it rose to 62\% in the period from 2008 to $2012^{5}$.

Caused by these developments, the number of people within the population who have survived cancer is growing. Who exactly is considered a cancer survivor depends on the definition that is used ${ }^{6-9}$. Broad definitions include anyone who has ever been diagnosed with cancer. Other definitions include family and friends who are affected indirectly by the disease as well 6 . Throughout this thesis, cancer survivors are defined as people diagnosed with cancer who have finished primary treatment with a curative intent. This excludes patients who are undergoing primary or palliative treatment. Statistics on the number of cancer survivors contain all people within the population who have ever had a cancer diagnosis and are still alive and thus do not reflect the exact definition that was used here. In the Netherlands, the number of cancer survivors according to this definition was 366,000 in the year 2000. It was expected to rise to 690,000 in 2015 and thus more than doubled ${ }^{10}$. The same development is observed in other industrialised countries $^{11,12}$. In the United Stated (US), the group of cancer survivors comprised $13.8 \mathrm{~m}$ people in $2013^{13}$.

About 35 years ago, research into the phase of cancer survivorship commenced as it became clear that most survivors experience late and long-term symptoms ${ }^{14}$. It was first recognized what symptoms and problems may occur after treatment and later how prevalent they are. This led to further research on optimal care and rehabilitation after cancer $^{9,15-18}$. The symptoms that survivors experience are caused by the disease itself, as well as by the treatment ${ }^{15}$. These can be divided into general and cancer type- or treatment-specific symptoms. Those that are applicable to all survivors include fatigue, sleep disturbance, depressive symptoms, anxiety, cognitive limitations, pain, functional limitations, and sexual dysfunction ${ }^{17}$. Examples of cancer-type specific symptoms of breast cancer include numbness in the chest; tightness, pulling, or stretching in the axilla or chest; hot flashes and night sweats; lymphedema; premature menopause; sexual 
problems; weight gain; and osteoporosis. For prostate cancer the most common are sexual, bladder, and bowel dysfunction, and osteoporosis; and for colorectal cancer bowel dysfunction ${ }^{15}$. Depending on the subgroup of patients and the study, the percentage of cancer survivors who suffer from at least one symptom ranges up to 100 per cent ${ }^{15,19,20}$ and people may suffer from 5 to 11 symptoms at a time ${ }^{19,21}$. These symptoms often lead to problems in performing tasks in daily life, in the relationship with family and friends, and in resuming work ${ }^{15}$. Depending on the social system of the respective country, problems in returning to work and paying privately for health care can lead to financial hardship and in many cases to private bankruptcy ${ }^{22-24}$. Moreover, cancer survivors have an increased risk for getting a new form of cancer and for chronic diseases in general, such as cardiovascular disease ${ }^{16}$. Considering the number of cancer survivors and its growth, this is a serious public health problem. It creates a huge symptom burden, prevents cancer survivors from returning to their daily life and workplace, and results in high societal costs. It is therefore essential that suitable rehabilitation is provided in order to alleviate these symptoms.

\section{Cancer rehabilitation}

According to the definition of the World Health Organization, rehabilitation for people with disabilities is "a process aimed at enabling [people with disabilities] to reach and maintain their optimal physical, sensory, intellectual, psychological and social functioning levels" ${ }^{25}$. Rehabilitation of cancer survivors is specifically developed for impairments resulting from cancer. The most effective intervention for which the largest evidence base exists is physical exercise ${ }^{26}$. It is effective for alleviating fatigue, improving physical fitness, reducing depression, and many other symptoms, and further increases healthrelated quality of life ${ }^{26-31}$. In addition, it reduces the risk of cancer in general and may also lead to a lower risk for recurrences ${ }^{32}$. As exercising is very challenging for most cancer survivors, an intervention specifically designed for cancer survivors is recommended. Cognitive behavioural therapy and psycho-education can be provided for alleviating, among others, fatigue, depression, and anxiety ${ }^{33}$. Return-to-work interventions are designed to support cancer survivors in returning to the workplace, which often is a difficult process, and mostly consist of counselling with an occupational physician $^{34}$. Many other forms of interventions are evaluated in the literature as well, such as mindfulness-based stress reduction, music interventions, tai chi, or yoga ${ }^{35}$.

Health care for cancer survivors in general consists of survivorship, follow-up, and supportive care. Survivorship care is a term for all care that takes place after active treatment and should include follow-up care, health promotion, prevention of new and 
secondary cancers, and management of late and long-term symptoms. However, it is unknown for how long follow-up of survivors should last and which care provider should be responsible ${ }^{3}$. What also strongly is recommended is a survivorship care plan (SCP). This plan details the treatment that the patient received, the symptoms that may occur in the long-run, what patients can do themselves for prevention, and how the follow-up care should be structured. Follow-up care consists of regular consultations in order to detect recurrence of the disease. It is the current standard and is provided to almost all cancer survivors ${ }^{36}$. Supportive care provides help for the physical, informational, emotional, psychological, social, spiritual, and practical needs that arise in the phases when people have cancer and beyond ${ }^{37}$.

The major limitation in the evidence base on cancer rehabilitation is that the mechanisms of cancer rehabilitation interventions are not well understood. It therefore remains unknown which interventions are most effective for particular cancer survivor subgroups $^{38}$. Moreover, the generalisability of study results in many cases is limited as the patient samples often are not representative for the general group of cancer survivors since they mostly include women with breast cancer ${ }^{39}$. In addition, hardly any evidence exists on the long-term outcomes of cancer rehabilitation ${ }^{18,40,41}$. Shortcomings in the provision of cancer rehabilitation in practice are that it is not always clear which care provider is responsible and what type of rehabilitation should be provided ${ }^{38}$. The interventions that have been implemented to date often treat single symptoms, such as lymphedema, while a comprehensive assessment of symptoms and patient needs leading to a tailored rehabilitation programme is missing ${ }^{42}$.

During the last years, guidelines on the rehabilitation of cancer survivors were published in many countries ${ }^{38}$. In the Netherlands, this was done by the Netherlands Comprehensive Cancer Organisation in 2011. Its guideline recommends that the rehabilitation need of all cancer survivors should be assessed and, if needed, be referred to a tailored rehabilitation programme. The general recommendation is that the importance of exercise is discussed with every patient and that all cancer survivors conduct at least moderate-intensity exercise. Further, cognitive behavioural therapy is recommended for survivors who are still fatigued one year after finishing curative treatment. Attention should be paid to the process of returning to work and to participating in society ${ }^{10}$.

Cancer rehabilitation is implemented to varying degrees in most European countries and in North America. Many countries introduced initiatives and plans to further implement and qualitatively improve survivorship care ${ }^{43}$. Reasons for why access to cancer rehabilitation is limited include that not all oncologists are yet aware of the 
possibilities that exist and that the capacities for providing interventions are insufficient, which might partly be caused by the lack of reimbursement ${ }^{43-49}$.

In the Netherlands, cancer rehabilitation started with a programme called "Herstel en Balans" (Recovery and Stability) which was introduced almost twenty years ago, but will now cease to exist as general cancer rehabilitation is being offered more widely. This 12week programme consists of physical exercise combined with psycho-education and is offered by most cancer centres ${ }^{43}$. It has not been covered by basic health insurance due to its limited evidence of effectiveness and because exercising and fitness were considered someone's individual responsibility ${ }^{50}$. It needed to be paid out-of-pocket or by a premium health insurance plan ${ }^{51}$. Rehabilitation in the Netherlands is reimbursed by health insurers when a multidisciplinary rehabilitation need is indicated. Thus, monodisciplinary interventions, interventions that have a preventive character, and "prehabilitation" that aims at improving physical functioning before surgery ${ }^{52}$ are not reimbursed. When hospitals still choose to offer these they have to cover the costs from the general hospital budget. In Germany, cancer rehabilitation typically is reimbursed. It is mostly offered as inpatient care and would need to be provided as outpatient treatment as well to increase flexibility ${ }^{53}$. In other countries such as Italy, however, cancer rehabilitation is hardly implemented yet ${ }^{47}$. In the US it is available, but highly fragmented and reimbursement is very much dependent on the individual insurance scheme ${ }^{24,42}$.

\section{Health care costs}

Implementing cancer rehabilitation more widely would lead to additional costs to the health system. As in most countries health budgets are under pressure health insurances are hesitant to reimburse cancer rehabilitation.

The Netherlands had the highest EU-percentage of GDP-spending on health care in 2012 with 11.8\%, and total spending increased from 41bn in 2000 to €85bn in $2013^{54,55}$. The fast growth in the costs has been one of the major policy issues in the Netherlands during the last years ${ }^{55}$. The US is the only country that spends a larger share of their GDP on health care than the Netherlands; about 20\%. If current trends continue this would be half of the US economy in a couple of decades ${ }^{56}$. Internationally, the development in cancer care spending is seen as problematic. The part of the health budget spent on cancer was 4.1\% in Europe, 5.3\% in the Netherlands in 2011, and 5\% in the US in $2010^{57,58}$. It is estimated that this will further increase in the coming years ${ }^{13}$. This development is caused by the increasing number of cancer patients, increasing prices especially for cancer drugs, innovations coming to the market that are more expensive than existing care, an increased use of screening, overutilization, and 
consumer demand ${ }^{57,59}$. As these developments are very concerning, any addition to the current care for cancer is critically evaluated.

In the Netherlands, interventions that are added to the benefit basket need to be necessary, effective, cost-effective, and affordable. As a weighing of the criteria takes place, these do not function as strict exclusion criteria. For analysing whether a health service is cost-effective, a cost-utility evaluation is the base-case approach, comparing the additional cost of an intervention to the incremental health benefits, being measured as quality-adjusted life years (QALYS). The outcome measure of the analysis is the incremental cost-effectiveness ratio (ICER) which expresses the incremental costs of the intervention for achieving one additional unit of effectiveness ${ }^{60}$. The adoption decision depends on the amount someone is willing to pay for the additional effectiveness (called the willingness-to-pay threshold, or ceiling ratio). An intervention is considered cost-effective, when its ICER falls below that threshold ${ }^{61}$. Still, cost-effective interventions can be so expensive that the available budget would not be sufficient to cover the costs, hence a budget impact analysis can be conducted that evaluates the affordability. This is done by comparing the total cost of illness in the current situation to that of the future situation when the new intervention is in use ${ }^{62}$.

These cost-effectiveness analyses can be conducted from different perspectives, as, depending on the stakeholder, different effects and costs are considered relevant. Recommended for health economic evaluations is the societal perspective, in which all costs and effects that are caused by an intervention are included in the analysis ${ }^{60}$. For budget impact analyses the perspective of the budget holder is recommended ${ }^{62}$.

\section{Cost-effectiveness of cancer rehabilitation}

At the start of this research project, the evidence base on cost-effectiveness of cancer rehabilitation was very limited. One review was available that summarized the findings on the cost-effectiveness of five psychosocial interventions for anxiety and depression ${ }^{63}$. It was found that the interventions were not very costly. The evidence on the costeffectiveness of the intervention was incomplete, as only three studies provided ICERs and were inconclusive, as the comparators varied between studies. Those costeffectiveness analyses that presented an ICER found that the interventions were more effective at higher costs and that these were within a reasonable range ${ }^{63}$. Evidence that decision-makers and health care providers require for taking well-informed decisions was thus hardly available ${ }^{64}$.

Several gaps can be identified in this evidence base. First, very little is known about the cost-effectiveness of rehabilitation for cancer survivors. In addition, many rehabilitation 
interventions have not been evaluated on cost-effectiveness. Moreover, it cannot be concluded whether cancer rehabilitation in general might be cost-effective. As this is one of the criteria in the decision of which type of rehabilitation interventions should be reimbursed, more evidence is needed to take a well-considered decision. This is especially important since the share of health care costs spent on cancer is growing very fast and therefore decision-makers might be very hesitant to decide to reimburse an additional type of care for cancer survivors.

Second, evidence on the affordability of cancer rehabilitation is unavailable. The expectation is that it may be rather unaffordable, since the number of cancer survivors is huge and rising. Assuming average rehabilitation costs of €200 per patient and using the cancer incidence of 102,000 in 2013, this would result in a budget impact of $€ 20.4 \mathrm{~m}$ in the Netherlands. The projected incidence for 2020 is 123,000 which would lead to costs of $€ 24 \mathrm{~m}$. For 2013, this would have represented $2.6 \%$ of the total health care spending of $€ 94.2 \mathrm{bn}$ in the Netherlands ${ }^{65}$. The considerations are thus legitimate. However, this calculation omits the possible financial benefits that might result from offering rehabilitation, such as may accrue from earlier return-to-work or higher productivity at work. Next to that, it is unknown what the average costs for rehabilitation are per cancer survivor, as a large variety of interventions exits.

Third, the standard methods in health economics are not sufficient for solving a specific decision problem in cancer rehabilitation. For many symptoms, such as fatigue, interventions consisting of several components, e.g. exercise and cognitive-behavioural therapy were developed. Often, the single or the multicomponent programme can be prescribed, but it is unknown if the multicomponent programme adds sufficient effectiveness to justify the additional resources that are required. However, when the effectiveness of the multicomponent programme is unknown, its cost-effectiveness cannot be compared to that of the single component with current methods, as for these data on the effectiveness of all interventions is required.

\section{This thesis}

The objective of this research is to increase the evidence base regarding the costeffectiveness of cancer rehabilitation and the budget impact of implementing cancer rehabilitation interventions more widely. Moreover, it aims to advance the methodology on pragmatically assessing the potential cost-effectiveness of multicomponent interventions in cases where full data on costs and effects are unavailable. Each chapter contributes towards reaching these goals. 
Chapter two contains a systematic literature review of the evidence base of the costeffectiveness of cancer rehabilitation interventions and of the effectiveness of multicomponent cancer rehabilitation interventions. Chapter three evaluates the costeffectiveness of cognitive behavioural therapy and physical exercise for breast cancer patients who suffer from treatment-induced menopausal symptoms. In chapter four, an approach was developed that allows estimating if a multicomponent intervention is more cost-effective than a single intervention in the absence of full evidence on its costs and effect. In chapter five, a budget impact analysis is presented of a multidisciplinary return-to-work intervention. This chapter also analyses in what way the allocation of the costs and benefits across the involved stakeholders that the intervention generates does incentivize to offer return-to-work interventions for cancer patients in a number of European countries. In chapter six, several implementation strategies for increasing adherence to (the guideline on) physical exercise were evaluated on their net benefit through a value of implementation analysis, as the adherence of professionals to the guideline advice and of patients to the prescribed intervention is low. In chapter seven the findings of this thesis are discussed and recommendations for policy and practice are given. Finally, this thesis' summary can be found, as well as a summary in Dutch.

The research of this thesis was conducted as part of the "Alpe d'HuZes Cancer Rehabilitation Research Programme" (A-CaRe), which started in 2009. The aim of ACaRe is to develop, implement, and evaluate cancer rehabilitation interventions. The first part of the project consists of clinical research into the effectiveness of exercise interventions in four clinical trials. The second part, A-CaRe 2 Move, is directed towards patient empowerment through ICT, a multidisciplinary return-to-work intervention, rehabilitation that can be conducted at home, and the implementation of cancer rehabilitation. The research presented in this thesis evaluates the cost-effectiveness and budget impact of (a part) of the A-CaRe 2 Move projects. 


\section{References}

1. The Netherlands Comprehensive Cancer Organisation. Incidence. 2015. cijfersoverkanker.nl (accessed 3 July 2015).

2. Signaleringscommissie Kanker van KWF Kankerbestrijding. Kanker in Nederland tot 2020 - trends en prognoses. Amsterdam: Dutch Cancer Society, 2011.

3. McCabe MS, Bhatia S, Oeffinger KC, et al. American Society of Clinical Oncology Statement: achieving high-quality cancer survivorship care. Journal of Clinical Oncology 2013; 31(5): 631-40.

4. Siesling $S$, Visser $O$, Luth $T$, et al. Volwassen kankerpatiënten overleven langer in Nederland. Nederlands Tijdschrift voor Geneeskunde 2011; 155: A3169.

5. The Netherlands Comprehensive Cancer Organisation. 5-year survival. 2015. cijfersoverkanker.nl (accessed 2 July 2015).

6. Feuerstein M. Defining cancer survivorship. Journal of Cancer Survivorship 2007; 1 : $5-7$.

7. Khan N, Rose P, Evans J. Defining cancer survivorship: a more transparent approach is needed. Journal of Cancer Survivorship 2012; 6(1): 33-6.

8. Jagielski C, Hawley S, Corbin K, Weiss M, Griggs J. A phoenix rising: Who considers herself a "survivor" after a diagnosis of breast cancer? Journal of Cancer Survivorship 2012.

9. Doyle N. Cancer survivorship: evalutionary concept analysis. Journal of Advanced Nursing 2008; 62(4): 499-509.

10. The Netherlands Comprehensive Cancer Organisation. Cancer rehabilitation nation-wide guideline. Utrecht: IKNL, 2011.

11. DeSantis $C E$, Lin CC, Mariotto $A B$, et al. Cancer treatment and survivorship statistics, 2014. CA: A Cancer Journal for Clinicians 2014; 64(4): 252-71.

12. Macmillan Cancer Support. The rich picutre - people with cancer London: Macmillan Cancer Support, 2015.

13. Mariotto AB, Yabroff $K$, Shao Y, Feuer E, Brown M. Projections of the costs of cancer care in the United States: 2010-2020. Journal of the National Cancer Institute 2011; 103: 117-28.

14. Ugolini D, Neri M, Cesario A, et al. Scientific production in cancer rehabilitation grows higher: a bibliometric analysis. Supportive Care in Cancer 2011; 20(8): 169238.

15. Hewitt M, Greenfield S, Stovall EE. From cancer patient to cancer survivor: Iost in transition. Washington, DC: The National Academies Press; 2005. 
16. Feuerstein M, editor. Handbook of cancer survivorship. New York: Springer; 2007.

17. Feuerstein M, Todd BL, Moskowitz M, Hansen JA, Harrington CB. It's not over when it's over: long-term symptoms in cancer survivors: a systematic review. The International Journal of Psychiatry in Medicine 2010; 40(2): 163-81.

18. Richardson A, Addington-Hall J, Amir Z, et al. Knowledge, ignorance, and priorities for research in key areas of cancer survivorship: findings from a scoping review. British Journal of Cancer 2011; 105: S82-S94.

19. Cheng KKF, Thompson DR, Ling WM, Chan CWH. Measuring symptom prevalence, severity and distress of cancer survivors. Clinical Effectiveness in Nursing 2005; 9(3-4): 154-60.

20. Mao JJ, Armstrong K, Bowman MA, Xie SX, Kadakia R, Farrar JT. Symptom burden among cancer survivors: impact of age and comorbidity. The Journal of the American Board of Family Medicine 2007; 20(5): 434-43.

21. Schmitz KH, Speck RM, Rye S, DiSipio T, Hayes S. Prevalence of breast cancer sequelae over 6 years of follow-up. The pulling through study. Cancer 2012; 118(8 Suppl): 2217-25.

22. Bradley CJ. Financial hardship: A consequence of survivorship? Journal of Clinical Oncology 2012; 30(14): 1579-80.

23. Jagsi R, Pottow J, Griffith K, et al. Long-term financial burden of breast cancer: experiences of a large cohort of survivors identified through population-based registries. Journal of Clinical Oncology 2014; 32(12): 1269-76.

24. Schmitz KH, DiSipio T, Gordon LG, Hayes SC. Adverse breast cancer treatment effects: the economic case for making rehabilitative programs standard of care. Supportive Care in Cancer 2015; 23(6): 1807-17.

25. World Health Organization. Rehabilitation. 2015. who.int/topics/rehabilitation/en/ (accessed August 4 2015).

26. Schmitz KH, Courneya KS, Matthews C, et al. American College of Sports Medicine roundtable on exercise guidelines for cancer survivors. Medicine \& Science in Sports \& Exercise 2010; 42(7): 1409-26.

27. Hayes S, Spence R, Galvao D, Newton R. Australian Association for Exercise and Sport Science position stand: optimising cancer outcomes through exercise. Journal of Science and Medicine in Sport 2009; 12: 428-32.

28. Brown J, Huedo-Medina T, Pescatello $L$, et al. The efficacy of exercise in reducing depressive symptoms among cancer survivors: a meta-analysis. Plos One 2012; 7(1): $1-9$. 
29. Mishra S, Scherer R, Geigle P, et al. Exercise interventions on health-related quality of life for cancer survivors. Cochrane Database of Systematic Reviews 2012; (8): 1-379.

30. Eickmeyer S, Gamble G, Shahpar S, Do K. The role and efficacy of exercise in persons with cancer Physical Medicine and Rehabilitation 2012; 4(12): 874-81.

31. Fong D, Ho J, Hui B, et al. Physical activity for cancer survivors: meta-analysis of randomised controlled trials. British Medical Journal 2012; 344(e70): 1-14.

32. Lahart I, Metsios G, Nevill A, Carmichael A. Physical activity, risk of death and recurrence in breast cancer survivors: a systematic review and meta-analysis of epidemiological studies. Acta Oncologica 2015; 54: 635-54.

33. Duijts SFA, Faber MM, Oldenburg HSA, van Beurden M, Aaronson NK. Effectiveness of behavioral techniques and physical exercise on psychosocial functioning and health-related quality of life in breast cancer patients and survivors-a meta-analysis. Psycho-Oncology 2011; 20(2): 115-26.

34. de Boer AGEM, Taskila TK, Frings-Dresen MHW, Feuerstein M, Verbeek JH. Interventions to enhance return-to-work for cancer patients. Cochrane Database of Systematic Reviews 2011; (9): 1-76.

35. Zhang J-M, Wang P, Yao J-X, et al. Music interventions for psychological and physical outcomes in cancer: a systematic review and meta-analysis. Supportive Care in Cancer 2012; 20(12): 3043-53.

36. National Cancer Institute. Follow-up care after cancer treatment. 2010. cancer.gov/about-cancer/coping/survivorship/follow-up-care/follow-up-factsheet (accessed 3 August 2015).

37. Fitch MI. Supportive care framework. Canadian Oncology Nursing Journal 2008; 18(1): 6-14.

38. Buffart L, Galvao D, Brug J, Chinapaw M, Newton R. Evidence-based physical activity guidelines for cancer survivors: current guidelines, knowledge gaps, and future research directions. Cancer Treatment Reviews 2013; 4(2): 327-40.

39. Rowland JH, Kent EF, LP, Havard Loge J, et al. Cancer survivorship research in Europe and the United States: Where have we been, where are we going, and what can we learn from each other? Cancer 2013; 19(S11): 2094-108.

40. Mutrie N, Campbell A, Barry S, et al. Five-year follow-up of participants in a randomised controlled trial showing benefits from exercise for breast cancer survivors during adjuvant treatment. Are there lasting effects? Journal of Cancer Survivorship 2012; 6: 420-30. 
41. Jankowski CM, Ory MG, Friedman DB, Dwyer A, Birken SA, Risendal B. Searching for maintenance in exercise interventions for cancer survivors. Journal of Cancer Survivorship 2014; 8(4): 697-706.

42. Alfano CM, Ganz PA, Rowland J, Hahn EE. Cancer survivorship and cancer rehabilitation: revitalizing the link. Journal of Clinical Oncology 2012; 30: 904-906.

43. Hellbom M, Bergelt C, Bergenmar M, et al. Cancer rehabilitation: a Nordic and European perspective. Acta Oncologica 2011; 50(2): 179-86.

44. Stubblefield MD, Hubbard G, Cheville A, Koch U, Schmitz KH, Dalton SO. Current perspectives and emerging issues on cancer rehabilitation. Cancer 2013; 119(Suppl 11): 2170-8.

45. Ross L, Petersen MA, Johnsen AT, Lundstrom LH, Groenvold M. Are different groups of cancer patients offered rehabilitation to the same extent? A report from the population-based study "The Cancer Patient's World". Supportive Care in Cancer 2012; 20(5): 1089-100.

46. Blanch-Hartigan D, Forsythe LP, Alfano CM, et al. Provision and discussion of survivorship care plans among cancer survivors: results of a nationally representative survey of oncologists and primary care physicians. Journal of Clinical Oncology 2014; 32(15): 1578-85.

47. Mattioli V, Montanaro R, Romito F. The Italian response to cancer survivorship research and practice: developing an evidence base for reform. Journal of Cancer Survivorship 2010; 4(3): 284-9.

48. Stricker $\mathrm{C}$, Jacobs L, Risendal B, et al. Survivorship care planning after the Institute of Medicine recommendations: How are we faring? Journal of Cancer Survivorship 2011; 5: 358-70.

49. Hewitt M, Maxwell S, Vargo MM. Policy issues related to the rehabilitation of the surgical cancer patient. Journal of Surgical Oncology 2007; 95(5): 370-85.

50. College voor Zorgverzekeringen. Pakketbeoordeling oncologisch revalidatieprogramma Herstel en Balans. Diemen: Dutch Health Insurance Board, 2006.

51. The Netherlands Comprehensive Cancer Organisation. Website of "Herstel en Balans". Deelname. herstelenbalans.nl/?page=26 (accessed 12 July 2015).

52. Silver JK. Cancer prehabilitation and its role in improving health outcomes and reducing health care costs. Seminars in Oncology Nursing 2015; 31(1): 13-30.

53. Mehnert A, Härter M, Koch U. Langzeitfolgen einer Krebserkrankung. Anforderungen an die Rehabilitation und Nachsorge. Bundesgesundheitsblatt 2012; 55: 509-15. 
54. OECD and European Commission. Health at a glance: Europe 2014. Paris, 2014.

55. van de Berg M, de Boer D, Gijsen R, Heijink R, Limburg L, Zwakhals S, editors. Zorgbalans 2014. De prestaties van de Nederlands gezondheidszorg. Bilthoven: National Institute for Public Health and Environment; 2014.

56. Keogh B. Curbing US health care costs: Lessons from Europe? Journal of the National Cancer Institute 2012; 105(15): 1119-20.

57. Sullivan R, Peppercorn J, Sikora K, et al. Delivering affordable cancer care in highincome countries. The Lancet Oncology 2011; 12(10): 933-80.

58. Gommer A, Poos M. Hoeveel zorg gebruiken mensen met kanker en wat zijn de kosten? 2014. nationaalkompas.nl/gezondheid-en-ziekte/ziekten-en-aandoenin gen/kanker/hoeveel-zorg-gebruiken-mensen-met-kanker-en-kosten/ (accessed 2 November 2015).

59. Elkin E, Bach P. Cancer's next frontier. Addressing high and increasing costs. Journal of the American Medical Association 2010; 303(11): 1086-7.

60. Drummond MF, Sculpher MJ, Torrance GW, O’Brien BJ, Stoddart GL. Methods for the economic evaluation of health care programmes Oxford: Oxford University Press; 2005.

61. O'Brien BJ, Briggs $\mathrm{AH}$. Analysis of uncertainty in health care cost-effectiveness studies: an introduction to statistical issues and methods. Statistical Methods in Medical Research 2002; 11(6): 455-68.

62. Sullivan S, Mauskopf J, Augustovski F, et al. Budget impact analysis-Principles of Good Practice: report of the ISPOR 2012 Budget Impact Analysis Good Practice II Task Force. Value in Health 2014; 17: 5-14.

63. Gordon LG, Beesley $V L$, Scuffham PA. Evidence on the economic value of psychosocial interventions to alleviate anxiety and depression among cancer survivors: a systematic review. Asia-Pacific Journal of Clinical Oncology 2011; 7(2): 96-105.

64. de Moor JS, Alfano CM, Breen N, Kent EE, Rowland J. Applying evidence from economic evaluations to translate cancer survivorship research into care. Journal of Cancer Survivorship 2015; 9(3): 560-6.

65. Statistics Netherlands. CBS: Laagste groei zorguitgaven in 15 jaar. 2014. cbs.nl/nlNL/menu/themas/gezondheid-welzijn/publicaties/artikelen/archief/2014/2014031-pb.htm (accessed October 25 2015). 


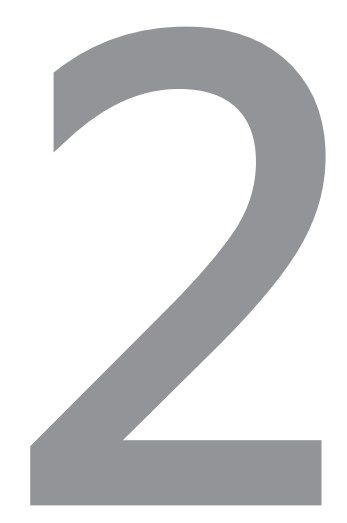

\section{Effectiveness of multidimensional cancer survivor rehabilitation and cost-effectiveness of cancer rehabilitation in general: a systematic review}

Janne C. Mewes

Lotte M.G. Steuten

Maarten J. IJzerman

Wim H. van Harten

The Oncologist 17(12):1581-1593, 2012 



\title{
Effectiveness of multidimensional cancer survivor rehabilitation and cost-effectiveness of cancer rehabilitation in general: a systematic review
}

\begin{abstract}
Introduction: Many cancer survivors suffer from a combination of disease- and treatment-related morbidities and complaints after primary treatment. There is a growing evidence base for the effectiveness of mono-dimensional rehabilitation interventions; in practice, however, patients often participate in multidimensional programs. This study systematically reviews evidence regarding effectiveness of multidimensional rehabilitation programs for cancer survivors and cost-effectiveness of cancer rehabilitation in general.

Methods: The published literature was systematically reviewed. Data were extracted using standardized forms and were summarized narratively.

Results: Sixteen effectiveness and six cost-effectiveness studies were included. Multidimensional rehabilitation programmes were found to be effective, but not more effective than mono-dimensional interventions, and not on all outcome measures. Effect sizes for quality of life were in the range of -0.12 (95\% confidence interval $[\mathrm{Cl}],-0.45-$ $0.20)$ to 0.98 (95\% Cl, 0.69 -1.29). Incremental cost-effectiveness ratios ranged from -€16,976, indicating cost savings, to €11,057 per quality-adjusted life year.

Conclusions: The evidence for multidimensional interventions and the economic impact of rehabilitation studies is scarce and dominated by breast cancer studies. Studies published so far report statistically significant benefits for multidimensional interventions over usual care, most notably for the outcomes fatigue and physical functioning. An additional benefit of multidimensional over mono-dimensional rehabilitation was not found, but this was also sparsely reported on. Available economic evaluations assessed very different rehabilitation interventions. Yet, despite low comparability, all showed favourable cost-effectiveness ratios. Future studies should focus their designs on the comparative effectiveness and cost-effectiveness of multidimensional programs.
\end{abstract}




\section{Introduction}

Progression in screening, early detection, and effective treatment of cancer has rapidly increased the percentage of cancer survivors in developed countries. In Europe, the 5year survival rate for all cancers has reached $\geq 47 \%$ for men and $56 \%$ for women, and these are expected to rise in future years. In the U.S., 5 -year survival rates of $68 \%$ for men and $67 \%$ for women were reported ${ }^{2}$. Accordingly, the demand for rehabilitation after primary cancer treatment is increasing. In The Netherlands, for example, the number of people living with or having survived cancer is estimated to be $\sim 692,500$ (4\%-5\% of the population) by the year $2015^{3}$, a large number of whom might benefit from cancer rehabilitation.

Because of the direct and long-term effects of cancer and its treatment, most survivors do not return to their previous state of well-being ${ }^{4,5}$. Cancer survivors suffer from a range of problems, varying from fatigue, reduced physical fitness, and psychological problems to symptoms related to specific cancer types, such as lymphedema or difficulties with speaking and swallowing after head and neck surgery ${ }^{6}$. Consequently, an important percentage of cancer survivors, $36 \%$ according to a recent review ${ }^{7}$, is not able to return to work. Furthermore, cancer survivors suffer from different symptoms and complaints. Cheng et al. ${ }^{8}$ reported an average of eight symptoms per patient. A combination of interventions, adjusted to the survivor's individual needs, is likely required to restore health-related quality of life (HRQoL). Indeed, multidimensional rehabilitation is increasingly being recommended in national and international cancer rehabilitation guidelines, ${ }^{9,10}$.

During previous decades, the volume of research on the rehabilitation of cancer survivors has increased faster than research on rehabilitation in general ${ }^{11}$. Most research conducted so far focused on physical exercise after cancer treatment, which has been shown to increase physical strength and HRQoL and to alleviate fatigue and other symptoms $^{12,13}$. Only a few studies suggest that cognitive and psychosocial rehabilitation interventions can reduce psychological symptoms ${ }^{14-16}$. Furthermore, return-to-work interventions appeared successful in helping survivors resuming work ${ }^{17}$. Besides alleviating particular post-treatment symptoms, rehabilitation likely mitigates cancer survivors' elevated risk for chronic diseases, such as cardiovascular disease and osteoporosis, and the risk for a second primary cancer or recurrence ${ }^{6}$. Performing physical activity has been shown to reduce the risk for cancer recurrence and chronic disease $^{18}$ and is suggested in several guidelines and recommendations ${ }^{9,10,12,19-21}$. The 
evidence base for the long-term effects of rehabilitation is rather small because the follow-up duration is usually short 22 .

Although there is a growing body of literature, to what extent the effect of multidimensional rehabilitation is greater than the effect of single interventions remains unknown, because the various interventions are mostly tested in isolation. Considering the increasing number of cancer survivors, not only the treatment effects but also the costs involved to society and health care systems become an issue, as recently underlined in leading journals ${ }^{23,24}$. Data on the cost-effectiveness of rehabilitation will undoubtedly become more important to decision makers.

The first aim of this study was therefore to systematically review the research conducted on the effectiveness of multidimensional rehabilitation programs for cancer survivors. Because all rehabilitation services inevitably come at a cost, the second aim was to critically review published cost-effectiveness studies of cancer rehabilitation.

\section{Methods}

A systematic literature review was undertaken on (a) the effectiveness of multidimensional cancer survivor rehabilitation programs and (b) the cost-effectiveness of cancer rehabilitation. MEDLINE, PsycINFO, and the Cochrane Library were searched electronically using various combinations of keywords and medical subject headings (MeSH): neoplasms (MeSH), survivors, chronic cancer patients, rehabilitation, multicomponent, multidimensional, multifaceted, multi treatment, multimodal, complex, program, exercise, physical activity, physical exercise, physical therapy, return-to-work, reintegration, back to work, vocational rehabilitation, occupational rehabilitation, workplace, cognitive therapy, costs and cost analysis (MeSH), cost, and economic. Table 1 provides a detailed overview of the combinations of search terms used. Further, reference lists of included papers were hand searched. 
Table 1: Search terms used per database

\section{Medline:}

Neoplasms [MeSH] AND survivors AND (Rehabilitation OR costs and cost analysis

[MeSH] OR (exercise OR "physical activity" OR "physical exercise" OR "physical

therapy") OR ("return to work" OR reintegration OR "back to work" OR "vocational rehabilitation" OR "occupational rehabilitation" OR workplace))

\section{Cochrane Library:}

Neoplasms AND (rehabilitation OR survivors)

\section{PsycINFO:}

Neoplasms AND survivors AND rehabilitation,

Neoplasms AND survivors AND (cost OR economic),

Neoplasms AND survivors AND (exercise OR "physical activity" OR "physical exercise" OR "physical therapy"),

Neoplasms AND survivors AND ("return to work" OR reintegration OR "back to work" OR "(vocational) rehabilitation" OR "occupational rehabilitation" OR workplace), Neoplasms AND (rehabilitation OR survivors)

\section{Selection criteria for all studies}

English language primary studies, systematic reviews, and meta-analyses were included, evaluating (a) the effectiveness of multidimensional cancer survivor rehabilitation programs and (b) the cost-effectiveness of cancer rehabilitation. Eligible study designs for primary studies were randomized controlled trials (RCTs) and quasi-experimental studies, including nonrandomized controlled studies and pretest-post-test studies. Nonsystematic reviews and qualitative and observational studies were excluded. The methodological quality of studies was assessed but did not function as a selection criterion. A rehabilitation intervention was defined as an intervention directed at enhancing the International Classification of Functioning, Disability and Health (ICF) domains in cancer survivors ${ }^{25}$, that is, body structure and function, activity, and participation. Studies evaluating medical devices were not included. Outcome measures included clinical endpoints and intermediate endpoints that could be linked to relevant endpoints. When two articles from the same study were found, only the most recent one that included follow-up and baseline data was included. 


\section{Selection criteria for effectiveness studies of multidimensional cancer survivor rehabilitation}

Effectiveness studies of multidimensional rehabilitation published in January 1994 to June 2012 were considered. The participants included were adult cancer survivors with any kind of cancer. Various definitions of cancer survivorship are in use ${ }^{26}$. Here, a "cancer survivor" is defined as a person diagnosed with any type of cancer who finished primary treatment either directly before the start of the study or earlier. The type of primary treatment did not function as a selection criterion. Hormone therapy could still be ongoing. The outcome of the therapy must have been positive to a degree that survival of one year was expected, which therefore also leads to the inclusion of chronic cancer patients. Palliative care patients, end-of-life patients, and adult survivors of paediatric cancer were excluded. Reviews, meta-analyses, and primary studies in which not all participants were cancer survivors were only considered when data were presented separately for cancer survivors.

Multidimensional rehabilitation was defined as a rehabilitation program that consisted of two or more rehabilitation interventions directed at the ICF dimensions. Interventions typically encompassed various types of exercise (also including exercise for specific tumour-type related complaints), cognitive-behavioural therapy (CBT), psychotherapy (also including psychotherapy, counselling, and self- and symptom management), and return-to-work interventions. Therefore, a rehabilitation program that included, for example, two different kinds of exercise (e.g., walking to relieve fatigue and weight lifting to increase muscle strength) was not considered multidimensional because both interventions target the dimension "physical functioning".

\section{Selection criteria for economic evaluations of cancer rehabilitation}

Cost-effectiveness studies of cancer rehabilitation were those published in January 1995 to December 2011 that included adults diagnosed with any kind of cancer of any stage. In contrast to the inclusion criteria for multidimensional rehabilitation programs, costeffectiveness studies could also include cancer patients who were still in treatment, chronic cancer patients who were not treated with curative intent, and cancer patients during or after treatment with a relatively short life expectancy. Adults experiencing late and long-term effects of paediatric cancer were excluded. Notably, economic evaluations assessing any cancer rehabilitation intervention, whether mono-dimensional or multidimensional, were included to obtain a sufficient evidence base for review. 


\section{Screening process}

All identified titles and abstracts were screened by two authors (J.M. and L.S.) for relevance and, if relevant, full text articles were obtained and assessed against the selection criteria (J.M. and L.S.). Disagreements were resolved by discussion or referred to a third author (W.v.H.). Because titles and abstracts provide insufficient information to assess multidimensionality according to our definition, full text articles were obtained for all articles evaluating cancer rehabilitation effectiveness.

\section{Data extraction}

Data were extracted using a standardized form. For effectiveness studies, study country, type of intervention, intervention design, control group, participants, methods, outcome measures, measurement instruments, retention, baseline characteristics, and results were extracted. For economic evaluations, study country, type of intervention, design of intervention, comparator, outcome measures, measurement instruments, participants, methods, perspective, uncertainty analyses performed, effect results, cost results, economic results, results of uncertainty analyses, and results of modelling were extracted.

\section{Data analysis}

The effect size (ES) of selected outcome measures was calculated using Cohen's $d^{27}$. Standard deviations were calculated according to Hedges ${ }^{28}$. For controlled trials, the ES was expressed as the difference in the mean between the experimental and control groups at the last measurement point. For pretest-post-test studies, the ES was computed for the difference between the baseline and last measurements. In calculating 95\% confidence interval $(\mathrm{Cl})$ for the $\mathrm{ES}$, a normal distribution was assumed with standard errors calculated according to Hunter and Schmidt ${ }^{29}$.

\section{Methodological quality assessment}

The methodological quality of papers was assessed using the Cochrane Collaboration's risk of bias tool ${ }^{30}$ for multidimensional effectiveness studies and the 10 -point Drummond checklist $^{31}$ for economic evaluations. 


\section{Results}

In total, 4,008 citations were identified from MEDLINE, PsycINFO, and the Cochrane Library. Of these, 187 were duplicates, leading to 3,821 unique articles. By reviewing titles and abstracts, 3,607 articles were excluded; full text papers were obtained for the remaining 214 articles. Of these, 195 articles were excluded. Three articles were identified through hand searching. Common exclusion reasons were that the intervention in question was not multidimensional and that the definition of survivor was unclear. A large number of studies that possibly fulfilled the inclusion criteria were excluded because the estimated life expectancy of the patients at the end of the primary treatment was not stated. Three articles were identified through hand searching, leading to a total of 22 articles included. Sixteen articles ${ }^{32-47}$ on the effectiveness of multidimensional cancer survivor rehabilitation were included, the data from which originated from 11 trials. The data from one of those trials were presented in two complementary articles ${ }^{46,47}$ and the data from another trial were used in four articles ${ }^{42-}$ ${ }^{45}$. Six health economic evaluations ${ }^{48-53}$ were identified. No review was identified in which the included studies fulfilled the inclusion criteria. Figure 1 depicts the study's flow chart. 


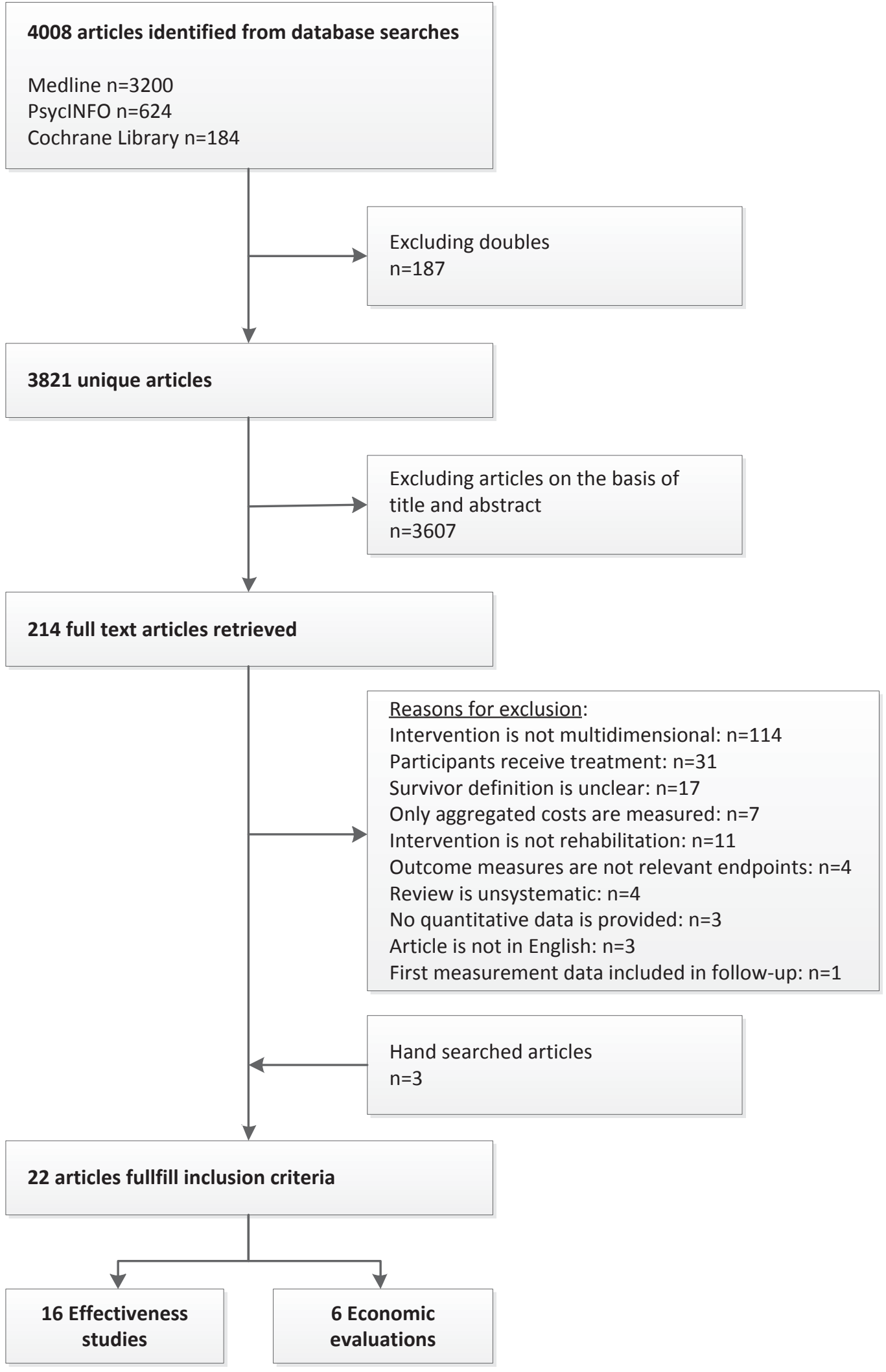

Figure 1: Flow chart of study selection 


\title{
Effectiveness of multidimensional interventions
}

\author{
Sixteen articles met the selection criteria for multidimensional cancer rehabilitation \\ effectiveness studies ${ }^{32-47}$ (Table 2).
}

Table 2: Summary of multidimensional effectiveness studies

\begin{tabular}{|c|c|c|c|c|}
\hline $\begin{array}{l}\text { Study, } \\
\text { year, } \\
\text { country }\end{array}$ & $\begin{array}{l}\text { Interven- } \\
\text { tion }\end{array}$ & $\begin{array}{l}\text { Method, } \\
\text { participants, } \\
\text { n }\end{array}$ & Measurement & Outcome measures \\
\hline
\end{tabular}

\begin{tabular}{|c|c|c|c|c|c|}
\hline $\begin{array}{l}\text { Berglund } \\
\text { et al. } \\
\text { (1994), } \\
\text { Sweden }\end{array}$ & $\begin{array}{l}\text { EXERC + } \\
\text { INF + } \\
\text { coping } \\
\text { skills } \\
\text { training / } \\
\text { control } \\
\text { group }\end{array}$ & $\begin{array}{l}\text { RCT; cancer } \\
\text { survivors; } 199 \\
\text { in total, } \\
\text { intervention } \\
\text { group: 98, } \\
\text { control group: } \\
101\end{array}$ & $\begin{array}{l}\text { Baseline (T0), } \\
\text { after } \\
\text { intervention } \\
\text { (T1), 3-months } \\
\text { follow-up (T2), } \\
\text { 6-months } \\
\text { follow-up (T3), } \\
\text { 12-months } \\
\text { follow-up }\end{array}$ & $\begin{array}{l}\text { Work status, sick leave, having } \\
\text { received sufficient information, } \\
\text { physical strength and activity, } \\
\text { anxiety, depression, (problems } \\
\text { with) QoL, activities at home } \\
\text { and in the community, physical } \\
\text { cancer symptoms, } \\
\text { communication with staff, } \\
\text { mental adjustment to cancer }\end{array}$ & $\begin{array}{l}\text { Significant improvement in the } \\
\text { intervention group at post- } \\
\text { intervention on fighting spirit } \\
\text { (subscale of mental adjustment } \\
\text { questionnaire); at six-months } \\
\text { follow-up on problems in } \\
\text { communication with doctors; and } \\
\text { throughout the whole follow-up } \\
\text { period on having received sufficie } \\
\text { information, physical strength, an } \\
\text { physical training. }\end{array}$ \\
\hline $\begin{array}{l}\text { Fillion et } \\
\text { al. (2008), } \\
\text { Canada }\end{array}$ & $\begin{array}{l}\text { PSY + } \\
\text { EXERC / } \\
\text { UC }\end{array}$ & $\begin{array}{l}\text { RCT; breast } \\
\text { cancer } \\
\text { survivors; } 87 \text { in } \\
\text { total PSY + } \\
\text { EXERC: } 44 \\
\text { UC: } 43\end{array}$ & $\begin{array}{l}\text { Baseline (T0), } \\
\text { after } \\
\text { intervention } \\
\text { (T1), 3-months } \\
\text { follow-up (T2) }\end{array}$ & $\begin{array}{l}\text { Fatigue, energy level, physical } \\
\text { QoL, mental QoL, fitness, } \\
\text { psychological distress }\end{array}$ & $\begin{array}{l}\text { At T1 significant effect in the } \\
\text { intervention group compared to } \\
\text { the usual care group on physical } \\
\text { QoL only. At T2 improvements or } \\
\text { fatigue and energy level only. }\end{array}$ \\
\hline $\begin{array}{l}\text { Hanssens } \\
\text { et al. } \\
\text { (2011), } \\
\text { Belgium }\end{array}$ & $\begin{array}{l}\text { EXERC + } \\
\text { PSY } \\
+ \text { counse- } \\
\text { ling }\end{array}$ & $\begin{array}{l}\text { Pre-test post- } \\
\text { test cancer } \\
\text { survivors; } 36\end{array}$ & $\begin{array}{l}\text { Baseline (T0), } \\
\text { after } \\
\text { intervention } \\
\text { (T1) }\end{array}$ & $\begin{array}{l}\text { QoL, fatigue, fear of } \\
\text { movement, distress, anxiety, } \\
\text { depression, physical condition }\end{array}$ & $\begin{array}{l}\text { Significant improvements on QoL } \\
\text { physical condition, fatigue, and } \\
\text { depression. }\end{array}$ \\
\hline
\end{tabular}

\begin{tabular}{|c|c|c|c|c|c|}
\hline $\begin{array}{l}\text { Hartmann } \\
\text { et al. } \\
\text { (2007), } \\
\text { Germany }\end{array}$ & $\begin{array}{l}\text { 4w INPR. + } \\
\text { extra } \\
\text { interventio } \\
\text { ns (A) / 3w } \\
\text { INPR + 2x } \\
1 \text { w follow- } \\
\text { up stays (B) }\end{array}$ & $\begin{array}{l}\text { RCT; breast } \\
\text { cancer } \\
\text { survivors; } \\
197 \text { in total, } \\
\text { intervention } \\
\text { group: 98, } \\
\text { control group: } \\
99\end{array}$ & $\begin{array}{l}\text { Baseline (T0), } \\
\text { after first 3-4w } \\
\text { stay (T1), 12- } \\
\text { months follow- } \\
\text { up (T2) }\end{array}$ & QoL & $\begin{array}{l}\text { No significant differences were } \\
\text { found between A and B at T1. T1- } \\
\text { T2: A improved on cognitive func- } \\
\text { tioning, while it deteriorated in B, } \\
\text { however, this was only significant } \\
\text { for the subgroup of participants } \\
\text { with impaired cognitive function at } \\
\text { baseline. For other subscales no } \\
\text { significant differences were found. }\end{array}$ \\
\hline $\begin{array}{l}\text { Heim et al. } \\
\text { (2007), } \\
\text { Germany }\end{array}$ & $\begin{array}{l}\text { INPR + } \\
\text { EXERC / } \\
\text { INPR }\end{array}$ & $\begin{array}{l}\mathrm{RCT} \text {; breast } \\
\text { cancer } \\
\text { survivors; } \\
63 \text { in total, } \\
\text { intervention } \\
\text { group: } 32, \\
\text { control group: } \\
31\end{array}$ & $\begin{array}{l}\text { Baseline (T0), } \\
\text { after } \\
\text { intervention } \\
\text { (T1), 3-months } \\
\text { follow-up (T2) }\end{array}$ & $\begin{array}{l}\text { QoL, anxiety, depression, } \\
\text { fatigue, physical activity, } \\
\text { motivation to perform exercise } \\
\text { and sport }\end{array}$ & $\begin{array}{l}\text { Both groups improved on muscle } \\
\text { strength, global QoL, physical well- } \\
\text { being, functionality, fatigue, aerobic } \\
\text { capacity, subjective physical fitness, } \\
\text { and health-related QoL from T0-T2. } \\
\text { Only the intervention group } \\
\text { improved further to T2 on } \\
\text { subjective physical fitness, muscle } \\
\text { strength, global QoL, physical well- } \\
\text { being, functionality. Fatigue } \\
\text { improved in both groups at T1 and } \\
\text { T2, but was reduced significantly } \\
\text { more in the intervention group. }\end{array}$ \\
\hline
\end{tabular}




\begin{tabular}{|c|c|c|c|c|c|}
\hline $\begin{array}{l}\text { Korstjens } \\
\text { et al. } \\
\text { (2006), } \\
\text { The } \\
\text { Nether--- } \\
\text { lands }\end{array}$ & $\begin{array}{l}\text { PSY + } \\
\text { EXERC }\end{array}$ & $\begin{array}{l}\text { Longitudinal } \\
\text { cohort study; } \\
\text { cancer } \\
\text { survivors; } 658\end{array}$ & $\begin{array}{l}\text { Baseline (T0), } \\
\text { halfway the } \\
\text { intervention } \\
\text { (T1), after } \\
\text { intervention } \\
\text { (T2) }\end{array}$ & $\begin{array}{l}\text { QoL subscales global QoL, } \\
\text { physical functioning, role } \\
\text { functioning, emotional } \\
\text { functioning, cognitive } \\
\text { functioning, social functioning, } \\
\text { fatigue }\end{array}$ & $\begin{array}{l}\text { At T1 significant improvements in all } \\
\text { domains of QoL, except of } \\
\text { cognitive functioning, in the } \\
\text { intervention groups compared to } \\
\text { baseline. At T2 significant } \\
\text { improvements on all QoL-domains, } \\
\text { except for role functioning, this only } \\
\text { improved significantly for those not } \\
\text { working at baseline. }\end{array}$ \\
\hline $\begin{array}{l}\text { Lee et al. } \\
\text { (2010), } \\
\text { South } \\
\text { Korea }\end{array}$ & $\begin{array}{l}\text { SHE + } \\
\text { EXERC }\end{array}$ & $\begin{array}{l}\text { One-group pre- } \\
\text { test post-test; } \\
\text { gastric cancer } \\
\text { survivors; } 21\end{array}$ & $\begin{array}{l}\text { Baseline (T0), } \\
\text { one week } \\
\text { after } \\
\text { intervention } \\
\text { (T1) }\end{array}$ & $\begin{array}{l}\text { Depression; QoL subscales } \\
\text { emotional well-being, } \\
\text { functional well-being, physical } \\
\text { well-being, social well-being, } \\
\text { general QoL }\end{array}$ & $\begin{array}{l}\text { No significant improvements were } \\
\text { found. }\end{array}$ \\
\hline $\begin{array}{l}\text { Rogers et } \\
\text { al. (2009), } \\
\text { US }\end{array}$ & $\begin{array}{l}\text { EXERC + } \\
\text { behavior } \\
\text { change / } \\
\text { UC }\end{array}$ & $\begin{array}{l}\text { RCT; breast } \\
\text { cancer } \\
\text { survivors; } 41 \text { in } \\
\text { total, } \\
\text { intervention } \\
\text { group: } 21 \text {, } \\
\text { usual care } \\
\text { group: } 20\end{array}$ & $\begin{array}{l}\text { Baseline (T0), } \\
\text { after } \\
\text { intervention (T1) }\end{array}$ & $\begin{array}{l}\text { Objective physical activity, } \\
\text { leisure time physical activity, } \\
\text { motivational readiness for } \\
\text { physical activity, fitness, muscle } \\
\text { strength, body composition } \\
\text { and anthropometrics, quality } \\
\text { of life, sleep dysfunction }\end{array}$ & $\begin{array}{l}\text { Significant improvements on } \\
\text { activity, left handgrip, back/leg } \\
\text { extensors, waist-to-hip ration, } \\
\text { quality of life-subscale social well- } \\
\text { being, and joint stiffness. }\end{array}$ \\
\hline $\begin{array}{l}\text { Sherman } \\
\text { et al. } \\
\text { (2010), } \\
\text { Australia }\end{array}$ & $\begin{array}{l}\text { INF + } \\
\text { EXERC / } \\
\text { WLC }\end{array}$ & $\begin{array}{l}\text { Quasi-experi- } \\
\text { mental trial; } \\
\text { breast cancer } \\
\text { survivors; } 129 \text { in } \\
\text { total INF + } \\
\text { EXERC: } 87 \\
\text { WLC: } 42\end{array}$ & $\begin{array}{l}\text { Baseline (T0), } \\
\text { after } \\
\text { intervention (T1) }\end{array}$ & $\begin{array}{l}\text { Functional ability score; self- } \\
\text { reported energy levels; Trial } \\
\text { Outcome Index; QoL subscales } \\
\text { general QoL, physical-, } \\
\text { social/family-, emotional-, } \\
\text { functional-, and breast cancer- } \\
\text { specific well-being; cancer- } \\
\text { specific distress: intrusion and } \\
\text { avoidance, perceived social } \\
\text { support, satisfaction with social } \\
\text { support, self-efficacy, } \\
\text { familiarity with exercise }\end{array}$ & $\begin{array}{l}\text { Significant effects at post } \\
\text { intervention compared to baseline } \\
\text { where found for the functional } \\
\text { ability score, self-reported energy } \\
\text { levels, Trial Outcome Index, } \\
\text { functional well-being, satisfaction } \\
\text { with social support, self-efficacy, } \\
\text { I and familiarity with exercise. }\end{array}$ \\
\hline
\end{tabular}

\begin{tabular}{|c|c|c|c|c|c|}
\hline $\begin{array}{l}\text { Van Weert } \\
\text { et al. } \\
\text { (2004), } \\
\text { The } \\
\text { Nether- } \\
\text { lands }\end{array}$ & $\begin{array}{l}\text { EXERC + } \\
\text { PSY + INF }\end{array}$ & $\begin{array}{l}\text { One-group pre- } \\
\text { test post-test; } \\
\text { cancer } \\
\text { survivors; } 37\end{array}$ & $\begin{array}{l}\text { Baseline (T0), } \\
\text { after } \\
\text { intervention (T1) }\end{array}$ & $\begin{array}{l}\text { Physical capacity performance, } \\
\text { muscle force, QoL, fatigue }\end{array}$ & $\begin{array}{l}\text { Significant improvements on all } \\
\text { physical outcome measures; the } \\
\text { QoL-subscales physical functioning, } \\
\text { role limitation, vitality, and change } \\
\text { of health; fatigue-subscales physical } \\
\text { fatigue and reduction of } \\
\text { motivation. }\end{array}$ \\
\hline
\end{tabular}

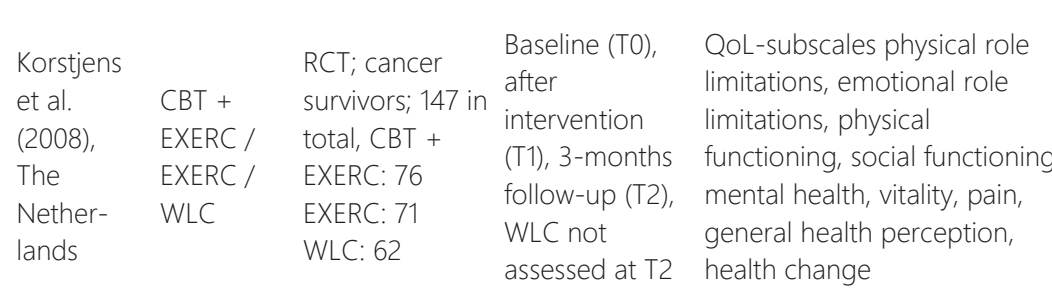

At T1 significant improvements on physical role limitations, physical functioning, vitality, and health change in the intervention groups compared to the WLC. At T2 the WLC was not assessed, and no significant difference emerged on any of the outcome measures between CBT+ EXERC compared to EXERC.

\begin{tabular}{|c|c|c|c|c|c|}
\hline $\begin{array}{l}\text { May et al. } \\
\text { (2008), } \\
\text { The } \\
\text { Nether- } \\
\text { lands }\end{array}$ & $\begin{array}{l}\text { CBT + } \\
\text { EXERC / } \\
\text { EXERC }\end{array}$ & $\begin{array}{l}\text { RCT; cancer } \\
\text { survivors; } 147 \text { in } \\
\text { total, CBT + } \\
\text { EXERC: } 75 \\
\text { EXERC: } 69\end{array}$ & $\begin{array}{l}\text { Baseline (T0), } \\
\text { after } \\
\text { intervention (T1) }\end{array}$ & $\begin{array}{l}\mathrm{VO}_{\text {2peak, }} \mathrm{W}_{\text {peak, }} \text { exercise time, } \\
\text { muscle strength left/right } \\
\text { elbow flexors, muscle strength } \\
\text { left/right elbow extensors, }\end{array}$ & $\begin{array}{l}\text { On all outcome measures } \\
\text { significant improvements were } \\
\text { found at } \mathrm{T} 1 \text { in the intervention } \\
\text { group compared to the control }\end{array}$ \\
\hline
\end{tabular}


extensors, and physical activity

\begin{tabular}{|c|c|c|c|c|c|}
\hline $\begin{array}{l}\text { May et al. } \\
\text { (2009), } \\
\text { The } \\
\text { Nether- } \\
\text { lands }\end{array}$ & $\begin{array}{l}\text { CBT+ } \\
\text { EXERC / } \\
\text { EXERC }\end{array}$ & $\begin{array}{l}\text { RCT; cancer } \\
\text { survivors; } \\
147 \text { in total, CBT } \\
\text { + EXERC: } 76 \\
\text { EXERC: } 71\end{array}$ & $\begin{array}{l}\text { Baseline (T0), } \\
\text { after } \\
\text { intervention } \\
\text { (T1), 3-months } \\
\text { follow-up (T2), } \\
\text { 9-months } \\
\text { follow-up (T3) }\end{array}$ & $\begin{array}{l}\text { QoL, physical activity after } \\
\text { rehabilitation }\end{array}$ & $\begin{array}{l}\text { In both groups QoL and physical } \\
\text { activity increased clinically } \\
\text { significant. No difference between } \\
\text { groups. }\end{array}$ \\
\hline
\end{tabular}

In the EXERC-group significant improvements were found in

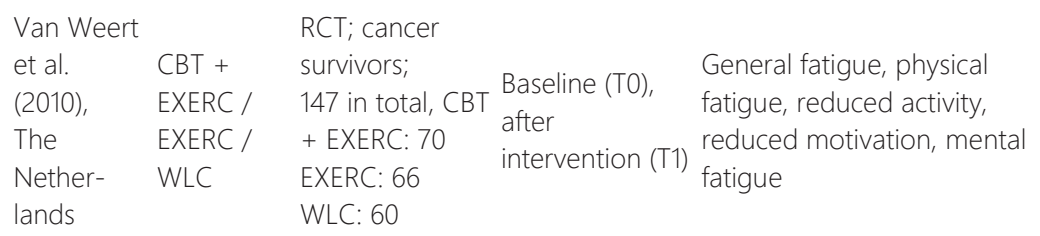
general and physical fatigue, and reduced motivation at T1 vs. WLC. In the CBT+EXERC-group a significant improvement was found on physical fatigue at T1 in comparison to WLC. Between EXERC and EXERC+CBT no differences were found.

\begin{tabular}{|c|c|c|c|c|c|}
\hline $\begin{array}{l}\text { Van Weert } \\
\text { et al. } \\
\text { (2005), } \\
\text { The } \\
\text { Nether- } \\
\text { lands }\end{array}$ & $\begin{array}{l}\text { PSY, INF + } \\
\text { EXERC / } \\
\text { choice of } \\
\text { these* }\end{array}$ & $\begin{array}{l}\mathrm{RCT} \text { (the results } \\
\text { are presented } \\
\text { as an aggregate } \\
\text { of both groups); } \\
\text { cancer } \\
\text { survivors; } 63\end{array}$ & $\begin{array}{l}\text { Baseline (T0), } \\
\text { after } \\
\text { intervention } \\
\text { (T1), 3-months } \\
\text { follow-up (T1) }\end{array}$ & $\begin{array}{l}\text { QoL subscales (measured by } \\
\text { RAND 36) physical functioning, } \\
\text { social functioning, role } \\
\text { limitations due to physical } \\
\text { problems, role limitations due } \\
\text { to emotional problems, mental } \\
\text { health, vitality, pain, general } \\
\text { health appraisal, change in } \\
\text { health; QoL subscales } \\
\text { (measured by RSCL) overall } \\
\text { valuation of life, psychological } \\
\text { distress, physical symptom } \\
\text { distress, activity level. }\end{array}$ & $\begin{array}{l}\text { At T1 significant improvements on } \\
\text { all outcome measures, except for } \\
\text { overall valuation of life, in the } \\
\text { intervention groups compared to } \\
\text { baseline. At T2 significant } \\
\text { improvement on all outcome } \\
\text { measures, except for pain and } \\
\text { general health appraisal, in the } \\
\text { intervention groups compared to } \\
\text { baseline. } \\
58 \% \text { of the participants who could } \\
\text { choose their program preferred the } \\
\text { multidimensional rehabilitation } \\
\text { program. }\end{array}$ \\
\hline
\end{tabular}

Van Weert

et al. One-group pre- Baseline (TO), General fatigue, physical

(2006), PSY + INF test post-test; Baseline (T0), fatigue, reduced activity, Significant improvements on all

The +EXERC cancer intervention (T1) reduced motivation, mental outcome measures.

Nether- $\quad$ survivors; 56 intervention (T1) fatigue

lands

/=Compared to

$P S Y=$ Psycho-education, $I N F=$ Information, $E X E R C=$ Exercise,$C B T=$ Cognitive-behavioral therapy, SHE=Self-help education, WLC=Waitlist control, $W=$ Weeks, INPR=Inpatient rehabilitation, QoL=Quality of life, UC=Usual care, RCT=Randomised controlled trial -----=Articles originate from the same study

Of these, the eight Dutch articles originate from four separate trials. The evaluated interventions all consisted of exercise combined with inpatient rehabilitation programs ${ }^{35}$, ${ }^{36}, \mathrm{CBT}^{39,42-45}$, psychological education ${ }^{33,34,37}$, psychological education and information ${ }^{41}$, 46,47 , self-help education ${ }^{38}$, information support ${ }^{40}$, and information support plus CBT $^{32}$. Interventions lasted 4-15 weeks. The designs used were RCTs 32-34, 36, 39, 41-46, pretestposttest studies ${ }^{35,38,47}$, a quasi-experiment ${ }^{40}$, and a longitudinal study ${ }^{37}$. RCTs included 
21-199 participants; the longitudinal study's sample size was 658. Participants were survivors of any type of cancer ${ }^{32,34,37,41-47}$, breast cancer $33,35,36,39,40$, and gastric cancer $^{38}$. Outcome measurements were performed directly at the end of the intervention $^{34,37,39-41,43,45,47}$ or after 1 week $^{38}, 3$ months $^{33,42,46,36}, 9$ months ${ }^{44}$, or 12 months ${ }^{32,35}$. Retention rates were in the range of 64\%-100\%.

Various outcome measures were reported (Table 2). All articles except one ${ }^{38}$ found significantly better outcomes in the intervention group(s) for all ${ }^{43,47}$ or for some $32-37,39-42$, 45, 46 of the outcome measures. Articles measuring subscales of fatigue $(n=8)$ found statistically significant benefits, but not for all subscales ${ }^{41,46}$ or for all measurements ${ }^{37}$. For physical outcome measures, such as muscle strength, physical functioning, and energy levels, 12 of 13 articles reported significant benefits ${ }^{32,34,37-39,41-47}$. HRQOL and emotional, cognitive, psychological, and social outcome measures, however, varied strongly among studies, although none reported significant deteriorations. Additionally, improvements observed at the end of an intervention were not always sustained on follow-up. Articles comparing mono-dimensional with multidimensional interventions ${ }^{42-}$ 45 all originated from one trial and did not find a significant difference between the mono-dimensional and multidimensional intervention groups. Two articles compared a more comprehensive inpatient rehabilitation program with the standard $\operatorname{program}^{35,36}$. One ${ }^{35}$ did not find significant between- group differences and the other ${ }^{36}$ found no significant difference at the end of the intervention but greater improvements in physical outcome measures and fatigue on follow-up. HRQoL was the only outcome measure reported in most articles $(n=13)^{32-42,44,46}$. When these could be calculated, ES values were in the range of $-0.12(95 \% \mathrm{Cl},-0.45$ to 0.20$)$ to $0.98(95 \% \mathrm{Cl}, 0.69$ to 1.29$)$ (Table 3). Statistically significant improvements at the last follow-up measurement were reported in three studies $36,38,40$. 
Table 3: Effect sizes of quality of life

\begin{tabular}{|c|c|c|c|c|c|c|}
\hline Article & $\mathrm{T}$ & $\begin{array}{l}\text { Measuremen } \\
\text { instrument }\end{array}$ & ${ }^{\mathrm{t}}$ Comparison & $\begin{array}{l}\text { Outcome } \\
\text { variable(s) }\end{array}$ & $\begin{array}{l}\text { Effect size } \\
\text { (Cohen's d) }\end{array}$ & $\begin{array}{l}\text { 95\%-confidence } \\
\text { interval }\end{array}$ \\
\hline \multirow{2}{*}{$\begin{array}{l}\text { Fillion et al. } \\
\text { (2008) }\end{array}$} & \multirow{2}{*}{$\begin{array}{l}\text { Follow-up at } \\
\text { three months } \\
\text { ( } 4 \text { weeks past } \\
\text { baseline) }\end{array}$} & \multirow{2}{*}{ SF-12 } & \multirow{2}{*}{$\begin{array}{l}\text { Psycho-education } \\
\text { combined with } \\
\text { exercise compared to } \\
\text { usual care }\end{array}$} & $\begin{array}{l}\text { Physical quality } \\
\text { of life } \\
\end{array}$ & 0.21 & -0.03 to 0.83 \\
\hline & & & & $\begin{array}{l}\text { Mental quality } \\
\text { of life }\end{array}$ & 0.40 & -0.22 to 0.63 \\
\hline $\begin{array}{l}\text { Korstjens et } \\
\text { al. (2006) }\end{array}$ & $\begin{array}{l}\text { Post- } \\
\text { intervention } \\
\text { (12 weeks past } \\
\text { baseline) }\end{array}$ & $\begin{array}{l}\text { EORTEC } \\
\text { QLQ-C30 }\end{array}$ & $\begin{array}{l}\text { One-group design; } \\
\text { post-intervention } \\
\text { compared to baseline }\end{array}$ & $\begin{array}{l}\text { Global quality } \\
\text { of life }\end{array}$ & 0.51 & 0.40 to 0.62 \\
\hline $\begin{array}{l}\text { Korstjens et } \\
\text { al. (2008) }\end{array}$ & $\begin{array}{l}\text { Post- } \\
\text { intervention } \\
\text { (12 weeks past } \\
\text { baseline) }\end{array}$ & RAND 36 & $\begin{array}{l}\text { Intervention groups } \\
\text { compared to waitlist } \\
\text { control }\end{array}$ & $\begin{array}{l}\text { General health } \\
\text { perception }\end{array}$ & 0.05 & -0.22 to 0.32 \\
\hline $\begin{array}{l}\text { Lee et al. } \\
(2010)\end{array}$ & $\begin{array}{l}\text { Post- } \\
\text { intervention } \\
\text { ( } 24 \text { weeks past } \\
\text { baseline) } \\
\end{array}$ & FACT-G & $\begin{array}{l}\text { One-group design; } \\
\text { post-intervention } \\
\text { compared to baseline }\end{array}$ & $\begin{array}{l}\text { Global quality } \\
\text { of life }\end{array}$ & -0.05 & -0.67 to 0.57 \\
\hline $\begin{array}{l}\text { May et al. } \\
(2009)\end{array}$ & $\begin{array}{l}\text { Follow-up at } \\
\text { nine months } \\
\text { (48 weeks past } \\
\text { baseline) }\end{array}$ & $\begin{array}{l}\text { EORTEC } \\
\text { QLQ-C30 }\end{array}$ & $\begin{array}{l}\text { Exercise combined } \\
\text { with cognitive- } \\
\text { behavioral therapy } \\
\text { compared to exercise }\end{array}$ & $\begin{array}{l}\text { Global quality } \\
\text { of life }\end{array}$ & -0.12 & -0.45 to 0.20 \\
\hline $\begin{array}{l}\text { Sherman et } \\
\text { al. (2010) }\end{array}$ & $\begin{array}{l}\text { Post- } \\
\text { intervention } \\
\text { ( } 8 \text { weeks past } \\
\text { baseline) } \\
\end{array}$ & FACT-B + 4 & $\begin{array}{l}\text { Exercise compared to } \\
\text { waitlist control }\end{array}$ & $\begin{array}{l}\text { Global quality } \\
\text { of life }\end{array}$ & 0.43 & 0.08 to 0.78 \\
\hline $\begin{array}{l}\text { Van Weert et } \\
\text { al. (2005) }\end{array}$ & $\begin{array}{l}\text { Follow-up at } \\
\text { three months } \\
\text { ( } 27 \text { weeks past } \\
\text { baseline) }\end{array}$ & RAND-36 & $\begin{array}{l}\text { Results of both } \\
\text { intervention groups } \\
\text { are presented as an } \\
\text { aggregate; follow-up } \\
\text { compared to baseline }\end{array}$ & $\begin{array}{l}\text { General health } \\
\text { appraisal } \\
\end{array}$ & 0.21 & -0.14 to 0.56 \\
\hline
\end{tabular}

When comparing results from RCTs with those from nonrandomized studies, the findings did not differ. The only article that did not find an improvement for any of the outcome measures was a pretest-post-test study ${ }^{38}$. The other nonrandomized studies, in general, found improvements for a greater proportion of the reported outcome measures than did the RCTs.

The methodological assessment (Table 4) showed that the risk for bias varied widely. The categories "selective reporting," "other source of bias," and "allocation concealment," when applicable, were predominantly assessed as having a low risk for bias, whereas the category "incomplete outcome data" was, in many cases, assessed as having a high risk for bias. Regarding the categories "blinding of participants and 
personnel" and "blinding of outcome assessment," most articles were assessed as having an unclear risk for bias.

Table 4: Quality assessment of multidimensional effectiveness articles

\begin{tabular}{|c|c|c|c|c|c|c|c|}
\hline & $\begin{array}{l}\text { Random } \\
\text { sequence } \\
\text { generation }\end{array}$ & $\begin{array}{l}\text { Allocation } \\
\text { conceal- } \\
\text { ment }\end{array}$ & $\begin{array}{l}\text { Blinding of } \\
\text { participants } \\
\text { and } \\
\text { personnel }\end{array}$ & $\begin{array}{l}\text { Blinding of } \\
\text { outcome } \\
\text { assessment }\end{array}$ & $\begin{array}{c}\text { Incomplete } \\
\text { outcome } \\
\text { data }\end{array}$ & $\begin{array}{l}\text { Selective } \\
\text { reporting }\end{array}$ & $\begin{array}{c}\text { Other } \\
\text { source of } \\
\text { bias }\end{array}$ \\
\hline Berglund et al., 2004 & $?$ & $?$ & $?$ & $?$ & + & + & - \\
\hline Fillion et al.,2008 & + & + & - & $?$ & + & + & - \\
\hline Hanssens et al., 2011 & $\mathrm{~N} / \mathrm{a}$ & $\mathrm{N} / \mathrm{a}$ & $\mathrm{N} / \mathrm{a}$ & $\mathrm{N} / \mathrm{a}$ & + & + & + \\
\hline $\begin{array}{l}\text { Hartmann et al., } \\
2007\end{array}$ & $?$ & $?$ & $?$ & $?$ & - & - & - \\
\hline Heim et al., 2007 & - & $?$ & $?$ & $?$ & - & + & - \\
\hline Korstjens et al., 2006 & $\mathrm{~N} / \mathrm{a}$ & $\mathrm{N} / \mathrm{a}$ & $\mathrm{N} / \mathrm{a}$ & $\mathrm{N} / \mathrm{a}$ & $?$ & + & + \\
\hline Korstjens et al., 2008 & - & + & - & $?$ & - & + & + \\
\hline Lee et al., 2010 & $\mathrm{~N} / \mathrm{a}$ & $\mathrm{N} / \mathrm{a}$ & $\mathrm{N} / \mathrm{a}$ & $\mathrm{N} / \mathrm{a}$ & - & + & + \\
\hline May et al., 2008 & + & + & $?$ & $?$ & - & + & + \\
\hline May et al., 2009 & - & + & $?$ & $?$ & - & + & + \\
\hline Rogers et al., 2009 & + & $?$ & - & $?$ & + & + & + \\
\hline Sherman et al., 2010 & $\mathrm{~N} / \mathrm{a}$ & $\mathrm{N} / \mathrm{a}$ & $?$ & $?$ & - & - & - \\
\hline $\begin{array}{l}\text { Van Weert et al., } \\
2004\end{array}$ & $\mathrm{~N} / \mathrm{a}$ & $\mathrm{N} / \mathrm{a}$ & $\mathrm{N} / \mathrm{a}$ & $?$ & + & + & + \\
\hline $\begin{array}{l}\text { Van Weert et al., } \\
2005\end{array}$ & $?$ & $?$ & $?$ & $?$ & + & - & $?$ \\
\hline $\begin{array}{l}\text { Van Weert et al., } \\
2006\end{array}$ & $\mathrm{~N} / \mathrm{a}$ & $\mathrm{N} / \mathrm{a}$ & $\mathrm{N} / \mathrm{a}$ & $\mathrm{N} / \mathrm{a}$ & + & + & + \\
\hline $\begin{array}{l}\text { Van Weert et al., } \\
2010\end{array}$ & + & + & - & + & + & + & - \\
\hline
\end{tabular}

-=High risk of bias, $+=$ Low risk of bias, ?=Unclear risk of bias, $n / a=$ not applicable

\section{Economic evaluations}

Six articles met the inclusion criteria for economic evaluations ${ }^{48-53}$ (Table 5). All economic evaluations were published in 2005-2011. Three articles were costeffectiveness analyses (CEA), one was a combined CEA and cost-utility analysis, one was a cost-utility analysis, and one contained both a cost-minimization analysis (CMA) and a CEA. Four articles adopted a societal perspective $48,49,51,53$, one used a health care system perspective ${ }^{50}$, and one used a hospital perspective ${ }^{52}$. Analyses were based on multicentre RCTs ${ }^{49-51,53}$, a quasi-experimental design ${ }^{48}$, and modelling ${ }^{52}$. Intervention patients were compared with a control group of patients who received no intervention $^{48}$, another intervention ${ }^{49}$, or standard care ${ }^{50-53}$. The included patients were 
breast cancer patients ${ }^{48-51}$, breast, colon, or cervical cancer patients ${ }^{53}$, and head and neck cancer patients ${ }^{52}$. The effectiveness outcomes measured in the articles were, in these combinations, the number of rehabilitated cases and quality-adjusted life years $(\mathrm{QALYS})^{48}$, distress and energy ${ }^{51}$, mood and pain ${ }^{50}$, fear of regression and QALYS ${ }^{53}$, and QALYS ${ }^{49,52}$. Significant benefits over the control group were found for QALYs ${ }^{48,52,53}$, energy $^{51}$, fear of regression ${ }^{53}$, and mood and pain ${ }^{50}$. The costs of the interventions were in the range of $€ 19$, for a videotape intervention ${ }^{41}$, to $€ 793$, for a group-based exercise and psychosocial intervention ${ }^{48}$. The incremental cost-effectiveness ratios (ICERs) when QALYs were measured and the intervention evaluated was effective were in the range of -€16,976 per QALY (which implies cost savings), for adding CBT to standard inpatient rehabilitation ${ }^{53}$, to $€ 11,072$ per QALY, for a group-based exercise and psychosocial intervention ${ }^{48}$. For other outcome measures, incremental costs of $-€ 78,742$, for adding CBT to standard inpatient rehabilitation ${ }^{53}$, to $€ 4,098$, for supportive-expressive group therapy ${ }^{40}$, were found for one unit of difference in effect. For outcomes for which no significant effect was established, usual care and doing nothing were the most costeffective strategies. The CMA did not find a significant difference in costs ${ }^{50}$. 
Table 5: Summary of economic evaluations

\begin{tabular}{|c|c|c|c|c|c|}
\hline Study & $\begin{array}{l}\text { Method, } \\
\text { perspective, } \\
\text { cost year }\end{array}$ & $\begin{array}{l}\text { Intervention and } \\
\text { comparator }\end{array}$ & $\begin{array}{l}\text { Outcome, } \\
\text { participants }\end{array}$ & Results & $\begin{array}{l}\text { Sensitivity analyses and } \\
\text { outcomes }\end{array}$ \\
\hline $\begin{array}{l}\text { Gordon et } \\
\text { al. (2005), } \\
\text { Australia }\end{array}$ & $\begin{array}{l}\text { CEA alongside } \\
\text { trial, societal } \\
\text { perspective, } \\
2004\end{array}$ & $\begin{array}{l}\text { Home-based } \\
\text { physiotherapy } \\
\text { (DAART), n=36/ } \\
\text { group-based } \\
\text { exercise and } \\
\text { psychosocial } \\
\text { intervention } \\
\text { (STRETCH), n=31; } \\
\text { versus non- } \\
\text { intervention group, } \\
\mathrm{n}=208\end{array}$ & $\begin{array}{l}\text { Rehabilitated } \\
\text { cases, QALYS; } \\
\text { primary breast } \\
\text { cancer patients }\end{array}$ & $\begin{array}{l}\text { Rehabilitated cases: Non- } \\
\text { intervention is more effective } \\
\text { and less costly than the } \\
\text { intervention groups. ICER for } \\
\text { DAART is AUS } \$ 2,217 \text { and for } \\
\text { STRETCH AUS } \$-31,367 \\
\text { compared to non- } \\
\text { intervention. QALY: The } \\
\text { intervention groups were } \\
\text { more effective and more } \\
\text { costly. ICER of DAART is AUS\$ } \\
1,344 \text { and of STRETCH AUS } \$ \\
14,478\end{array}$ & $\begin{array}{l}\text { One-way. Most values } \\
\text { did not influence the } \\
\text { outcome. Leisure time } \\
\text { valuation, health care } \\
\text { expenditure and utility } \\
\text { scores were most } \\
\text { influential. }\end{array}$ \\
\hline $\begin{array}{l}\text { Haines } \\
\text { (2010), } \\
\text { Australia }\end{array}$ & $\begin{array}{l}\text { CEA, societal } \\
\text { perspective, } \\
2006\end{array}$ & $\begin{array}{l}\text { Multimedia physical } \\
\text { activity program } \\
\text { consisting of home- } \\
\text { based strength, } \\
\text { balance, shoulder } \\
\text { mobility and a } \\
\text { cardiovascular } \\
\text { endurance program, } \\
\mathrm{n}=37 \text {; versus control } \\
\text { group receiving an } \\
\text { active intervention } \\
\text { of flexibility and } \\
\text { relaxation exercises, } \\
\mathrm{n}=36\end{array}$ & $\begin{array}{l}\text { QALYs; breast } \\
\text { cancer patients }\end{array}$ & $\begin{array}{l}\text { The intervention group had } \\
\text { greater effects at three- } \\
\text { months but not at six months- } \\
\text { follow-up. Total mean costs } \\
\text { were AUS } \$ 3,864 \text { for the } \\
\text { physical activity program and } \\
\text { AUS } \$ 3,594 \text { for the control } \\
\text { condition. Intervention was } \\
\text { more expensive but not more } \\
\text { effective. Willingness-to-pay } \\
\text { would need to be } \\
\text { AUS } \$ 484,884 \text { or AUS } \$ 340,391 \\
\text { when health care cost-outliers } \\
\text { are excluded. }\end{array}$ & $\begin{array}{l}\text { One-way analysis } \\
\text { excluding outlier costs. } \\
\text { Without these the costs } \\
\text { of the intervention group } \\
\text { are lower than costs of } \\
\text { the control group } \\
\text { (AUS } \$ 3,290 \text { vs. } \\
\text { AUS } \$ 3,775 \text { respectively). } \\
\end{array}$ \\
\hline $\begin{array}{l}\text { Lemieux et. } \\
\text { al. (2006), } \\
\text { Canada }\end{array}$ & $\begin{array}{l}\text { CMA \& CEA } \\
\text { alongside trial, } \\
\text { health care } \\
\text { system } \\
\text { perspective, } \\
\text { Fiscal period } \\
\text { 2002/2003 }\end{array}$ & $\begin{array}{l}\text { Supportive- } \\
\text { expressive group } \\
\text { therapy, } \mathrm{n}=43 \text {, } \\
\text { versus control } \\
\text { group, } \mathrm{n}=82\end{array}$ & $\begin{array}{l}\text { CMA: health } \\
\text { care utilization } \\
\text { costs, } \\
\text { CEA: mood, } \\
\text { pain; metastatic } \\
\text { breast cancer } \\
\text { patients }\end{array}$ & $\begin{array}{l}\text { Health care utilization costs } \\
\text { were the same in both } \\
\text { groups. The intervention was } \\
\text { more effective and more } \\
\text { costly. Incremental costs are } \\
\text { CAN } \$ 5,550 \text { and CAN } \$ 4,309 \\
\text { for an effect size of change in } \\
\text { mood and pain respectively. }\end{array}$ & $\begin{array}{l}\text { One-way. Not any of the } \\
\text { analyses resulted in a } \\
\text { difference of health care } \\
\text { utilization costs in the } \\
\text { two arms. }\end{array}$ \\
\hline $\begin{array}{l}\text { Mandel- } \\
\text { blatt et al. } \\
\text { (2008), US }\end{array}$ & $\begin{array}{l}\text { CEA alongside } \\
\text { trial, societal } \\
\text { perspective; not } \\
\text { stated, patient- } \\
\text { time costs are } \\
\text { from } 2002\end{array}$ & $\begin{array}{l}\text { Videotape } \\
\text { intervention, } n=128 \text { / } \\
\text { Videotape } \\
\text { intervention }+ \\
\text { psycho-educational } \\
\text { counseling, } n=135 ; \\
\text { versus control group } \\
\text { receiving printed } \\
\text { information, } n=389 \\
\end{array}$ & $\begin{array}{l}\text { Distress and } \\
\text { energy, breast } \\
\text { cancer patients } \\
\text { in any stage } \\
\text { after surgery }\end{array}$ & $\begin{array}{l}{ }^{1} \text { Counseling was less effective } \\
\text { and more expensive than the } \\
\text { videotape intervention. } \\
\text { Distress: Videotape } \\
\text { intervention costs } \$ 7,275 \text { per } \\
\text { unit of change in distress. } \\
\text { Energy: Videotape } \\
\text { intervention costs } \$ 2.22 \text { per } \\
\text { unit of change in energy. }\end{array}$ & $\begin{array}{l}\text { One-way. Counseling } \\
\text { intervention would need } \\
\text { to be six times more } \\
\text { effective on increasing } \\
\text { energy and } 20 \% \text { more } \\
\text { effective on lowering } \\
\text { distress to be as cost- } \\
\text { effective as the videotape } \\
\text { arm. }\end{array}$ \\
\hline $\begin{array}{l}\text { Retèl et al. } \\
\text { (2011), The } \\
\text { Nether- } \\
\text { lands }\end{array}$ & $\begin{array}{l}\text { Cost-utility } \\
\text { analysis based } \\
\text { on modeling, } \\
\text { health care } \\
\text { perspective of } \\
\text { the Netherlands } \\
\text { Cancer } \\
\text { Institute, } 2008 \\
\end{array}$ & $\begin{array}{l}\text { Preventive } \\
\text { (swallowing) exercise } \\
\text { program, } n=37 ; \\
\text { versus standard } \\
\text { care, } n=53\end{array}$ & $\begin{array}{l}\text { QALYS, head } \\
\text { and neck } \\
\text { cancer patients }\end{array}$ & $\begin{array}{l}\text { Intervention is more effective } \\
\text { and more costly. ICER of } \\
€ 3,197 \text { per QALY. }\end{array}$ & $\begin{array}{l}\text { One-way and two-way. } \\
\text { Majority of analyses } \\
\text { resulted in an ICER below } \\
€ 20,000 \text { per QALY. For } \\
\text { lower costs, the } \\
\text { intervention is more } \\
\text { effective and less costly } \\
\text { than standard care. }\end{array}$ \\
\hline $\begin{array}{l}\text { Sabariego } \\
\text { (2011), }\end{array}$ & $\begin{array}{l}\text { CEA, societal } \\
\text { perspective, not }\end{array}$ & $\begin{array}{l}\text { Standard inpatient } \\
\text { rehabilitation }\end{array}$ & $\begin{array}{l}\text { Fear of } \\
\text { progression }\end{array}$ & $\begin{array}{l}\text { CBT is slightly more effective } \\
\text { and less costly, with an ICER }\end{array}$ & $\mathrm{N} / \mathrm{a}$ \\
\hline
\end{tabular}




\begin{tabular}{|c|c|c|c|c|}
\hline Germany & $\begin{array}{l}\text { stated. Patient- } \\
\text { time costs are } \\
\text { from } 2002\end{array}$ & $\begin{array}{l}\text { program plus } \\
\text { cognitive-behavioral } \\
\text { therapy (CBT), } n=91 \text {; } \\
\text { versus standard } \\
\text { inpatient rehabilita- } \\
\text { tion program plus } \\
\text { non-directive and } \\
\text { unspecific } \\
\text { intervention (SET), } \\
n=83\end{array}$ & $\begin{array}{l}\text { and quality of } \\
\text { life; breast, } \\
\text { colon, and } \\
\text { cervical cancer } \\
\text { patients }\end{array}$ & $\begin{array}{l}\text { of minus } € 16,976 \text { for an } \\
\text { additional unit of effect in fear } \\
\text { of progression. The ICER for } \\
\text { quality of life was minus } \\
€ 78,742 \text { suggesting CBT has } \\
\text { similar effects and fewer costs } \\
\text { than SET. }\end{array}$ \\
\hline
\end{tabular}

QAL=Quality-adjusted life year, CEA=Cost-effectiveness analysis, CMA=Costminimization analysis, ICER=Incremental cost-effectiveness ratio 1) This evaluation used the measurement at six-months. The original trial did not find any significant effect at the 12-months follow-up.

The methodological quality was moderate to good (Table 6). Positive aspects of the articles reviewed are that almost all economic evaluations gave a description of the interventions, non-intervention or, for ethical reasons, an intervention similar to doing nothing. Five articles ${ }^{48-51,53}$ were CEAs alongside RCTs in the natural setting, reflecting what probably would happen in practice. A methodological limitation is that none of the economic evaluations were based on a systematic review of effectiveness data. Also, four articles assessed the cost-effectiveness of interventions that have not been shown or have only partly been shown to be effective ${ }^{48-51}$. Finally, two articles did not include all relevant costs and effects ${ }^{50,51}$ and three articles did not cover all relevant viewpoints ${ }^{51-53}$. 
Table 6: Assessment of methodological quality of economic evaluations

\begin{tabular}{|c|c|c|c|c|c|c|}
\hline & $\begin{array}{l}\text { Gordon } \\
\text { et al. } \\
(2005)\end{array}$ & $\begin{array}{l}\text { Haines } \\
\text { et al. } \\
\text { (2010) }\end{array}$ & $\begin{array}{l}\text { Lemieux } \\
\text { et al. } \\
(2006)\end{array}$ & $\begin{array}{c}\text { Mandel- } \\
\text { blatt et } \\
\text { al. } \\
\text { (2008) }\end{array}$ & $\begin{array}{l}\text { Retèl et } \\
\text { al. (2011) }\end{array}$ & $\begin{array}{l}\text { Sabarie- } \\
\text { go et al. } \\
\text { (2011) }\end{array}$ \\
\hline 1. Well-defined question posed? & Yes & Yes & No & Yes & Yes & Yes \\
\hline $\begin{array}{l}\text { Were both costs and effects } \\
\text { examined? }\end{array}$ & Yes & Yes & Yes & Yes & Yes & Yes \\
\hline $\begin{array}{l}\text { Did the study compare } \\
\text { alternatives? }\end{array}$ & Yes & Yes & Yes & Yes & Yes & Yes \\
\hline $\begin{array}{l}\text { Was the viewpoint of the analysis } \\
\text { stated? }\end{array}$ & Yes & Yes & Yes & Yes & Yes & Yes \\
\hline $\begin{array}{l}\text { Was the study placed in specific } \\
\text { decision-making context? }\end{array}$ & Yes & Yes & No & Yes & Yes & Yes \\
\hline $\begin{array}{l}\text { 2. Was a description of the } \\
\text { alternatives given? }\end{array}$ & No & Yes & Yes & Yes & Yes & No \\
\hline $\begin{array}{l}\text { Were any relevant alternatives } \\
\text { omitted? }\end{array}$ & No & No & No & No & No & Yes \\
\hline $\begin{array}{l}\text { Was (should) doing-nothing (be) } \\
\text { considered? }\end{array}$ & Yes & Yes & $\mathrm{n} / \mathrm{a}$ & $\mathrm{n} / \mathrm{a}$ & $\mathrm{n} / \mathrm{a}$ & Yes \\
\hline $\begin{array}{l}\text { 3. Was the effectiveness } \\
\text { established? }\end{array}$ & Partly & No & Partly & Partly & Yes & Yes \\
\hline $\begin{array}{l}\text { Randomized controlled trial: } \\
\text { Reflection of what happens in } \\
\text { practice? }\end{array}$ & $n / a$ & Yes & Yes, n/a & Yes & Yes, n/a & Yes \\
\hline $\begin{array}{l}\text { Effectiveness data summarized } \\
\text { through systematic review? Search } \\
\text { strategy outlined? }\end{array}$ & No & No & No & No & No & No \\
\hline $\begin{array}{l}\text { Observational data or assumptions } \\
\text { used: What are potential biases in } \\
\text { the results? }\end{array}$ & $\mathrm{n} / \mathrm{a}$ & No & $\mathrm{n} / \mathrm{a}$ & $\mathrm{n} / \mathrm{a}$ & $\mathrm{n} / \mathrm{a}$ & No \\
\hline $\begin{array}{l}\text { 4. Were all relevant and important } \\
\text { costs and consequences identified } \\
\text { for each alternative? }\end{array}$ & Yes & Yes & No & No & Yes & Yes \\
\hline $\begin{array}{l}\text { Was the range wide enough for } \\
\text { the question? }\end{array}$ & Yes & Yes & No & No & Yes & Yes \\
\hline $\begin{array}{l}\text { Did it cover all relevant } \\
\text { viewpoints? }\end{array}$ & Yes & Yes & Yes & No & No & No \\
\hline $\begin{array}{l}\text { Were capital and operating costs } \\
\text { included? }\end{array}$ & $\mathrm{n} / \mathrm{a}$ & $\mathrm{N} / \mathrm{a}$ & Yes, n/a & Yes, n/a & $\mathrm{n} / \mathrm{a}$ & Yes \\
\hline $\begin{array}{l}\text { 5. Were costs and consequences } \\
\text { measured accurately in } \\
\text { appropriate units? }\end{array}$ & Yes & Yes & Partly & Yes & Yes & Yes \\
\hline $\begin{array}{l}\text { Sources of utilization described } \\
\text { and justified? }\end{array}$ & Yes, Yes & Yes & Yes, No & Yes, Yes & Yes, Yes & No \\
\hline
\end{tabular}




\begin{tabular}{|c|c|c|c|c|c|c|}
\hline $\begin{array}{l}\text { Were any identified items omitted } \\
\text { from measurement? }\end{array}$ & No & No & Yes & No & No & No \\
\hline $\begin{array}{l}\text { Special circumstances that made } \\
\text { measurement difficult: Handled } \\
\text { appropriately? }\end{array}$ & No & $\mathrm{N} / \mathrm{a}$ & Yes & $\mathrm{n} / \mathrm{a}$ & $\mathrm{n} / \mathrm{a}$ & Yes \\
\hline $\begin{array}{l}\text { 6. Costs and consequences valued } \\
\text { credibly? }\end{array}$ & Partly & Yes & Partly & Yes & Yes & Unclear \\
\hline $\begin{array}{l}\text { Were the sources of all values } \\
\text { clearly identified? }\end{array}$ & No & Partly & Yes & Yes & Yes & No \\
\hline Were market values used? & Yes & Yes & Partly & Yes & Yes & Unclear \\
\hline $\begin{array}{l}\text { Market value absent: } \\
\text { Approximations used? }\end{array}$ & Unclear & Yes & Partly & Yes & Yes & Unclear \\
\hline $\begin{array}{l}\text { Valuation of consequences } \\
\text { appropriate? }\end{array}$ & Yes & Yes & Yes & Yes & Yes & Yes \\
\hline $\begin{array}{l}\text { 7. Were costs and consequences } \\
\text { adjusted for differential timing? }\end{array}$ & $\mathrm{n} / \mathrm{a}$ & $\mathrm{N} / \mathrm{a}$ & $\mathrm{n} / \mathrm{a}$ & $\mathrm{n} / \mathrm{a}$ & Yes & N/a \\
\hline $\begin{array}{l}\text { Were future costs and } \\
\text { consequences discounted to their } \\
\text { present value? }\end{array}$ & $\mathrm{n} / \mathrm{a}$ & $\mathrm{N} / \mathrm{a}$ & $n / a$ & $\mathrm{n} / \mathrm{a}$ & Yes & $\mathrm{N} / \mathrm{a}$ \\
\hline $\begin{array}{l}\text { Justification given for the discount } \\
\text { rate used? }\end{array}$ & $\mathrm{n} / \mathrm{a}$ & $\mathrm{N} / \mathrm{a}$ & $\mathrm{n} / \mathrm{a}$ & $\mathrm{n} / \mathrm{a}$ & $\mathrm{n} / \mathrm{a}$ & N/a \\
\hline $\begin{array}{l}\text { 8. Was an incremental analysis of } \\
\text { costs and consequences of } \\
\text { alternatives performed? }\end{array}$ & Yes & Yes & Yes & Yes & Yes & $\mathrm{N} / \mathrm{a}$ \\
\hline $\begin{array}{l}\text { Additional costs compared to } \\
\text { additional effect? }\end{array}$ & Yes & Yes & Yes & Yes & Yes & N/a \\
\hline $\begin{array}{l}\text { 9. Was allowance made for } \\
\text { uncertainty for the estimates of } \\
\text { costs and consequences? }\end{array}$ & Yes & Yes & Yes & Yes & Yes & No \\
\hline $\begin{array}{l}\text { Appropriate statistical analyses of } \\
\text { patient-level data? }\end{array}$ & Unclear & Yes & Yes & Yes & Unclear & Yes \\
\hline $\begin{array}{l}\text { Justification for the ranges or } \\
\text { distributions of values for the } \\
\text { sensitivity analysis given? }\end{array}$ & Yes & Yes & Yes & Yes & No & N/a \\
\hline $\begin{array}{l}\text { Were conclusions sensitive to } \\
\text { uncertainty? }\end{array}$ & Yes & Yes & No & No & Yes & $\mathrm{N} / \mathrm{a}$ \\
\hline $\begin{array}{l}\text { 10. Did the presentation and } \\
\text { discussion of study results includes } \\
\text { all relevant issues? }\end{array}$ & No & No & No & No & No & Yes \\
\hline $\begin{array}{l}\text { Were the conclusion based on a } \\
\text { cost-effect-ratio? }\end{array}$ & Yes & Yes & Yes & Yes & Yes & Yes \\
\hline $\begin{array}{l}\text { Were the results compared to } \\
\text { previous studies? }\end{array}$ & No & No & No & Yes & No & Partly \\
\hline Was the generalizability discussed? & Yes & No & No & Yes & Yes & No \\
\hline Were any other important factors & Yes & No & Yes & $n / a$ & Yes & Yes \\
\hline
\end{tabular}




\begin{tabular}{lllllll}
\hline discussed? & & & & & & \\
\hline $\begin{array}{l}\text { Were issues of implementation } \\
\text { discussed? }\end{array}$ & Yes & No & No & No & No & No \\
\hline
\end{tabular}

$\mathrm{n} / \mathrm{a}=$ Not applicable

\section{Discussion}

Evidence on the effectiveness of multidimensional cancer survivor rehabilitation and the cost-effectiveness of cancer rehabilitation in general was systematically assessed in this review. The number of papers meeting the inclusion criteria, 16 effectiveness studies and 6 economic evaluations, shows that the evidence base for the effectiveness and economic impact of multidimensional cancer survivor rehabilitation and for cancer rehabilitation in general is scarce. Moreover, the majority of existing studies focused on exercise interventions plus a CBT or psychological educational intervention, whereas studies including other interventions, like return-to-work programs or patient empowerment, are lacking. A similar pattern was found for mono-dimensional interventions in the economic evaluations.

Regarding the type of participants, 5 of the 16 multidimensional studies exclusively included breast cancer patients, and of the articles that aimed to include survivors of any type of cancer, the majority of participants were breast cancer survivors. This pattern applies to the economic evaluations as well, of which the majority exclusively included breast cancer patients. Therefore, generalizability of the results to other tumour groups might be limited, and when using these findings for other cancer types this should be considered carefully. In conclusion, the evidence base for cancer rehabilitation is dominated by exercise intervention studies in breast cancer survivors, whereas published evidence for other aspects of cancer rehabilitation and other tumour populations is lagging behind.

Most studies evaluating the effectiveness of multidimensional rehabilitation (i.e., programs with exercise plus another intervention) reported statistically significant $32-34,36$, 37, 39-47 and clinically relevant ${ }^{44}$ benefits in at least one of the outcome measures reported. Although two studies found significant benefits in all outcome measures ${ }^{43,47}$, most studies only reported significant benefits in some outcome measures, mostly fatigue and physical outcomes $33,37,38,40,42,44,45$. The nonrandomized studies found significant improvements in a greater proportion of outcome measures than did RCTs, but in terms of conclusions the outcomes of randomized and nonrandomized studies 
were the same. When a multidimensional rehabilitation program was compared with the mono-dimensional interventions (i.e., exercise plus another intervention vs. exercise alone), no additional effect was reported ${ }^{42-45}$. Adding another exercise intervention to a rehabilitation program that was already multidimensional resulted in further benefits for physical outcome measures and quality of life ${ }^{36}$, whereas adding longer follow-up to inpatient rehabilitation did not result in greater effectiveness ${ }^{35}$.

Statistically significant benefits associated with multidimensional rehabilitation were reported in all the studies that employed a one-group design (pretest-post-test studies and longitudinal cohort studies), except one ${ }^{38}$, and in all quasi-experimental and experimental studies that compared multidimensional rehabilitation with usual care without dedicated rehabilitation or with waitlist controls $32,37,38,46$. The four articles, based on one trial that compared a multidimensional rehabilitation program with a monodimensional intervention ${ }^{42-45}$ did not observe the multidimensional intervention to be more (or less) effective than the exercise only control for outcomes that included physical activity, muscle strength, fatigue, and HRQoL. Although not evident from the quality score, methodological aspects may have contributed to this finding, for example, the open-access character of the program and operational differences among treatment sites. Furthermore, studies might have been underpowered to evaluate secondary outcomes such as HRQOL.

The economic evaluations all assessed very different interventions. Despite the low comparability of studies, all showed acceptable cost-effectiveness ratios for interventions that produced significant health gains. The included cost-utility studies reported ICERS well below the prevailing willingness-to-pay thresholds, or even cost savings, suggesting that cancer rehabilitation is potentially a cost-effective means of allocating scarce health care resources, if effective. When interpreting the results, it should be noted that trial participants could be cancer patients during treatment, chronic cancer patients, and cancer survivors. This could influence the results considerably, because a shorter life expectancy results in a lower potential to generate QALYs, and active disease causes higher treatment costs. Also, it is increasingly argued that higher ceiling ratios should be applied for patients with a high burden of disease, although this is currently not formalized nor a prevailing practice for any of the decision-making bodies.

Our results correspond to the findings of a previous review ${ }^{54}$ on economic evaluations of psychosocial interventions. Gordon et al. ${ }^{54}$ also reported acceptable ICERs, although the available studies showed great heterogeneity and were of suboptimal quality. Our review included four additional studies with acceptably low ICERs, which further adds to the evidence suggesting that cancer rehabilitation can be cost-effective. However, in 
view of the large expected number of survivors, detailed information on costeffectiveness from both the societal and health care perspectives is needed for making informed decisions. It might be relevant to use the experience from cardiac rehabilitation, for which multidimensional rehabilitation-though for a limited number of conditions - is recommended as standard practice and more evidence on the costeffectiveness of multidisciplinary rehabilitation is available ${ }^{55,56}$. For other diseases, such as low back pain ${ }^{57}$, neglect ${ }^{58}$, and traumatic brain injury ${ }^{59}$, mixed results have been found for the greater effectiveness of multidimensional rehabilitation programs comapred single interventions.

Several methodological issues identified in this review give rise to recommendations for future studies. First, the underlying assumption of the need for multidimensional rehabilitation is that cancer survivors have one or more symptoms that, to be addressed appropriately, require multiple rehabilitation interventions. In addition, one would expect that the intervention or combination of interventions offered depends on the specific symptoms a patient experiences. However, in about half of the articles ${ }^{32-40}$, it was not an explicit inclusion criterion for patients to have one or more specific symptoms. In the remaining articles ${ }^{41-47}$, having several symptoms was specified as an inclusion criterion, but because the nature and severity of the symptoms at baseline were not described in a standardized way, it is unclear to what extent the interventions addressed the specific symptoms appropriately. Therefore, it is difficult to assess the ES that could reasonably have been expected for the chosen primary endpoints and whether or not the sample sizes were large enough to observe an incremental effect from multidimensional interventions over mono-dimensional interventions in a heterogeneous population.

Although many studies are available that report the prevalence of the symptoms from which cancer survivors suffer, a more detailed description of the prevalence of combinations of symptoms is lacking ${ }^{6}$. Because trial participants might suffer from a great variety of symptoms, patient samples may actually be more heterogeneous than the predominantly clinical baseline measures show. In future studies on both multidimensional and mono-dimensional interventions, the match between the nature and severity of specific patient symptoms and the interventions offered should be described more explicitly.

Another potential methodological flaw in the current evidence base is the length of patient follow-up. In most articles, the follow-up duration was very short and the measurement was performed directly at the end of the intervention $34,37-41,43,45,47$. Therefore, some effects that may typically occur over the longer run (e.g., changes in 
emotional distress, depression) may not have been observed within these short followup times and could interfere, even if not chosen as the primary endpoint.

Moreover, the incorporated studies included cancer survivors with an estimated life expectancy $\sim 1$ year. This can lead to the inclusion of chronic cancer patients with a life expectancy of 1-2 years or more and also cured cancer survivors in whom the disease will not return. Depending on life expectancy (and potentially other factors), these patients and survivors may have very different rehabilitation needs. However, from the included studies, it is not possible to distinguish firmly to which group the results apply: cancer survivors with a very good life expectancy outlook or chronic cancer patients. Future studies should provide more detailed descriptions of the treatment outcomes and the estimated life expectancy of the participants.

The quality assessment showed that future trials could be improved by using blinding in outcome assessments when possible. Regarding trial design, future studies should compare the multidimensional intervention with the single components it consists of and with usual care to detect any additional effect of multidimensional rehabilitation. An example of this design is a trial by Duijts et al. ${ }^{60}$, in which CBT and relaxation combined with exercise was compared with CBT and relaxation, exercise, and a waitlist control for relieving symptoms of treatment-induced menopause. In addition, pragmatic trials, which are more suitable for providing information for clinical and policy decision making ${ }^{61}$, could form a valuable addition to the evidence derived from RCTs. Research should also involve cancer types other than breast cancer. If all types of cancer are to be included in studies, greater effort should be made to obtain samples representative of the various subgroups and tumour types.

Regarding economic evaluations, it is recommended to use QALYs for enabling comparability among various rehabilitation programs and with other health services. Furthermore, the scarcity of economic evaluations should lead researchers to routinely include cost data in their studies.

\section{Conclusion}

Cancer rehabilitation guidelines are increasingly being implemented in many western countries and the evidence base is growing rapidly. Evidence for multidimensional interventions and the economic impact of rehabilitation interventions is still scarce, but studies published so far report statistically significant benefits for multidimensional interventions over usual care, particularly for fatigue and physical outcome measures. 
No additional benefit of multidimensional rehabilitation over mono-dimensional intervention was found, but this was also sparsely reported on. These findings should be interpreted with caution because the existing literature base is dominated by exercise intervention studies in breast cancer survivors. Published evidence for combinations with other interventions in cancer rehabilitation, like return-to-work programs, and evidence for other cancer populations are lagging behind. The available economic evaluations assessed very different rehabilitation interventions. Yet, despite their low comparability, all showed acceptable cost-effectiveness ratios or cost savings for those interventions that produced significant health gains. Recommendations for future studies include better targeting of all available interventions to patients' needs, longer trial follow-up, and the use of QALYs and cost data in all studies. 


\section{References}

1. Verdecchia A, Francisci S, Brenner $H$ et al. Recent cancer survival in Europe: A 2000-02 period analysis of EUROCARE-4 data. Lancet Oncology 2007; 8: 784-96.

2. Surveillance Epidemiology and End Results. SEER Cancer Statistics Review 19752008.

seer.cancer.gov/csr/1975_2008/browse_csr.php?section_2\&page_sect_02_table.08 .html (accessed 9 December 2011).

3. Signaleringscommissie Kanker van KWF Kankerbestrijding. Kanker in Nederland: trends, prognoses en implicaties voor zorgvraag. Amsterdam: KWF Kankerbestrijding, 2004.

4. Hewitt M, Rowland JH, Yancik R. Cancer survivors in the United States: age, health, and disability. The Journals of Gerontology Series A: Biological Sciences and Medical Sciences 2003; 58: 82-91.

5. Harrington CB, Hansen JA, Moskowitz $M$ et al. It's not over when it's over: longterm symptoms in cancer survivors: a systematic review. International Journal of Psychiatry in Medicine 2010; 40:163-81.

6. Hewitt M, Greenfield S, Stovall E, eds. From cancer patient to cancer survivor: lost in transition. Washington, DC: The National Academies Press, 2006.

7. Mehnert A. Employment and work-related issues in cancer survivors. Critical Reviews in Oncology/Hematology 2011; 77: 109-30.

8. Cheng KK, Thompson DR, Ling WM et al. Measuring symptom prevalence, severity and distress of cancer survivors. Clinical Effectiveness in Nursing 2005; 9: $154-60$.

9. The Netherlands Comprehensive Cancer Organisation. Oncologische revalidatie landelijke richtlijn, versie 1.0. Utrecht: Integraal Kankercentrum Nederland, 2011.

10. Deutsche Rentenversicherung. Reha-Therapiestandards bei Brustkrebs - Leitlinie für die Medizinische Rehabilitation der Rentenversicherung. Berlin: Deutsche Rentenversicherung, 2009.

11. Ugolini D, Neri M, Cesario A et al. Scientific production in cancer rehabilitation grows higher: a bibliometric analysis. Supportive Care in Cancer 2012; 20(8): 162938.

12. Schmitz KH, Courneya KS, Matthews C et al. American College of Sports Medicine roundtable on exercise guidelines for cancer survivors. Medicine \& Science in Sports \& Exercise 2010; 42: 1409-26. 
13. Fong DY, Ho JW, Hui BP et al. Physical activity for cancer survivors: meta-analysis of randomized controlled trials. British Medical Journal 2012; 344: e70.

14. Osborn RL, Demoncada AC, Feuerstein M. Psychosocial interventions for depression, anxiety, and quality of life in cancer survivors: meta-analyses. International Journal of Psychiatry Medicine 2006; 36: 13-34.

15. Kangas M, Bovbjerg DH, Montgomery GH. Cancer-related fatigue: a systematic and meta-analytic review of non-pharmacologic therapies for cancer patients. Psychological Bulletin 2008; 134: 700-41.

16. Duijts SF, Faber MM, Oldenburg HS et al. Effectiveness of behavioral techniques and physical exercise on psychosocial functioning and health-related quality of life in breast cancer patients and survivors: a meta-analysis. Psycho-Oncology 2011; 20: 115-26.

17. De Boer AG, Taskila T, Tamminga SJ et al. Interventions to enhance return-towork for cancer patients. Cochrane Database Systematic Reviews 2011; (2).

18. Speck RM, Courneya KS, Mâsse LC et al. An update of controlled physical activity trials in cancer survivors: a systematic review and meta-analysis. Journal of Cancer Survivorship 2010; 4: 87-100.

19. Doyle C, Kushi LH, Byers $T$ et al. Nutrition and physical activity during and after cancer treatment: an American Cancer Society guide for informed choices. CA: A Cancer Journal for Clinicians 2006; 56: 323-53.

20. National Comprehensive Cancer Network: NCCN clinical practice guidelines in oncology: cancer-related fatigue, version 1.2011. Fort Washington, PA: National Comprehensive Cancer Network, 2010.

21. World Cancer Research Fund/American Institute for Cancer Research. Food, Nutrition, Physical Activity, and the Prevention of Cancer: A Global Perspective. Washington, DC: World Cancer Research Fund/American Institute for Cancer Research, 2007.

22. Richardson A, Addington-Hall J, Amir Z et al. Knowledge, ignorance and priorities for research in key areas of cancer survivorship: findings from a scoping review. British Journal of Cancer 2011; 105(suppl 1): S82-\$94.

23. Sullivan R, Peppercorn J, Sikorak et al. Delivering affordable cancer care in highincome countries. Lancet Oncology 2011; 12: 933-80.

24. Theriault RL. Health care costs: How do we decide value? When do we decide? How do we particularize the decisions? The Oncologist 2012; 17: 157-59. 
25. World Health Organization. International Classification of Functioning, Disability and Health (ICF). Geneva: World Health Organization, 2001. http://www.who.int/classifications/icf/en/, (accessed 11 December 2011).

26. Feuerstein M. Defining cancer survivorship. Journal of Cancer Survivorship 2007; 1: 5-7.

27. Cohen J. Statistical Power Analysis for the Behavioral Sciences. Hillsdale, NJ: Lawrence Erlbaum Associates, 1988.

28. Hedges LV. Distribution theory for Glass's estimator of effect size and related estimators. Journal of Statistics Education 1981; 6: 107-28.

29. Hunter JE, Schmidt FL. Methods of meta-analysis: correcting error and bias in research findings. Thousand Oakes, CA: Sage Publications, 2004.

30. Higgins JPT, Green S, eds. Cochrane Handbook for Systematic Reviews of Interventions, Version 5.1.0. http://www.cochranehandbook.org/, (accessed 1 December 2012).

31. Drummond MF, Sculpher MJ, Torrance GW et al. Methods for the Economic Evaluation of Health Care Programs. Oxford, U.K.: Oxford University Press, 2005.

32. Berglund C, Bolund C, Gustafsson UL et al. One year follow-up of the 'Starting Again' group rehabilitation programme for cancer patients. European Journal of Cancer 1994; 30A: 1744-51.

33. Fillion L, Gagnon P, Leblond $F$ et al. A brief intervention for fatigue management in breast cancer survivors. Cancer Nursing 2008; 31: 145-59.

34. Hanssens S, Luyten R, Watthy $C$ et al. Evaluation of a comprehensive rehabilitation program for posttreatment of patients with cancer. Oncology Nursing Forum 2011; 38: E418-E424.

35. Hartmann U, Muche R, Reuss-Borst M. Effects of a step-by-step inpatient rehabilitation programme on quality of life in breast cancer patients. A prospective randomized study. Onkologie 2007; 30: 177-82.

36. Heim ME, von der Malsburg ML, Niklas A. Randomized controlled trial of a structured training program in breast cancer patients with tumor-related chronic fatigue. Onkologie 2007; 30: 429-34.

37. Korstjens I, Mesters I, van der Peet E et al. Quality of life of cancer survivors after physical and psychosocial rehabilitation. European Journal of Cancer Prevention 2006; 15: 541-7.

38. Lee EO, Chae YR, Song $R$ et al. Feasibility and effects of a tai chi self-help education program for Korean gastric cancer survivors. Oncology Nursing Forum 2010; 37: E1-E6. 
39. Rogers LQ, Hopkins-Price P, Vicari S et al. A randomized trial to increase physical activity in breast cancer survivors. Medical Science in Sports and Exercise 2009; 41: 935-46.

40. Sherman KA, Heard G, Cavanagh KL. Psychological effects and mediators of a multi-component program for breast cancer survivors. Journal of Behavioural Medicine 2010; 33: 378-91.

41. Van Weert E, Hoekstra-Weebers JE, Grol BM et al. Physical functioning and quality of life after cancer rehabilitation. International Journal of Rehabilitation Research 2004; 27: 27-35.

42. Korstjens I, May AM, van Weert E et al. Quality of life after self-management cancer rehabilitation: a randomized controlled trial comparing physical and cognitive-behavioural training versus physical training. Psychosomatic Medicine 2008; 70: 422-29.

43. May AM, Van Weert E, Korstjens I et al. Improved physical fitness of cancer survivors: a randomised controlled trial comparing physical training with physical and cognitive-behavioural training. Acta Oncologica 2008; 47: 825-34.

44. May AM, Korstjens I, van Weert $E$ et al. Long-term effects on cancer survivors: quality of life of physical training versus physical training combined with cognitive behavioral therapy: results from a randomised trial. Supportive Care in Cancer 2009; 17: 653-63.

45. Van Weert E, May AM, Korstjens I et al. Cancer-related fatigue and rehabilitation: a randomized controlled multicenter trial comparing physical training combined with cognitive-behavioral therapy with physical training only and with no intervention. Physical Therapy 2010; 90: 1413-25.

46. van Weert E, Hoekstra-Weebers J, Grol B et al. A multidimensional cancer rehabilitation program for cancer survivors. Effectiveness on health-related quality of life. Journal of Psychosomatic Research 2005; 58: 485-96.

47. van Weert E, Hoekstra-Weebers J, Otter R et al. Cancer-related fatigue: predictors and effects of rehabilitation. The Oncologist 2006; 11: 184-96.

48. Gordon LG, Scuffham P, Battistutta D et al. A cost-effectiveness analysis of two rehabilitation support services for women with breast cancer. Breast Cancer Research and Treatment 2005; 94: 123-33.

49. Haines TP, Sinnamon P, Wetzig NG et al. Multimodal exercise improves quality of life of women being treated for breast cancer, but at what cost? Randomized trial with economic evaluation. Breast Cancer Research and Treatment 2010; 124: 163 75. 
50. Lemieux J, Topp A, Chappell H et al. Economic analysis of psychosocial group therapy in women with metastatic breast cancer. Breast Cancer Research and Treatment 2006; 100: 183-90.

51. Mandelblatt JS, Cullen J, Lawrence WF et al. Economic evaluation alongside a clinical trial of psychoeducational interventions to improve adjustment to survivorship among patients with breast cancer. Journal of Clinical Oncology 2008; 26: 1684-90.

52. Retèl V, van der Molen L, Hilgers FJ et al. A cost-effectiveness analysis of a preventive exercise program for patients with advanced head and neck cancer treated with concomitant chemo-radiotherapy. BMC Cancer 2011; 11: 475.

53. Sabariego C, Brach M, Herschbach P et al. Cost-effectiveness of cognitivebehavioral group therapy for dysfunctional fear of progression in cancer patients. European Journal of Health Economics 2011; 12: 489-97.

54. Gordon LG, Beesley VL, Scuffham PA. Evidence on the economic value of psychosocial interventions to alleviate anxiety and depression among cancer survivors: a systematic review. Asia-Pacific Journal of Clinical Oncology 2011; 7: 96105.

55. Papadakis S, Oldridge NB, Coyle D et al. Economic evaluation of cardiac rehabilitation: a systematic review. European Journal of Cardiovascular Prevention \& Rehabilitation 2005; 12: 513-20.

56. Brown A, Taylor R, Noorani $H$ et al. Exercise-based cardiac rehabilitation programs for coronary artery disease: a systematic clinical and economic review. Technology Report Issue 34. Ottawa, Canada: Canadian Coordinating Office for Health Technology Assessment, 2003.

57. Institute for Clinical and Economic Review. Final appraisal documentmanagement options for patients with low back disorders. Boston, MA: 2001.

58. Saevarsson S, Halsband U, Kristjánsson A. Designing rehabilitation programs for neglect: Could 2 be more than 1+1? Applied Neuropsychology 2011; 18: 95-106.

59. Institute of Medicine. Cognitive rehabilitation therapy for traumatic brain injury: evaluation of the evidence. Washington, DC: The National Academies Press, 2011.

60. Duijts SF, Oldenburg HS, Van Beurden M et al. Cognitive behavioral therapy and physical exercise for climacteric symptoms in breast cancer patients experiencing treatment-induced menopause: design of a multicentre trial. BMC Women's Health 2009; 9: 15.

61. Treweek S, Zwarenstein M. Making trials matter: pragmatic and explanatory trials and the problem of applicability. Trials 2009; 10: 37. 
Systematic review 


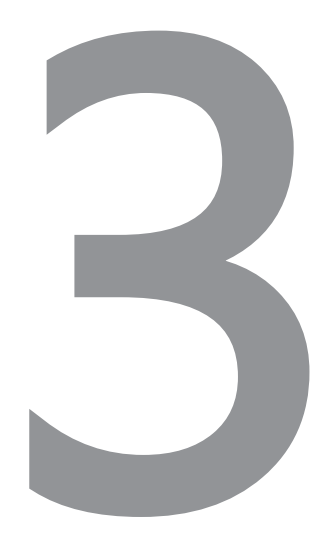

Cost-effectiveness of cognitive behavioral therapy and physical exercise for alleviating treatment-induced menopausal symptoms in breast cancer patients

Janne C. Mewes

Lotte M.G. Steuten

Saskia F.A. Duijts

Hester S.A. Oldenburg

Marc van Beurden

Martijn M. Stuiver

Myra S. Hunter

Jacobien M. Kieffer

Wim H. van Harten

Neil K. Aaronson

Journal of Cancer Survivorship 9(1):126-135. 



\title{
Cost-effectiveness of cognitive behavioral therapy and physical exercise for alleviating treatment-induced menopausal symptoms in breast cancer patients
}

\begin{abstract}
Introduction: Many breast cancer patients experience (severe) menopausal symptoms after an early onset of menopause caused by cancer treatment. The aim of this study was to assess the cost-effectiveness of cognitive behavioral therapy (CBT) and physical exercise (PE) compared to usual care.

Methods: We performed a cost-effectiveness analysis using a Markov model from a healthcare system perspective. Effectiveness data came from a recent randomized controlled trial that evaluated the efficacy of CBT and PE. Cost data were obtained from relevant Dutch sources. Outcome measures were incremental treatment costs (ITCs) per patient with a clinically relevant improvement on a measure of endocrine symptoms, the FACT-ES, and on a measure of hot flushes, the Hot Flush Rating Scale (HFRS); and costs per quality-adjusted life years (QALY) gained over a five-year time period.

Results: ITCS for achieving a clinically relevant decline in endocrine symptoms for one patient were $€ 1,051$ for $C B T$ and $€ 1,315$ for $P E$, compared to the waiting list control group (WLC). The corresponding value for the HFRS was $€ 1,067$ for CBT, while PE alone was not more effective than the WLC. Incremental cost utility ratios were $€ 22,502 / Q A L Y$ for CBT and $€ 28,078 / Q A L Y$ for PE, suggesting each intervention is cost-effective compared to WLC.

Conclusion: CBT is likely the most cost-effective strategy for alleviating treatmentinduced menopausal symptoms in breast cancer patients, followed by PE. The outcomes are sensitive to a reduction of the assumed duration of the treatment effect, from 5 to 3 and 1.5 years.

Implications for cancer survivors: Patients should be prescribed CBT, or, depending on individual need and preferences, PE.
\end{abstract}




\section{Introduction}

Many breast cancer survivors who undergo adjuvant chemotherapy experience a premature, treatment-induced onset of the menopause and associated symptoms, including hot flashes, night sweats, and vaginal dryness. The most common pharmacologic treatment for (severe) menopausal symptoms, hormone-replacement therapy, is contraindicated in breast cancer patients ${ }^{1-3}$. Thus, effective nonpharmacologic treatments are needed to alleviate these symptoms.

$A$ recent randomized controlled trial $(R C T)^{4}$ comparing cognitive behavioral therapy $(C B T)$, physical exercise $(P E)$, and the combination of both $(C B T+P E)$, demonstrated that PE leads to a significant decline in endocrine symptoms, urinary symptoms, and improvement in physical functioning over time, compared to usual care. CBT led to a significant decrease in the perceived burden of hot flushes and night sweats, and improved sexual activity. The combination of CBT and PE, however, did not lead to

additional health benefits compared to CBT or PE only ${ }^{4}$. Given the increase in the number of cancer survivors and the concomitant need for supportive care services, wellconducted health economic studies are needed to support efficient allocation of limited health care resources ${ }^{5-10}$. The objective of this study was to estimate the short- and long-term incremental cost-effectiveness of CBT and PE, versus a waiting list control group (WLC) in the alleviation of chemotherapy-induced menopause in women with primary breast cancer. Because the combined CBT+PE treatment would always be more costly at no additional patient benefit, this treatment option was not considered in the analysis.

\section{Methods}

\section{Overview}

A cost-effectiveness analysis (CEA) from the Dutch healthcare system perspective was undertaken based on the RCT of Duijts et al. ${ }^{4}$, investigating the efficacy of CBT, PE, and $C B T+P E$ in alleviating menopausal symptoms in breast cancer patients who experienced a premature, treatment-induced menopause. The data from this RCT were combined with additional (cost) data in a health economic model to compare the incremental costs for achieving a relevant decline in symptoms with CBT, PE or CBT+PE versus WLC over a time horizon of five years. 


\section{Trial description}

The RCT participants were female breast cancer patients who were under 50 years of age, premenopausal at time of diagnosis, had undergone adjuvant chemotherapy and/or hormonal therapy, had experienced a treatment-induced menopause and reported at least a minimal level of menopausal symptoms. The CBT-intervention involved six weekly group sessions of 90 minutes each. The PE-intervention consisted of a 12-week home-based exercise program, individually tailored during an intake session with a physiotherapist. Each intervention arm was compared to a usual care, waiting list control group (WLC). Outcomes were measured at baseline, at twelve-weeks and at six months follow-up. We refer to Duijts et al. $2009^{11}$ and $2012^{4}$ for more details on the sample characteristics and interventions.

Primary outcomes of the RCT were endocrine symptoms, as measured by the endocrine subscale of the Functional Assessment of Cancer Therapy Questionnaire (FACT-ES) ${ }^{12}$, and perceived burden of hot flashes and night sweats, assessed with the 3-item subscale of the Hot Flush Rating Scale (HFRS) ${ }^{13,14}$. Health-related quality of life (HRQOL), as measured by the 36 -Item Short Form Health Survey $(\mathrm{SF}-36)^{15}$, was a secondary outcome. For the HFRS, a change of at least two points on the ten-point scale is considered a relevant improvement ${ }^{14}$. As a definition of clinically relevant difference for the FACT-ES has not been published, we used a distribution-based definition: an effect size of 0.5 , which represents a half standard deviation difference based on the baseline score distribution ${ }^{16}$.

The primary outcome of the economic evaluation was incremental treatment costs (ITC's) for reducing one patient's endocrine symptoms (FACT-ES) by a clinically relevant degree. The FACT-ES was chosen as the primary outcome because it assesses a broad range of endocrine symptoms relevant to women with breast cancer ${ }^{12}$. The secondary outcome was the ITC's for reducing one patient's perceived burden of key menopausal symptoms (i.e., hot flushes and night sweats) by a clinically relevant degree. The tertiary outcome was the incremental cost per quality-adjusted life year (QALY) gained over a five year period.

\section{Model}

We programmed a Markov model (Excel, Microsoft, Redmond, WA) consisting of four health states; "menopausal symptoms," "reduction in menopausal symptoms," "recurrence," and "death". The criterion used for menopausal symptoms reflect the inclusion criteria used in the previous RCT; experiencing two or more menopausal 
symptoms "sometimes" or "often". A recurrence could be local, regional, or a distant metastasis.

The accumulating costs and QALYs of a hypothetical cohort of 1000 patients with a starting age of 48 years, matched with the participants of the trial in terms of clinical characteristics, were analyzed over ten consecutive six-month cycles. The first cycle reflects the effectiveness and costs of the respective treatments as measured in the RCT. The outcomes were extrapolated up to a five-year time horizon. A longitudinal study on the duration of bothersome vasomotor symptoms showed symptoms to last 5.2 years on average ${ }^{17}$. Other studies, summarized by Nachtigall et al. ${ }^{18}$ found that symptoms peak after 2-3 years, and then fade-out over the next 10-12 years. We therefore assumed that the time-period during which we can expect the interventions to have an impact on bothersome vasomotor symptoms as occurring in the natural course of the menopause, is five years ${ }^{17,18}$. This assumption is varied in a sensitivity analysis to assess its impact on model outcomes (see sensitivity analyses) ${ }^{17,18}$.

The hypothetical cohort starts in the Markov health state "menopausal symptoms." After the first cycle, and only at that point, patients could move from the health state "menopausal symptoms" to "reduction in menopausal symptoms", as well as to "menopausal symptoms". The probability of this transition is based on the proportion of patients who reported a clinically relevant improvement of at least half a standard deviation of the baseline score of the FACT-ES. From the health state "menopausal symptoms" and "improvement of menopausal symptoms," patients could move to the health state "recurrence" in every subsequent cycle. Patients who did not move to "recurrence" stayed in their current health state. From each health state, patients could move to "death".

\section{Data input for the model}

We calculated transition probabilities on the basis of the number of participants per trial-arm who had a clinically relevant improvement on the FACT-ES (N=100/235 across all groups). We calculated transition probabilities for local or regional recurrence and distant metastases on the basis of data from the Netherlands Cancer Registry (NCR) ${ }^{19}$ using the NCR cohort data matching the RCT sample characteristics for the period 2003-2006 ( $\mathrm{N}=3,716)$. For background mortality, publicly available age- and genderspecific mortality data, excluding mortality due to breast cancer, were used to calculate transition probabilities ${ }^{20}$. See Table 1 for the transition probabilities. 
Table 1: Parameters

\begin{tabular}{|c|c|c|c|}
\hline Parameter & Values & $\begin{array}{l}\text { Values used } \\
\text { in sensitivity } \\
\text { analysis; } \\
\text { distribution } \\
\text { used in PSA }\end{array}$ & Source \\
\hline \multicolumn{4}{|l|}{ Transition probabilitites } \\
\hline $\begin{array}{l}\text { CBT: } \\
\text { "menopausal symptoms" to } \\
\text { "reduction in menopausal } \\
\text { symptoms" }\end{array}$ & $\begin{array}{l}\text { Cycle 1: } 0.484 \\
\text { From cycle } 2 \text { on: } 0\end{array}$ & $\begin{array}{l}+20 \%,-20 \%, \\
\text { effect lasts } 1.5 \\
\text { years, effect } \\
\text { lasts } 3 \text { years; } \\
\text { Dirichlet }\end{array}$ & $\begin{array}{l}\text { Patient-level data of } \\
\text { Duijts et al,. } 2012\end{array}$ \\
\hline $\begin{array}{l}\text { PE: } \\
\text { "menopausal symptoms" to } \\
\text { "reduction in menopausal } \\
\text { symptoms" }\end{array}$ & $\begin{array}{l}\text { Cycle 1: } 0.453 \\
\text { From cycle } 2 \text { on: } 0\end{array}$ & $\begin{array}{l}+20 \%,-20 \%, \\
\text { effect lasts } 1.5 \\
\text { years, effect } \\
\text { lasts } 3 \text { years; } \\
\text { Dirichlet }\end{array}$ & $\begin{array}{l}\text { Patient-level data of } \\
\text { Duijts et al, } 2012\end{array}$ \\
\hline $\begin{array}{l}\text { CBT+PE: } \\
\text { "menopausal symptoms" to } \\
\text { "reduction in menopausal } \\
\text { symptoms" }\end{array}$ & $\begin{array}{l}\text { Cycle 1: } 0.482 \\
\text { From cycle } 2 \text { on: } 0\end{array}$ & $\begin{array}{l}+20 \%,-20 \%, \\
\text { effect lasts } 1.5 \\
\text { years, effect } \\
\text { lasts } 3 \text { years; } \\
\text { Dirichet }\end{array}$ & $\begin{array}{l}\text { Patient-level data of } \\
\text { Duijts et al,. } 2012\end{array}$ \\
\hline $\begin{array}{l}\text { WLC: "menopausal } \\
\text { symptoms" to "reduction in } \\
\text { menopausal symptoms" }\end{array}$ & $\begin{array}{l}\text { Cycle 1: } 0.303 \\
\text { From cycle } 2 \text { on: } 0\end{array}$ & n/a, Dirichlet & $\begin{array}{l}\text { Patient-level data of } \\
\text { Duijts et al,. } 2012\end{array}$ \\
\hline $\begin{array}{l}\text { From "menopausal } \\
\text { symptoms" and "reduction in } \\
\text { menopausal symptoms" to } \\
\text { "recurrence" }\end{array}$ & 0.003 & $\begin{array}{l}\mathrm{n} / \mathrm{a} \text {, fixed } \\
\text { values }\end{array}$ & $\begin{array}{l}\text { Netherlands Cancer } \\
\text { Registry }\end{array}$ \\
\hline "Recurrence" to "death" & 0.427 & $\begin{array}{l}\mathrm{n} / \mathrm{a}, \text { fixed } \\
\text { values }\end{array}$ & $\begin{array}{l}\text { Netherlands Cancer } \\
\text { Registry }\end{array}$ \\
\hline Background mortality & $\begin{array}{l}\text { Depending on age of } \\
\text { cohort; } 0.0009 \text { at age } 48 \text { to } \\
0.0013 \text { at age } 52\end{array}$ & $\begin{array}{l}\mathrm{n} / \mathrm{a}, \text { fixed } \\
\text { values }\end{array}$ & $\begin{array}{l}\text { Statistics Netherlands } \\
2011\end{array}$ \\
\hline \multicolumn{4}{|l|}{ Utilities } \\
\hline Menopausal symptoms & $\begin{array}{l}\text { Cycle 1: } 0.7811 \\
\text { Cycle 2: } 0.8126 \\
\text { From cycle } 2 \text { on gradually } \\
\text { increasing to } 0.8526 \text { in the } \\
\text { last cycle }\end{array}$ & +/-20\%, Beta & $\begin{array}{l}\text { Patient-level data of } \\
\text { Duijts et al., } 2012\end{array}$ \\
\hline
\end{tabular}




\begin{tabular}{llll}
\hline $\begin{array}{l}\text { Reduction in menopausal } \\
\text { symptoms }\end{array}$ & $\begin{array}{l}\text { Cycle 2:0.8277 } \\
\text { From cycle 2 on gradually } \\
\text { increasing to 0.8677 in the } \\
\text { last cycle }\end{array}$ & $-20 \%, 1.0$; Beta & $\begin{array}{l}\text { Patient-level data of } \\
\text { Duijts et al,. 2012 }\end{array}$ \\
\hline Recurrence & 0.7320 & n/a, Beta & Lidgren et al, 2007 \\
\hline Death & 0 & $\begin{array}{l}\text { n/a, fixed } \\
\text { values }\end{array}$ & n/a \\
\hline
\end{tabular}

\begin{tabular}{llll}
\hline Costs & & \\
\hline \hline $\begin{array}{l}\text { Cognitive behavioral therapy, average } \\
\text { intervention costs per participant }\end{array}$ & $€ 190.07$ & $\begin{array}{l}-20 \% ;+20 \%, \\
\text { overhead of }\end{array}$ & $\begin{array}{l}\text { Program } \\
\text { specification, } \\
\text { Hakkaart-Van }\end{array}$ \\
Material & Total material costs: $€ 5$ & 6 and 10 & Roijen et al,. 2008 \\
CD & $€ 2$ & participants a & \\
Booklet & $€ 3$ & group; fixed & \\
& & values
\end{tabular}

Social worker's salary

Costs per participant:

$1 \mathrm{~h}$ individual intake session

Costs for a group of eight:

6 sessions of $1.5 \mathrm{~h}$

$0.75 \mathrm{~h}$ preparation for every session

1 follow-up session of $1.5 \mathrm{~h}$

0.75h for preparing follow-up session

Staff training:

$24 \mathrm{~h}$ training per 4 groups of eight

Total costs

Total costs including $42 \%$ overhead

Physical exercise, average intervention costs per participant

Material

Booklet

Heart rate monitor (one for every 4

participant)

Physiotherapist's salary
Total salary costs:

$€ 128.86$

(Hourly rate: €34.65)

$€ 34.65$

$€ 311.85 / 8$

$€ 155.93 / 8$

$€ 51.98 / 8$

$€ 25.99 / 8$

$€ 207.90 / 8$

$€ 133.86$

$€ 190.07$

$€ 196.98$

Total material costs: $€ 30$

$€ 5$

$€ 100 / 4$

Total salary costs

physiotherapist:

$€ 99,50$

(Hourly rate: €34.65)
$-20 \% ;+20 \%, \quad$ Program overhead is specification,

$25 \%$,

6 and 10

participants

group; fixed

values
Hakkaart-Van

Roijen et al.,

2008

Costs per participant: 
1h intake session

$0.5 \mathrm{~h}$ preparation for intake session

$0.34 \mathrm{~h}$ two calls

$0.75 \mathrm{~h}$ final session

$0.25 \mathrm{~h}$ preparation of final session

Costs for a group of eight:

$2 \mathrm{~h}$ staff training per 8 groups

\section{Secretary's salary}

0.33h per participant

\section{Total costs \\ Total costs including $42 \%$ overhead \\ Cognitive behavioral therapy and \\ physical exercise, average intervention costs per participant \\ Sum of costs of cognitive behavioral therapy and physical exercise}

$€ 34.65$

$€ 17.33$

$€ 11.79$

$€ 25.99$

$€ 8.66$

$€ 8.66 / 8$

Total salary costs secretary: €9.22

(Hourly rate: €27.96)

$€ 9.22$

$€ 138.72 *$

$€ 196.98 *$

$€ 387.05$

$-20 \%$; +20\%, See above overhead is

25\%,

six and ten

participants a

group; fixed

values

\begin{tabular}{|c|c|c|c|}
\hline Disease state "menopausal symptoms" & $\begin{array}{l}€ 310.39 \text { in first cycle, } \\
\text { gradually decreasing to } \\
€ 247.38 \text { in last cycle }\end{array}$ & $\begin{array}{l}-20 \%,+20 \% \\
\text { Gamma }\end{array}$ & $\begin{array}{l}\text { Patient-level data } \\
\text { of Duijts et } \\
\text { al.2012, } \\
\text { assumption }\end{array}$ \\
\hline Health care use & $\begin{array}{l}\text { €210.39 in first cycle, } \\
\text { gradually decreasing to } \\
€ 182.39 \text { in last cycle }\end{array}$ & & \\
\hline Medication & $\begin{array}{l}€ 100 \text { in first cycle, } \\
\text { gradually decreasing to } \\
€ 65 \text { in last cycle }\end{array}$ & & \\
\hline $\begin{array}{l}\text { Disease state "perceived reduction in } \\
\text { menopausal symptoms" }\end{array}$ & $\begin{array}{l}€ 316.17 \text { in first cycle, } \\
\text { gradually decreasing to } \\
€ 220.17 \text { in last cycle }\end{array}$ & $\begin{array}{l}-20 \%,+20 \% \\
\text { Gamma }\end{array}$ & $\begin{array}{l}\text { Patient-level data } \\
\text { of Duijts et al. } \\
\text { 2012, assumption }\end{array}$ \\
\hline Health care use & $\begin{array}{l}\text { €216.17in first cycle, } \\
\text { gradually decreasing to } \\
€ 160,17 \text { in last cycle }\end{array}$ & & \\
\hline Medication & $\begin{array}{l}€ 100 \text { in first cycle, } \\
\text { gradually decreasing to } \\
€ 60 \text { in last cycle }\end{array}$ & & \\
\hline Disease state "recurrence" & $\begin{array}{l}€ 12,181 \text { in first year in } \\
\text { recurrence, } € 2,359 \text { from }\end{array}$ & $\begin{array}{l}\text { Fixed values, } \\
\text { Gamma }\end{array}$ & Retel et al., 2010 \\
\hline
\end{tabular}


second year on in

recurrence

First year: $\quad € 12.181$

In- and outpatient costs $€ 10.263$

Drug costs $\quad € 1.918$

From second year on: $\quad € 2.359$

In- and outpatient costs $\quad € 2.294$

Drug costs $€ 65$

*) Numbers may not add up due to rounding

PSA=Probabilistic sensitivity analysis, $C B T=$ Cognitive behavioral therapy, $P E=$ Physical exercise, $C B T+P E=$ Cognitive behavioral therapy combined with physical exercise, WLC=Waiting list control group

\section{Health-related quality of life}

The health-related quality of life (HRQoL) for the health states "menopausal symptoms" and "improvement in menopausal symptoms" were derived by converting the SF-36 data from the trial $(\mathrm{N}=233)$ to $E Q-5 D$ values, using the algorithm by Ara and Brazier ${ }^{21}$. The average HRQoL of the trial participants who had a clinically relevant improvement on the FACT-ES was assigned to the health state "reduction in menopausal symptoms", and the average HRQoL of trial participants who did not have a relevant improvement on the FACT-ES to the health state "menopausal symptoms". The HRQoL for "recurrence" was the weighted average of the HRQoL for local recurrence and metastasis ${ }^{22}$. See Table 1 for the utility values.

\section{Intervention costs}

The intervention costs consisted of health professional labor, staff training, administration, and material costs. Program managers provided detailed descriptions of the interventions, from which cost items and corresponding volumes were identified. Costs were calculated by multiplying cost prices or appropriate tariffs by volumes, following Dutch pharmaco-economic costing guidelines ${ }^{23}$. We assumed that staff training costs were incurred once for every four groups of eight participants that were offered CBT, and once for every eight groups of PE.

\section{Data input health care resource use}

The number of healthcare visits was obtained from the $\mathrm{RCT}^{4}$ and valued at an average cost of €210 for patients who improved and €216 for who did not improve. As 
menopausal symptoms diminish over a time period of approximately five years ${ }^{17}$, we assumed average health care costs to steadily decrease with the costs of two GP visits and one GP visit for those who did and did not improve, respectively. For pharmaceuticals (including analgesics, sleeping pills, anti-depressants, medication for hypertension, homeopathy, and others) we assumed an average cost of €100 in the first cycle, which then steadily decreased until reaching $€ 60$ in the last cycle in the group which improved, and $€ 65$ in the group that did not improve. We used published data to estimate the health care costs associated with the health state "recurrence" ${ }^{24}$. The volumes of resources used and the associated unit costs are given in Table 1.

\section{Base case analysis}

We calculated the incremental treatment costs (ITCS) over a six-month time period for achieving a relevant difference on the FACT-ES and HFRS as follows:

Incremental treatment costs $=\mathrm{NNT} \times \mathrm{IC}$

NNT $=$ Number needed to treat

$\mathrm{IC}=\quad$ Intervention costs

See Table 2 for the numeric values. 
Table 2: Base case results

\begin{tabular}{|c|c|c|c|}
\hline & CBT & PE & WLC \\
\hline \multicolumn{4}{|l|}{ Incremental treatment costs } \\
\hline Intervention costs & $€ 190$ & $€ 197$ & None \\
\hline $\begin{array}{l}\text { NNT to achieve a relevant improvement on } \\
\text { HFRS }\end{array}$ & 5.61 & $\begin{array}{l}\text { Lower than in } \\
\text { WLC }\end{array}$ & $\mathrm{n} / \mathrm{a}$ \\
\hline NNT to achieve relevant improvement on ES & 5.53 & 6.68 & $\mathrm{n} / \mathrm{a}$ \\
\hline $\begin{array}{l}\text { Incremental treatment costs to achieve } \\
\text { relevant improvement on the HFRS }\end{array}$ & $€ 1,067$ & $\begin{array}{l}\text { Not more } \\
\text { effective than } \\
\text { WLC }\end{array}$ & $\mathrm{n} / \mathrm{a}$ \\
\hline $\begin{array}{l}\text { Incremental treatment costs to achieve } \\
\text { relevant improvement on the ES }\end{array}$ & $€ 1,051$ & $€ 1,315$ & $\mathrm{n} / \mathrm{a}$ \\
\hline \multicolumn{4}{|l|}{ Model outcomes } \\
\hline Total costs over a five-year period & $€ 2,983$ & $€ 2,983$ & $€ 2,798$ \\
\hline $\begin{array}{l}\text { Incremental costs (including treatment and } \\
\text { health care costs) }\end{array}$ & $€ 184$ & $€ 185$ & $\mathrm{n} / \mathrm{a}$ \\
\hline Total QALYs & 4.400 & 4.399 & 4.392 \\
\hline Incremental QALYs (compared to WLC) & 0.0079 & 0.0067 & $\mathrm{n} / \mathrm{a}$ \\
\hline ICER (Incremental costs/incremental QALYS) & $€ 22,502$ & $€ 28,078$ & $\mathrm{n} / \mathrm{a}$ \\
\hline
\end{tabular}

NNT=Number needed to treat, $Q A L Y=$ Quality-adjusted life year, ICER=Incremental cost-effectiveness ratio, CBT=Cognitive behavioral therapy, PE=Physical exercise, WLC=Waiting list control group, n/a=Not applicable, HFRS=Hot Flush Rating Scale

The incremental cost utility ratio (ICUR), representing the additional costs required for the particular intervention to generate one additional QALY in comparison to WLC, was calculated as follows:

\section{ICUR}

$=\frac{\text { (Incremental costs of the intervention group - incremental costs of the WLC group) }}{\text { (Incremental QALYs of the intervention group - incremental QALYs of the WLC group) }}$

To indicate whether an intervention can be considered cost-effective, the ICUR was compared to a range of societal "willingness-to-pay" values for one QALY, ranging from $€ 20 \mathrm{k}$ to $€ 80 \mathrm{k}$ in the Netherlands, with €30k per QALY commonly accepted as the prevailing ceiling ratio ${ }^{25}$. In line with Dutch pharmaco-economic guidelines, future costs were discounted at $4 \%$ and effects at $1.5 \%$ annually ${ }^{23}$. 


\section{Sensitivity analyses}

We performed one-way sensitivity analyses by varying input parameters across a range of plausible values (see Table 1). Probabilistic sensitivity analysis (PSA) was employed to estimate the joint decision uncertainty resulting from the uncertainty in the input parameters. To better reflect parameter uncertainty, parameter distributions in PSA were propagated through the model using 5,000 Monte Carlo simulations, instead of single point estimates. For the transition probabilities we used a Dirichlet, for costs a gamma, and for utilities a beta distribution. Distributions were fitted using the method of moments approach ${ }^{26}$. The resulting 5,000 model outcomes were plotted on the costeffectiveness plane. In addition, we generated cost-acceptability curves (CEAC's), representing the probability of the interventions being cost-effective depending on the WTP for one additional QALY. Structural uncertainty in the model was addressed by varying the assumption regarding the duration of treatment effect from 5 years, to 3 and 1.5 years respectively, as informed by relevant literature on this topic.

\section{Results}

\section{Base case analysis}

Table 2 shows the results of all base case analyses. The costs of the interventions were $€ 190$ for CBT, and €197 for PE. The number needed to treat (NNT) to achieve a relevant difference on the FACT-ES was lower for CBT (5.53) than for PE (6.68). To achieve a relevant difference in one patient on the HFRS, the NNT was 5.61 for CBT, while PE was outperformed by the WLC. CBT required the lowest ITCS for one patient to achieve a relevant difference on the FACT-ES and the HFRS (€1,051 and €1,067, respectively).

For the Markov model outcomes, total costs accumulated per patient over the five-year time period were higher in the PE and CBT groups compared to WLC. The total QALYgain was similar across the intervention groups. ICURs indicate that CBT is likely the most cost-effective treatments, followed by PE.

\section{Sensitivity analysis}

The outcomes were most influenced by 1) the utility in the health states "menopausal symptoms" and "reduction in menopausal symptoms", and 2) the duration of the treatment effect, with shorter effect duration resulting in lower cost-effectiveness. At a ceiling ratio of $€ 30.000 / Q A L Y$, the interventions would no longer be considered costeffective when the duration of treatment effect is 3 or 1.5 years. The results were very 
robust to the assumption that health care costs decrease and utilities increase during time. When these values were kept stable, the conclusions did not change. For the outcomes of this analysis see Figure 1.

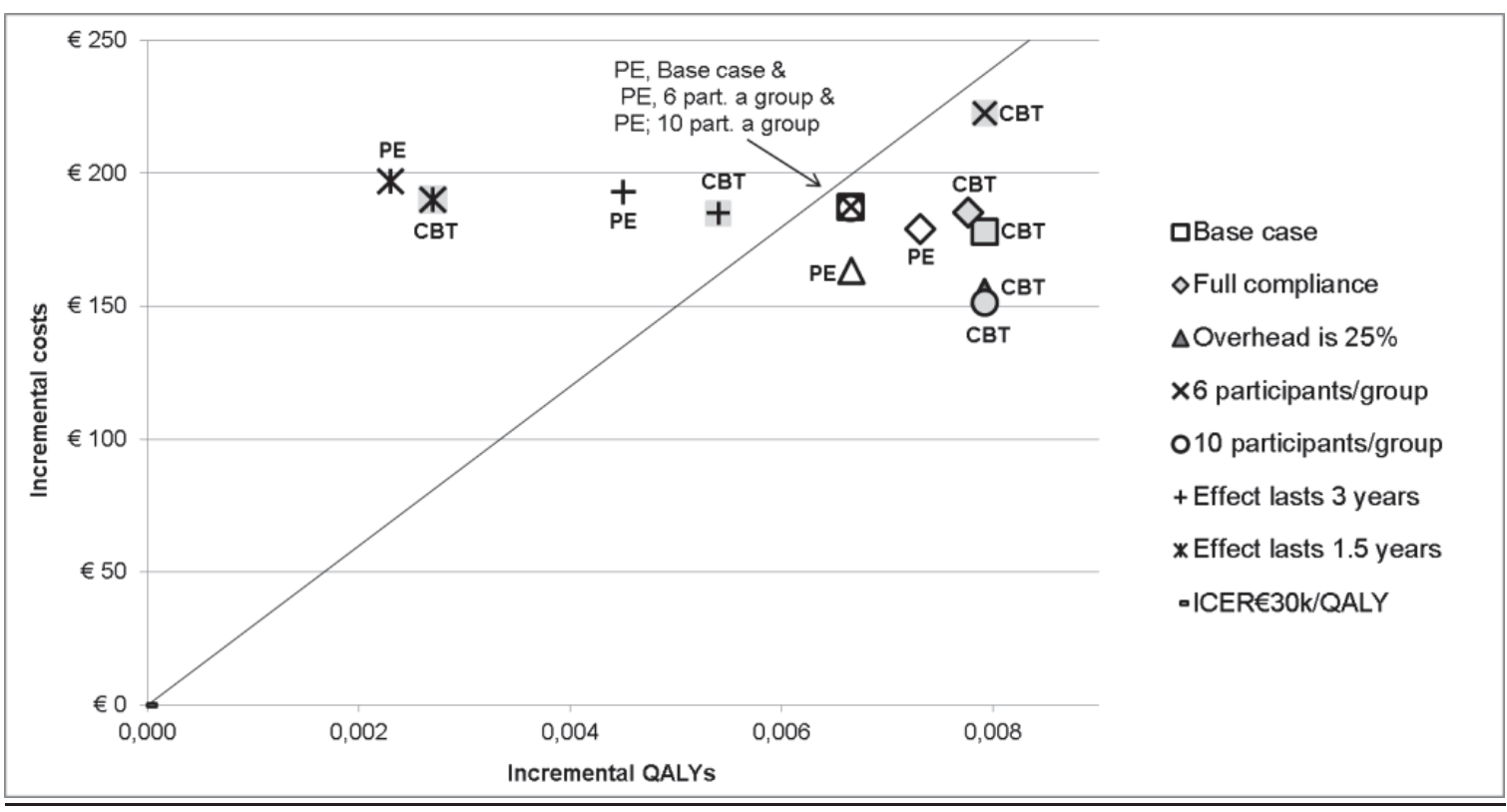

Figure 1: Outcomes of sensitivity analyses with values relevant for decision-making

CBT=Cognitive-behavioral therapy, PE=Physical exercise, QALYs=Quality-adjusted life years, ICER=Incremental cost-effectiveness ratio, part.=Participants

\section{Probabilistic sensitivity analysis}

The cost-effectiveness plane (see appendix 1) showed that most simulated model outcomes are situated in the northeast quadrant, followed by the northwest quadrant. This indicates that all interventions add costs, with the majority of the outcomes of CBT also adding effectiveness in comparison to WLC. The CEAC's (see Figure 2) showed that PE has the highest probability of being cost-effective only up to a ceiling ratio of circa $€ 26,000 / Q A L Y$. Beyond that ceiling ratio, CBT has the highest probability of being costeffective, with a probability of $49 \%$ of at a ceiling ratio of $€ 30,000 / Q A L Y$, up to $56 \%$ at $€ 80.000 / \mathrm{QALY}$. 


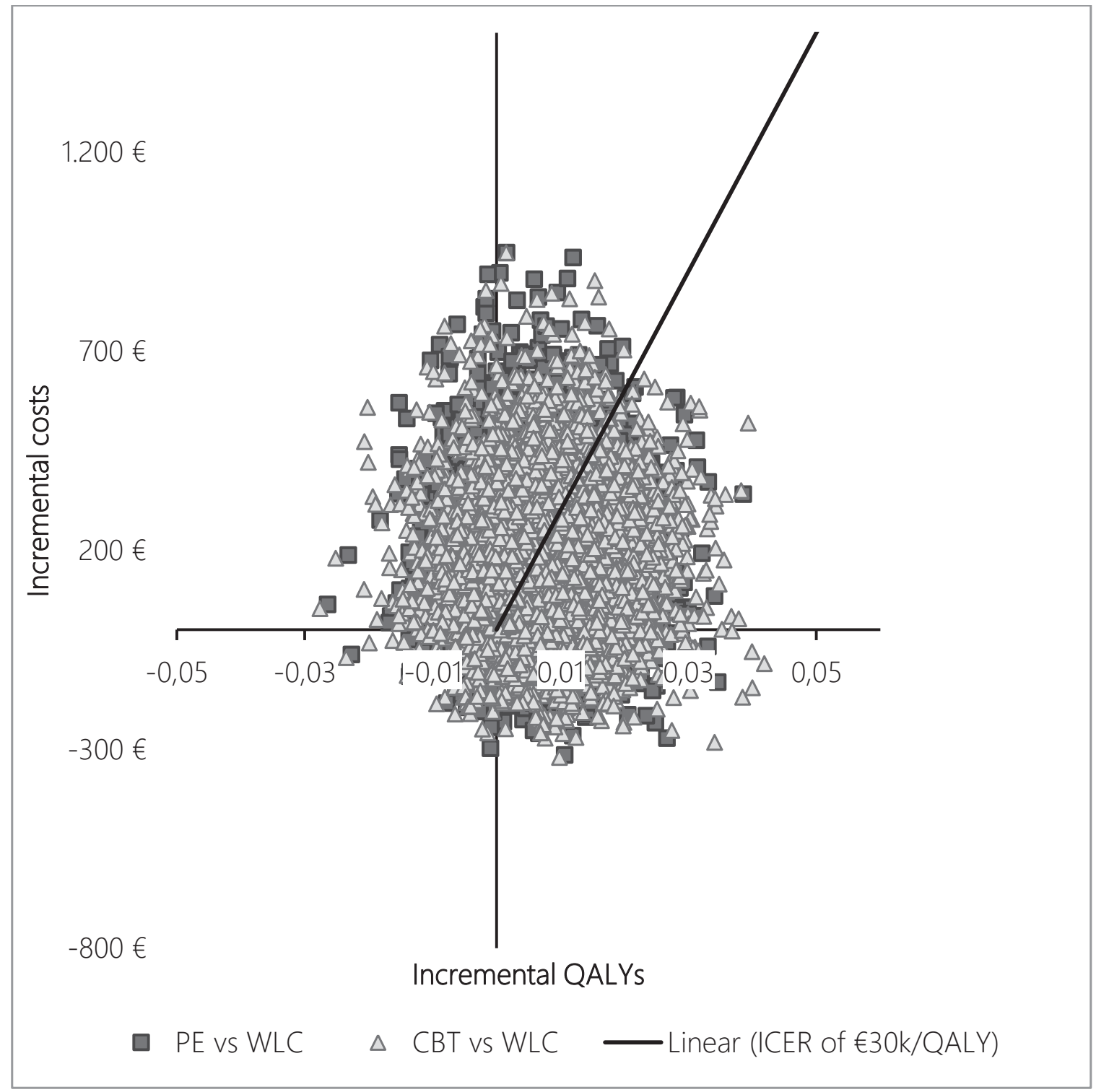

Appendix 1: Cost-effectiveness plane

$\mathrm{CBT}=$ Cognitive-behavioral therapy, PE=Physical exercise, $\mathrm{QALYs}=$ quality-adjusted life years, ICER = incremental cost-effectiveness ratio 


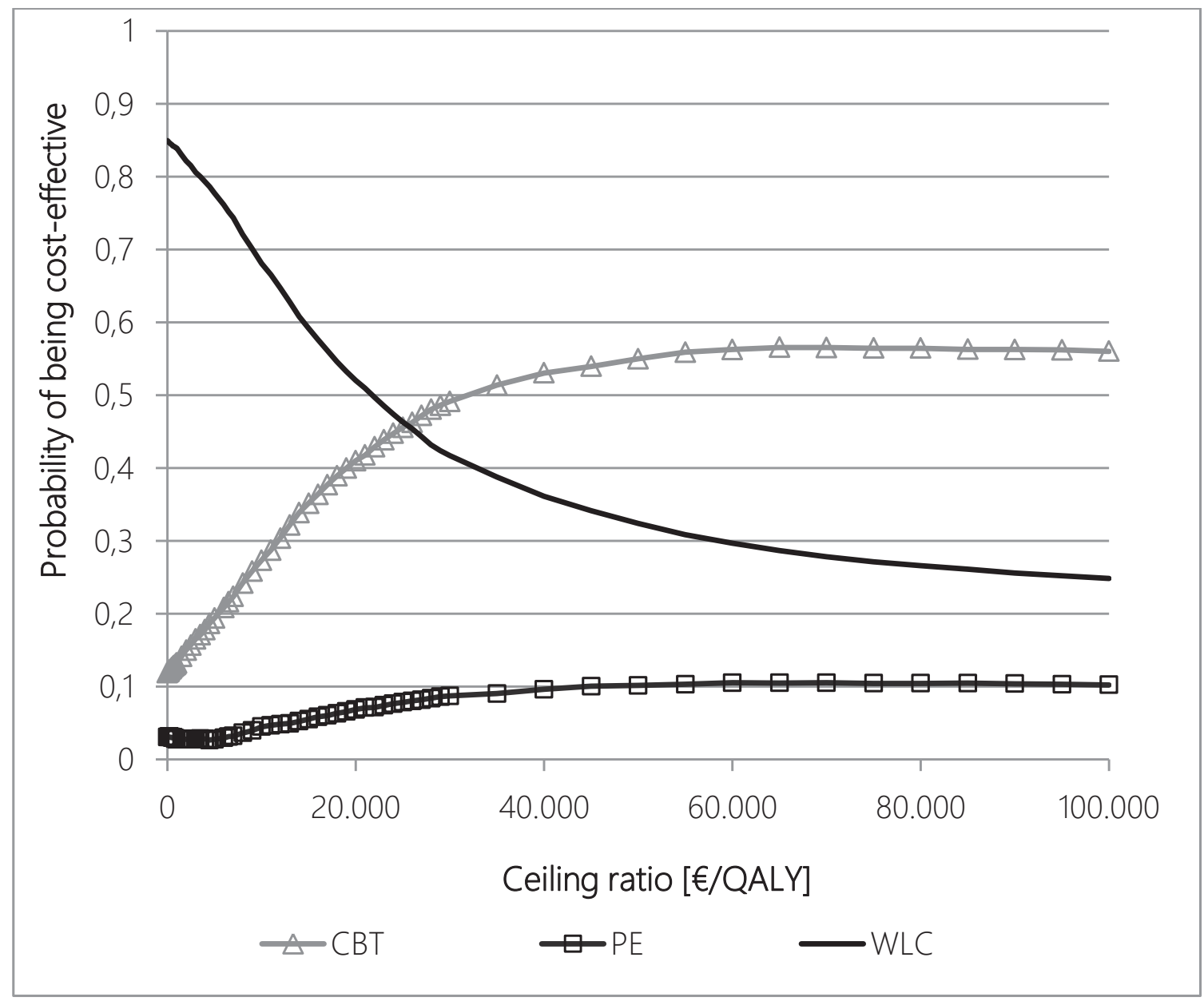

Figure 2: Cost-effectiveness acceptability curves

QALY=Quality adjusted life-year, $C B T=$ Cognitive behavioral therapy, $P E=$ Physical exercise, WLC=Waiting list control group

\section{Discussion}

The results of this study indicate that CBT is likely to be a most cost-effective strategy for alleviating treatment-induced menopausal symptoms in women with breast cancer, followed by PE which is also cost-effective compared to WLC. As both CBT and PE improve patients' symptoms and are both effective and cost-effective, we believe that both can be recommended as non-pharmacological treatments for treatment-induced menopausal symptoms among women with breast cancer. The outcomes of this study were most sensitive to a reduction of the duration of the treatment effect from 5 to 3 
and 1.5 years, which would in fact alter the adoption recommendation for both CBT and PE. This indicates that better empirical data on the duration of the intervention effects is necessary. These findings are in line with two systematic reviews, which found that effective cancer rehabilitation interventions are also cost-effective ${ }^{27,28}$.

In a recent UK trial (MENOS1) ${ }^{14}$, CBT was compared to usual care with higher compliance and effect sizes $(d=1.19$ and 1.07 at 9 weeks and 6 months post randomization respectively). This suggests that the current analyses might underestimate the cost-effectiveness of $\mathrm{CBT}^{14}$, as compliance in the RCT underlying this cost-effectiveness analysis was relatively low. In addition, the symptom burden required to be eligible to participate in the trial of Duijts and colleagues was minimal. Arguably, a sub-group of women with higher symptom burden might benefit more from the interventions, and also yield a better cost-effectiveness ratio.

For cancer survivors, supportive care and rehabilitation interventions are often offered using a "one size fits all" approach, where all patients are prescribed the same intervention, independent of their actual level of need or their preferences ${ }^{28}$. This study shows that CBT and PE are similarly effective in relieving symptoms and both have acceptable ICURs. We would therefore recommend that the choice of intervention be based on the patients' lifestyle and preferences. For example, patients, who already meet exercise targets or, conversely, have an aversion to physical exercise, would probably benefit more from learning how to cope with their symptoms via the CBT program. Women who (believe that they already) have the behavioral skills and attitudes conducive to reducing symptoms, but nonetheless continue to be bothered by them, might benefit most from the physical exercise intervention. In addition, a more targeted approach may also improve patients' compliance with the interventions, which was notably low in the trial ${ }^{4}$. While this may lead to better intervention outcomes which would benefit the patient and potentially his/her family, it might also affect the patient's (un)paid productivity losses in two ways: 1) an increase in productivity losses due to more time spent at the intervention and 2) a potential decrease in productivity losses as (un)paid work would be disrupted less by menopausal symptoms. As productivity losses are typically the concerns of social insurance or governmental bodies, such other stakeholders may have an incentive and/or a responsibility in facilitating cancer survivors' access to these interventions. Future analyses are thus strongly recommended to consider the (longer term) cost-effectiveness of these interventions from a societal perspective. More specifically, these should include the impact on productivity loss from (un-)paid work and the wider societal benefits in order to inform the multiple stakeholders to whom the costs and benefits of cancer rehabilitation apply. 


\section{References}

1. Holmberg L, Iversen $\mathrm{OE}$, Rudenstam CM, et al. Increased risk of recurrence after hormone replacement therapy in breast cancer survivors. Journal of the National Cancer Institute 2008; 100: 475-82.

2. Toniolo PG, Levitz M, Zeleniuch-Jacquotte $A$, et al. A prospective study of endogenous estrogens and breast cancer in postmenopausal women. Journal of the National Cancer Institute 1995; 87: 190-97.

3. Quella SK, Loprinzi CL, Sloan JA, et al. Long term use of megestrol acetate by cancer survivors for the treatment of hot flashes. Cancer 1998; 82: 1784-88.

4. Duijts SFA, Van Beurden M, Oldenburg HSA, et al. Efficacy of cognitive behavioral therapy and physical exercise in alleviating treatment-induced menopausal symptoms in patients with breast cancer: results of a randomized, controlled, multicenter trial. Journal of Clinical Oncology 2012; 30: 4124-33.

5. Short PF, Moran JR, Punekar R. Medical expenditures of adult cancer survivors aged < 65 years in the United States. Cancer 2011; 117: 2791-800.

6. Parry $C$, Kent EE, Mariotto $A B$, et al. Cancer survivors: a booming population. Cancer Epidemiology, Biomarkers \& Prevention 2011; 20: 1996-2005.

7. Herrmann C, Cerny T, Savidan A, et al. Cancer survivors in Switzerland: a rapidly growing population to care for. BMC Cancer 2013; 13: 1.

8. Jefford M, Rowland J, Grunfeld E, et al. Implementing improved post-treatment care for cancer survivors in England, with reflections from Australia, Canada and the USA. British Journal of Cancer 2013; 108: 14-20.

9. Hellbom M, Bergelt C, Bergenmar M, et al. Cancer rehabilitation: a Nordic and European perspective. Acta Oncologica 2011; 50: 179-86.

10. Mattioli V, Montanaro R, Romito F. The Italian response to cancer survivorship research and practice: developing an evidence base for reform. Journal of Cancer Survivorship 2010; 4: 284-9.

11. Duijts SFA, Oldenburg HSA, van Beurden M, et al. Cognitive behavioral therapy and physical exercise for climacteric symptoms in breast cancer patients experiencing treatment-induced menopause: design of a multicenter trial. BMC Women's Health 2009; 9: 15.

12. Fallowfield LJ, Leaity SK, Howell A, et al. Assessment of quality of life in women undergoing hormonal therapy for breast cancer: validation of an endocrine symptom subscale for the FACT-B. Breast Cancer Research and Treatment 1999; 55: 189-99. 
13. Hunter MS, Liao KLM. A psychological analysis of menopausal hot flushes. British Journal of Clinical Psychology 1995; 34: 589-99.

14. Mann E, Smith MJ, Hellier J, et al. Cognitive behavioural treatment for women who have menopausal symptoms after breast cancer treatment (MENOS 1): a randomised controlled trial. The Lancet Oncology 2012; 13: 309-18.

15. Ware Jr JE, Sherbourne CD. The MOS 36-item short-form health survey (SF-36). I. Conceptual framework and item selection. Medical Care 1992; 30: 473-83.

16. Yost KJ, Eton DT. Combining distribution- and anchor-based approaches to determine minimally important differences: the FACIT experience. Evalualtion \& the Health Professions 2005; 28: 172-91.

17. Col NF, Guthrie JR, Politi M, et al. Duration of vasomotor symptoms in middleaged women: a longitudinal study. Menopause 2009; 16: 453-7.

18. Nachtigall LE, Nachtigall MJ. Menopausal changes, quality of life, and hormone therapy. Clinical Obstetrics and Gynecology 2004; 47: 485-88.

19. Netherlands Cancer Registry managed by CCCN. Requested data. Utrecht, 2012.

20. Statistics Netherlands. Mortality statistics. The Hague: Statistics Netherlands, 2011.

21. Ara R, Brazier J. Deriving an algorithm to convert the eight mean SF-36 dimension scores into a mean EQ-5D preference-based score from published studies (where patient level data are not available). Value in Health 2008; 11: 113143.

22. Lidgren $M$, Wilking $N$, Jönsson $B$, et al. Health related quality of life in different states of breast cancer. Quality of Life Research 2007; 16: 1073-81.

23. Hakkaart-Van Roijen L, Tan SS, Bouwmans CAM. Manual for cost research: methods and standard cost prices for economic evaluations in health care. Diemen: Health Care Insurance Board, 2010.

24. Retèl VP, Joore MA, Knauer M, et al. Cost-effectiveness of the 70-gene signature versus St. Gallen guidelines and Adjuvant Online for early breast cancer. European Journal of Cancer 2010; 46(8):1382-91.

25. Raad voor de Volksgezondheid en Zorg. Zinnige en duurzame zorg. Zoetermeer, 2006.

26. Briggs AH, Goeree R, Blackhouse $\mathrm{G}$, et al. Probabilistic analysis of costeffectiveness models: Choosing between treatment strategies for gastroesophageal reflux disease. Medical Decision Making 2002; 22: 290-308.

27. Gordon LG, Beesley VL, Scuffham PA. Evidence on the economic value of psychosocial interventions to alleviate anxiety and depression among cancer 
survivors: a systematic review. Asia-Pacific Journal of Clinical Oncology 2011; 7: 96 105.

28. Mewes JC, Steuten LMG, IJzerman MJ, et al. Effectiveness of multidimensional cancer survivor rehabilitation and cost-effectiveness of cancer rehabilitation in general: a systematic review. The Oncologist 2012; 17: 1581-93. 


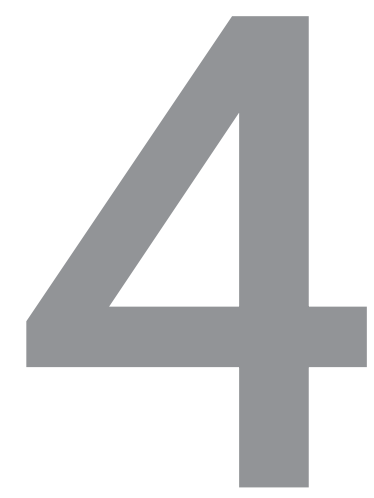

\section{A systematic approach for assessing, in the absence of full evidence, whether multicomponent interventions - "doing more" - can be more cost-effective than single component interventions}

Janne C. Mewes

Lotte M.G. Steuten

Maarten J. IJzerman

Wim H. van Harten

Submitted 



\title{
A systematic approach for assessing, in the absence of full evidence, whether multicomponent interventions - "doing more" - can be more cost-effective than single component interventions
}

\begin{abstract}
Introduction: Multicomponent interventions ( $\mathrm{MCls}$ ), consisting of at least two interventions, are common in rehabilitation and other healthcare fields. When the effectiveness of the $\mathrm{MCl}$ versus that of its single interventions is comparable or unknown, evidence of their expected incremental cost-effectiveness can be helpful in deciding which intervention to recommend. As such evidence often is unavailable this study proposes an approach to estimate what is more cost-effective; the $\mathrm{MCl}$ or the single intervention(s).

Methods: We reviewed the literature for potential methods. Of those identified, headroom analysis was selected as the most suitable basis for developing the approach, based on the criteria of being able to estimate the cost-effectiveness of the single interventions vs. the $\mathrm{MCl}$ a) within a limited time frame, b) in the absence of full data, and c) taking into account carry-over and interaction effects. We illustrated the approach with an $\mathrm{MCl}$ for cancer survivors.

Results: The approach starts with analysing the costs of the $\mathrm{MCl}$. Given a specific willingness-to-pay-value, it is analysed how much effectiveness the $\mathrm{MCI}$ would need to generate to be considered cost-effective, and if this is likely to be attained. Finally, the cost-effectiveness of the single interventions relative to the potential of the $\mathrm{MCl}$ for being cost-effective can be compared.

Conclusions: A systematic approach using headroom analysis was developed for estimating whether an $\mathrm{MCl}$ is likely to be more cost effective than one (or more) of its single interventions.
\end{abstract}




\section{Introduction}

In many fields, such as rehabilitation or self-management, multicomponent interventions (MCls) are common'. They may be recommended as part of guidelines, on the basis of evidence, or in situations where little or no evidence exists, based on the expectation that combining two or more interventions in an $\mathrm{MCl}$ is more effective than the single intervention $^{2-4}$. Recommending an $\mathrm{MCl}$ on the basis of assumed incremental effectiveness over a single intervention is only reasonable when "doing more" indeed leads to better patient outcomes. However, it is not automatically the case that more interventions are better, nor that the combined effectiveness of more than one intervention follows an additive function. Reasons for this include interaction effects between interventions, which can cause an $\mathrm{MCl}$ consisting of two single interventions to have an effect that is greater or smaller than the sum of the two ${ }^{5-13}$.

As the financial pressure on health budgets compels consideration of cost-effectiveness data to inform reimbursement and implementation decisions, it is desirable to also take information on cost-effectiveness into account when recommending and using $\mathrm{MCls}$. For this purpose, the incremental cost-effectiveness of an $\mathrm{MCl}$ versus its single composite interventions ideally should be derived from clinical trials comparing the effects and costs of both the $\mathrm{MCl}$ and the single interventions against doing-nothing. However, as estimating the cost-effectiveness of all relevant interventions in clinical trials is expensive and time-consuming, the data on costs and effects of all interventions under comparison is in most cases incomplete and thus prohibits a full economic evaluation.

In order to still take cost-effectiveness considerations into account in the choice of an $\mathrm{MCls}$ versus its single interventions, a pragmatic approach is needed that allows to estimate whether the $\mathrm{MCl}$ is more cost-effective than its single interventions in cases where empirical data on the effect and costs of the $\mathrm{MCl}$ are not (yet) or only partly available. This paper describes the development of such an approach and illustrates it using the example of the Dutch cancer rehabilitation guideline ${ }^{1}$.

\section{Methods}

The decision-problem is defined as follows; in absence of sufficient data to evaluate an MCl's cost-effectiveness, how can it be estimated whether that $\mathrm{MCl}$ is likely to be more 
cost-effective than the single interventions it consists of? "Sufficient data" is data on key parameters required for analysing the MCl's (cost)-effectiveness with quality that meets the standards of evidence-based medicine and health economic evaluations ${ }^{14-16}$.

First, the literature was reviewed to identify methods for similar decision-problems that could contribute to developing an approach to solve the decision problem just defined. As it became clear during the development of the approach that the most important part would be to estimate the effectiveness of the $\mathrm{MCl}$, a large part of the search strategy was directed to this issue. Scopus, including literature from fields other than health care, was searched up to March 2013. Key words used were multidimensional, multicomponent, complex, multimodal, multifaceted, multi-treatment, program*, system, evaluation, assessment, prediction, impact, "estimat* effects", influencing factors, treatment impact, sequential design, combined design, carry-over effect, interaction effects, cost-effectiveness, costs, economic evaluation, and effectiveness. To qualify for inclusion, articles had to describe and/or apply a method that provided information for the development of the approach. Once included, the following information was retrieved descriptively from each of the articles: the methodological problem or the respective method addressed, the aim of the method, and a description of the method. If more than one paper on a respective method was identified, papers were included until saturation occurred. If papers from leading professional associations were identified that contained methodology guidelines, no more articles for the respective method were included. After data extraction, the identified methods, the number of included articles reporting that method and the type of articles per method found (methods description, methods development, application, or a mix of any of these), were summarized descriptively.

By analysing the Dutch cancer rehabilitation guideline ${ }^{1}$ the requirements that the approach needs to fulfil were identified:

(a) The guideline recommends an assessment of the patients' needs and subsequently a tailored rehabilitation programme, consisting of exercise, cognitive behavioural therapy, psycho-education, return-to-work, etc., or a combination of two or more of these interventions. As a large amount of intervention-combinations needs to be compared, the approach should be applicable within a limited time frame, i.e. within up to 5-15 hours for performing the approach, excluding time for information retrieval and assessment, identical to the typical timeframe for mini-HTAs ${ }^{17}$.

(b) For many of the recommended combinations of interventions in this guideline, none or limited data regarding the costs and/or effects were available. Thus, it 
should be possible to carry out the approach when data on costs and effects of the $\mathrm{MCl}$ are limited.

(c) When single interventions are combined into an $\mathrm{MCl}$, interaction and carryover effects are likely to occur. In an interaction effect the independent variable's effect on the dependent variable depends on the level of another independent variable ${ }^{18}$. Carry-over effects occur when participation in one intervention influences the performance of the participant in and/or the additional effectiveness of another intervention ${ }^{18}$. The final method should be able to take these effects into account.

Subsequently, all methods that were identified in the literature review were evaluated on fulfilling requirement one. Those who passed were evaluated on fulfilling requirement two, and those who passed this step on requirement three. Method(s) fulfilling all requirements were analysed on how to adapt them to fully suit the decision-problem. Finally, the developed approach was applied to an exemplar $\mathrm{MCl}$ from supportive care for cancer patients. It was illustrated how the approach can be used to estimate what is expected to be more cost-effective, the $\mathrm{MCl}$ or one of the composite interventions.

\section{Results}

\section{Literature review}

In the review, 30 papers were included from which six unique methods were extracted. These methods are: (1) assessing the influence of mediating factors, (2) statistical modelling of the (cost-)effectiveness of interventions (such as extrapolation and transfer of model results to other settings, logistic regression analysis, whole disease modelling, etc.), (3) retrospectively identifying success factors of interventions, (4) using decisionrules for estimating the effectiveness of multicomponent interventions based on its single components, (5) network meta-analyses/indirect treatment comparisons, and (6) headroom analysis/cost-effectiveness gap analysis. The methods are described in Table 1. 
Table 1: Methods identified in the literature review and their descriptions

\begin{tabular}{|c|c|c|c|}
\hline Method & $\begin{array}{l}\text { Number and types of } \\
\text { papers included in } \\
\text { review }\end{array}$ & Aim of the method & Description of the method \\
\hline $\begin{array}{l}\text { Assessing the } \\
\text { influence of } \\
\text { mediating } \\
\text { variables }\end{array}$ & $\begin{array}{l}4 \text { papers included }{ }^{19-22} \\
\text { All papers are } \\
\text { applications. }\end{array}$ & $\begin{array}{l}\text { To assess the impact of } \\
\text { a mediating variable } \\
\text { that influences the } \\
\text { effect of an } \\
\text { intervention on an } \\
\text { outcome variable. } \\
\text { Knowing about the } \\
\text { mediating variable } \\
\text { helps to find out about } \\
\text { the mechanism } \\
\text { through which the } \\
\text { effectiveness of } \\
\text { interventions is caused } \\
\text { and about the } \\
\text { potential effectiveness } \\
\text { of a certain } \\
\text { combination of } \\
\text { interventions. }\end{array}$ & $\begin{array}{l}\text { The association between the } \\
\text { independent and the } \\
\text { dependent variables are re- } \\
\text { analysed on the influence of } \\
\text { mediating variables. }\end{array}$ \\
\hline $\begin{array}{l}\text { Statistical } \\
\text { modelling of } \\
\text { the (cost-) } \\
\text { effectiveness } \\
\text { of } \\
\text { interventions }\end{array}$ & $\begin{array}{l}10 \text { papers included } \\
31 \\
\text { Application of the } \\
\text { method: } n=2^{19,30} \\
\text { Methodology: } n=2^{24,31} \\
\text { Both: } n=6^{22,23,25-29}\end{array}$ & $\begin{array}{l}\text { To assess the potential } \\
\text { (cost-) effectiveness of } \\
\text { an intervention in } \\
\text { another setting or for } \\
\text { another population } \\
\text { through modelling. }\end{array}$ & $\begin{array}{l}\text { Various methods were } \\
\text { described, such as statistical } \\
\text { techniques, e.g. logistic } \\
\text { regression analysis, a causal } \\
\text { modelling approach, whole } \\
\text { disease modelling, and } \\
\text { health economic modelling. }\end{array}$ \\
\hline $\begin{array}{l}\text { Retrospec- } \\
\text { tively } \\
\text { identifying } \\
\text { success } \\
\text { factors of an } \\
\text { intervention }\end{array}$ & $\begin{array}{l}6 \text { papers included } \\
\text { 20,32-35 } \\
\text { All papers are } \\
\text { methodology } \\
\text { development and } \\
\text { application. }\end{array}$ & $\begin{array}{l}\text { To assess the } \\
\text { contribution of the } \\
\text { single interventions to } \\
\text { the overall } \\
\text { effectiveness of the } \\
\text { multicomponent } \\
\text { intervention. }\end{array}$ & $\begin{array}{l}\text { Two methods were } \\
\text { identified: (a) Decomposing } \\
\text { interventions: the } \\
\text { components of an } \mathrm{MCl} \text { are } \\
\text { analysed on the primary } \\
\text { entity and dimensions they } \\
\text { targeted, their delivery } \\
\text { characteristics, and intensity. } \\
\text { It is then analysed to what } \\
\text { degree these contribute to } \\
\text { the effectiveness, which } \\
\text { enables to analyse which } \\
\text { components probably } \\
\text { caused the effect. (b) A }\end{array}$ \\
\hline
\end{tabular}




\begin{tabular}{|c|c|c|c|}
\hline & & & $\begin{array}{l}\text { questionnaire was used to } \\
\text { elicit expert opinion about } \\
\text { which intervention } \\
\text { components caused the } \\
\text { effect. }\end{array}$ \\
\hline $\begin{array}{l}\text { Using } \\
\text { decision- } \\
\text { rules or } \\
\text { assumptions } \\
\text { for } \\
\text { estimating } \\
\text { (cost-) } \\
\text { effectiveness } \\
\text { of combined } \\
\text { interventions }\end{array}$ & $\begin{array}{l}4 \text { papers included } 22,30, \\
36-38 \\
\text { All papers are } \\
\text { applications. }\end{array}$ & $\begin{array}{l}\text { To estimate the } \\
\text { effectiveness of an } \\
\mathrm{MCl} \text {, when only the } \\
\text { effectiveness of the } \\
\text { single interventions of } \\
\text { which it consists is } \\
\text { known. }\end{array}$ & $\begin{array}{l}\text { Clear-cut decision-rules are } \\
\text { used to analyse the } \\
\text { effectiveness of combined } \\
\text { interventions, such as using } \\
\text { the sum (or a similar } \\
\text { measure) of the effect of } \\
\text { two single interventions for } \\
\text { the effectiveness of the } \mathrm{MCl} \text {. }\end{array}$ \\
\hline $\begin{array}{l}\text { Network } \\
\text { meta-analysis } \\
\text { and indirect } \\
\text { treatment } \\
\text { comparison }\end{array}$ & $\begin{array}{l}2 \text { papers included }{ }^{39,40} \\
\text { Both papers include } \\
\text { the methodology } \\
\text { guidelines of a leading } \\
\text { professional } \\
\text { association }\end{array}$ & $\begin{array}{l}\text { To assess the relative } \\
\text { effectiveness of two } \\
\text { treatments that were } \\
\text { not compared head- } \\
\text { to-head, but to a } \\
\text { common comparator. }\end{array}$ & $\begin{array}{l}\text { Statistical methods are used } \\
\text { to establish the comparative } \\
\text { effectiveness of two } \\
\text { treatments that were not } \\
\text { evaluated head-to-head. } \\
\text { Preconditions are that the } \\
\text { evidence was generated in } \\
\text { randomised controlled trials } \\
\text { and included homogenous } \\
\text { participants across the trials. }\end{array}$ \\
\hline $\begin{array}{l}\text { Headroom } \\
\text { analysis/cost- } \\
\text { effectiveness } \\
\text { gap analysis }\end{array}$ & $\begin{array}{l}3 \text { papers included }{ }^{41-43} \\
\text { Methods description: } \\
n=1^{41} \\
\text { Methods development: } \\
n=1^{42} \\
\text { Methods application: } \\
n=1^{43}\end{array}$ & $\begin{array}{l}\text { To assess the minimum } \\
\text { required incremental } \\
\text { effect or the maximum } \\
\text { incremental costs of an } \\
\text { intervention that is } \\
\text { needed to achieve } \\
\text { cost-effectiveness, in } \\
\text { cases where either the } \\
\text { incremental effect or } \\
\text { the incremental costs } \\
\text { are unknown. }\end{array}$ & $\begin{array}{l}\text { When the willingness-to-pay } \\
\text { for one unit of the effect is } \\
\text { given, the equation for the } \\
\text { ICER can be transformed. } \\
\text { This allows assessing the } \\
\text { minimum effectiveness an } \\
\text { intervention is required to } \\
\text { attain, given its costs and } \\
\text { the willingness-to-pay, in } \\
\text { order to be considered cost- } \\
\text { effective. }\end{array}$ \\
\hline
\end{tabular}

$\mathrm{MCl}=$ Multicomponent intervention, ICER=Incremental cost-effectiveness ratio 


\section{Development of the stepwise approach}

\section{Choice of a method}

Requirement $\mathrm{a}$, being able to estimate the cost-effectiveness of an $\mathrm{MCl}$ versus its single interventions, was fulfilled by two methods; headroom analysis and using decision-rules. The remaining methods require statistical data analysis which is time-consuming, especially when conducted for several MCls, and require advanced statistical expertise. Requirement $b$, being able to estimate cost-effectiveness in the absence of full data on incremental effects and costs, was fulfilled by both the methods that also fulfilled the first requirement. Requirement $c$, being able to take carry-over and interaction effects into account, was fulfilled by headroom analysis only, which therefore was used as a starting point for further development into an approach that enables to compare the cost-effectiveness of $\mathrm{MCl}$ to that of its composite interventions. Using decision-rules did not fulfil this requirement. The reason is that the same algorithm for determining the effect of combining interventions into an $\mathrm{MCl}$ is used for all interventions, irrespective of what kind of interventions are combined. For example, when the decision-rule is that the effect of the $\mathrm{MCl}$ is the sum of the effects of the single interventions, this is true for all interventions that are combined. Thus, this would apply irrespectively of whether an interaction or carry-over effect is assumed to occur that diminishes the effect or would lead to a synergy effect. Table 2 shows which methods fulfilled the requirements. 
Table 2: Analysis of which methods fulfil the requirements

\begin{tabular}{|c|c|c|}
\hline $\begin{array}{l}\text { Methods that were found } \\
\text { in the literature review }\end{array}$ & \multicolumn{2}{|c|}{$\begin{array}{l}\text { - Using decision-rules for estimating the effectiveness of } \\
\text { - } \quad \text { Statistically modelling (cost-) effectiveness } \\
\text { - } \quad \text { Retrospectively identifying success factors } \\
\text { - } \quad \text { Assessing the influence of mediating factors } \\
\text { - } \quad \text { Network meta-analysis and indirect treatment comparison } \\
\text { - } \quad \text { Headroom analysis / cost-effectiveness gap analysis }\end{array}$} \\
\hline \multirow[t]{2}{*}{$\begin{array}{l}\text { Methods that fulfil } \\
\text { requirement a): } \\
\text { Being able to estimate the } \\
\text { cost-effectiveness of the } \\
\text { single interventions vs. the } \\
\text { MCI within a reasonable } \\
\text { time frame: }\end{array}$} & $\begin{array}{l}\text { Using decision-rules } \\
\text { for estimating the } \\
\text { effectiveness of } \\
\text { combined } \\
\text { interventions: }\end{array}$ & $\begin{array}{l}\text { A decision-rule (such as the effectiveness of } \\
\text { the } \mathrm{MCl} \text { being the sum of that of the single } \\
\text { interventions) is applied, which does not } \\
\text { require time-consuming analyses or data } \\
\text { collection. }\end{array}$ \\
\hline & $\begin{array}{l}\text { Headroom analysis / } \\
\text { cost-effectiveness } \\
\text { gap analysis: }\end{array}$ & $\begin{array}{l}\text { Assessing the required incremental effect or } \\
\text { cost for achieving cost-effectiveness does } \\
\text { not take much time. Analysing whether the } \\
\text { specific intervention is likely to reach the } \\
\text { required incremental effect is done by } \\
\text { expert opinion, which requires selecting } \\
\text { and approaching experts, and experts } \\
\text { gathering sufficient information for doing } \\
\text { the estimation. }\end{array}$ \\
\hline \multirow[t]{2}{*}{$\begin{array}{l}\text { Of the above, methods } \\
\text { that fulfil requirement b): } \\
\text { Being able to estimate } \\
\text { (cost-) effectiveness in the } \\
\text { absence of full data }\end{array}$} & $\begin{array}{l}\text { Using decision-rules } \\
\text { for estimating the } \\
\text { effectiveness of } \\
\text { combined } \\
\text { interventions: }\end{array}$ & $\begin{array}{l}\text { Can be used for estimating the } \\
\text { effectiveness of the } \mathrm{MCl} \text { when only that of } \\
\text { the single interventions is known, thus the } \\
\text { effectiveness of the } \mathrm{MCl} \text { may be unknown. }\end{array}$ \\
\hline & $\begin{array}{l}\text { Headroom analysis / } \\
\text { cost-effectiveness } \\
\text { gap analysis: }\end{array}$ & $\begin{array}{l}\text { Aim of the method is to figure out what } \\
\text { either the incremental effect or costs may } \\
\text { be, in order to achieve cost-effectiveness, in } \\
\text { cases where one of them is unknown. Thus, } \\
\text { either the incremental costs or the } \\
\text { incremental effect may be unknown. }\end{array}$ \\
\hline $\begin{array}{l}\text { Of the above, } \\
\text { Methods that fulfil } \\
\text { requirement c): } \\
\text { Being able to take into } \\
\text { account carry-over and } \\
\text { interaction effects }\end{array}$ & $\begin{array}{l}\text { Headroom analysis / } \\
\text { cost-effectiveness } \\
\text { gap analysis }\end{array}$ & $\begin{array}{l}\text { When headroom analysis is adapted to } \\
\mathrm{MCls} \text {, it can be accounted for carry-over } \\
\text { and interaction effects in the analysis of } \\
\text { whether the required minimum effect is } \\
\text { attained. }\end{array}$ \\
\hline
\end{tabular}


The basis of headroom-analysis is the net-benefit framework, which is used to determine the incremental cost-effectiveness ratio (ICER) of an intervention:

Incremental cost - effectiveness ratio $($ ICER $)=(\Delta$ Costs $\div \Delta$ Effect $)$

Headroom-analysis is used in cases in which either the incremental costs or the incremental effect of an intervention are unknown. The pivotal parameter in the headroom method is the maximum amount someone is willing to spend on one unit of additional effect, i.e. the willingness-to-pay (WTP). Then, depending on which of the other two parameters is known, i.e. either the minimum required incremental effect (MRIE) an intervention needs to attain, or the maximum costs it may have in order to be considered cost-effective can be calculated with the following equations:

$M R \Delta E \geq(\Delta$ Costs $\div$ WTP $)$

$\operatorname{Max} \Delta C \leq(\Delta E f f e c t \times W T P)$

$\mathrm{MR} \Delta \mathrm{E}=$ Minimum required incremental effect

WTP = Willingness-to-pay

$\operatorname{Max} \Delta \mathrm{C}=$ Maximum incremental costs

The next step is to estimate to what extent the respective intervention is likely to attain the required effectiveness or to stay below a maximum cost. For being fully suitable to solve our decision-problem, headroom analysis should explicitly accommodate the estimation of whether the $\mathrm{MCl}$ can attain the minimum effect or stay below the maximum costs, and compare this to the cost-effectiveness of the single intervention. The "conventional" headroom analysis does not explicitly allow for this. Therefore, this was developed as part of this study and is described below.

\section{Development of the approach}

As costs of an intervention can be calculated relatively easily, i.e. in comparison to the effectiveness, this approach focuses on whether the MRIE would be attained. In order to accommodate $\mathrm{MCls}$ in the headroom analysis-approach, the incremental effect and costs of a single intervention are replaced by those of the $\mathrm{MCl}$ in equation 2. The $\mathrm{MCl}$ is labelled "AB" and consists of the single interventions " $A$ " and " $B$ ".

$M R \Delta$ Effect of $A B \geq(\triangle \operatorname{Cost} A B \div$ WTP $)$

Afterwards, a qualitative estimation of how likely the respective intervention is to attain the minimum required effect (MRIE), given the incremental effects or costs and the WTP, needs to be performed. Then, it needs to be estimated if the $\mathrm{MCl}$ is likely to attain the MRIE, and how this compares to the cost-effectiveness of the single interventions. It is 
not a precondition for the approach that the single interventions are cost-effective by themselves, as the $\mathrm{MCl}$ can be cost-effective when super-additive effects occur.

\section{The step-wise approach}

The approach consists of the following six steps:

\section{Estimate intervention costs}

When the costs of the $\mathrm{MCl}$ are not empirically investigated, these can be estimated using the cost calculation of the single interventions. It needs to be analysed which costs are (super-) additive when the composite interventions are merged into an $\mathrm{MCl}$, and which costs are redundant or sub-additive 44,45 . Further, detailed intervention descriptions can be used and, when required, the intervention developers may be willing to share more details and data upon request.

\section{Choose a common outcome measure}

Since the incremental effectiveness of the interventions under comparison is expressed in one outcome measure, of which the monetary value is determined through the WTP, the effectiveness of all interventions needs to be expressed in that same outcome measure. Most suitable for economic evaluations are generic outcome measures, such as quality-adjusted life years (QALYs).

\section{Determine the WTP}

The WTP for the selected outcome measure, i.e. the maximum amount society is willing to pay for an additional unit of effect, needs to be determined.

\section{Analyse the minimum required incremental effect (MRIE)}

The MRIE of the $\mathrm{MCl}$ needs to be assessed by completing equation 4, using the WTP and the cost of the $\mathrm{MCl}$ as determined in step 1.

\section{Qualitatively assess how likely the $\mathrm{MCl}$ is to attain the MRIE}

The potential for the $\mathrm{MCl}$ to attain the required MRIE needs to be assessed. For this the following information and any other information that is considered relevant to assess the potential effect of the $\mathrm{MCl}$ should be gathered from experts or identified in the literature (as far as available):

- The effectiveness of the single interventions, as this indicates the potential effect size. 
- The interaction and carry-over effects that are assumed to occur in an $\mathrm{MCl}$, and whether these diminish, enlarge, or do not influence the MCl's effectiveness.

- The intensity of the intervention (e.g. in physical exercise interventions this could be walking vs. running). More intense interventions may lead to larger effect sizes. Too high intensity might lead to exhaustion and diminish the effect of the $\mathrm{MCl}$.

- The effect-causing mechanisms of the single interventions and whether these differ. When this is the case, it can be assumed that the effect is larger than that of one intervention.

- The effect of similar (combinations of) interventions or of the respective intervention in another patient group can give an impression of the reachable effect.

- The symptom burden at baseline. A higher burden may lead to a greater potential for achieving high effect.

- The natural course of the symptoms. If, e.g., the symptoms fade out by themselves, the potential for a high effect of the $\mathrm{MCl}$ is smaller than when symptoms would increase without any treatment.

- The duration of the treatment effect. As QALYs are a function of utility and the duration in which the utility is higher than in the comparison group, this has a high influence on the QALY-gain.

Based on these aspects, a qualitative estimation could be conducted of how likely the $\mathrm{MCl}$ is to attain the MRIE; for example on a 4-point Likert-scale defined as 'very likely', 'likely', 'unlikely', 'or very unlikely'.

6. Compare the cost-effectiveness of the single interventions to the potential of the $\mathrm{MCl}$ for being cost-effective

The potential for the $\mathrm{MCl}$ to be cost-effective depends on the cost-effectiveness of the single interventions. If the $\mathrm{MCl}$ is likely or very likely to be cost-effective, but the single interventions are not, the $\mathrm{MCl}$ should be adopted. In turn, when one or both single interventions are cost-effective, but the $\mathrm{MCl}$ is unlikely or very unlikely to be costeffective, the most cost-effective single intervention is recommended. In Table 3 it is shown in which cases the $\mathrm{MCl}$ or the single interventions should be adopted. 
Table 3: Overview of which intervention is identified as most cost-effective

\begin{tabular}{|c|c|c|c|}
\hline & $\begin{array}{l}\text { The single } \\
\text { interventions are cost- } \\
\text { effective }\end{array}$ & $\begin{array}{l}\text { The single } \\
\text { interventions are not } \\
\text { cost-effective }\end{array}$ & $\begin{array}{l}\text { One of the single } \\
\text { interventions is cost- } \\
\text { effective }\end{array}$ \\
\hline $\begin{array}{l}\text { The } \mathrm{MCl} \text { is estimated } \\
\text { to be likely or very } \\
\text { likely cost-effective }\end{array}$ & Undecided* & The $\mathrm{MCl}$ & Undecided* \\
\hline $\begin{array}{l}\text { The } \mathrm{MCl} \text { is estimated } \\
\text { to be unlikely or very } \\
\text { unlikely cost-effective }\end{array}$ & $\begin{array}{l}\text { The most cost- } \\
\text { effective single } \\
\text { intervention }\end{array}$ & Undecided* & $\begin{array}{l}\text { The cost-effective } \\
\text { single intervention }\end{array}$ \\
\hline \multicolumn{4}{|c|}{$\begin{array}{l}\text { MCI=Multicomponent intervention, ICER=Incremental cost-effectiveness ratio, } \\
\text { WTP=Willingness-to-pay } \\
\text { *) In case of "undecided" the choice can be based on patient preferences or on the } \\
\text { budget impact. Another possibility is to repeat the approach with a willingness-to-pay } \\
\text { that resembles the ICER of the (most) cost-effective single intervention. In that way, it } \\
\text { can be analysed if the MCI still is considered cost-effective when the WTP is as high as } \\
\text { the ICER of the single intervention. }\end{array}$} \\
\hline
\end{tabular}

\section{Application of the stepwise approach}

An example from supportive cancer care is used as an illustration, which consists of interventions for alleviating treatment-induced menopausal symptoms in breast cancer patients. The $\mathrm{MCl}$ consists of two single interventions, cognitive behavioural therapy (CBT) and physical exercise (PE), which are both also prescribed as stand-alone interventions $^{46}$. CBT has a cost of $€ 190$ and adds 0.0079 QALYs compared to usual care, PE costs $€ 197$ and adds 0.0067 QALYs $^{47}$. The ICER for CBT is $€ 22,500 /$ QALYS and $€ 28,100 / Q A L Y$ for PE (differences from directly dividing these values are due to rounding).

\section{Estimate intervention costs}

For the $\mathrm{MCl}$, the costs of CBT and PE are additive, i.e. the sum of those for PE and for CBT; $€ 387$. They are not sub-additive, as the time for planning appointments and the required resources for providing the interventions remain the same.

\section{Choose a common outcome measure}

QALYs are chosen as the common outcome measure for all interventions involved in the comparison, as these are recommended for health economic analyses. 


\section{Determine the WTP}

Willingness-to-pay is assumed at $€ 30.000$ per QALY.

4. Analyse the minimum required incremental effect (MRIE)

The MRIE for the $\mathrm{MCl}$ consisting of both PE and CBT is 0.0129 :

$$
\begin{aligned}
& \text { Min } \Delta E \text { ffect } A+\text { Min } \Delta E \text { ffect } B \geq((\Delta \text { Costs } A+\Delta \text { Costs } B) \div \text { WTP }) \\
& \text { Min } \Delta E f f e c t A+\text { Min } \Delta E \text { ffect } B \geq(€ 387 \div 30,000)=0.0129
\end{aligned}
$$

5. Estimate if the $\mathrm{MCl}$ and the composite interventions are likely to attain the MRIE The following information was considered:

- In order to attain the MRIE, an effect of almost the sum of that of CBT and PE is required.

- When combining CBT and PE it is likely that an interaction effect occurs. For participating in the $\mathrm{MCl}$, patients need to travel to the hospital at least twice a week, which might be exhausting and could reduce the effect of the interventions as patient might be more tired.

- CBT and PE have different effect-causing mechanisms ${ }^{46,48-51}$. While CBT aims to influence the perception of the symptoms, PE is assumed to actually reduce the severity and frequency of symptoms ${ }^{49-51}$. Therefore, the $\mathrm{MCl}$ is expected to be more effective than CBT or PE alone.

- The baseline quality-of-life was $0.78^{47}$, indicating a relatively low symptom burden.

- Menopausal symptoms fade out during a period of approximately five years ${ }^{52}$, leading to an average maximum effect duration of five years.

- The evidence on the effectiveness of exercise for reducing vasomotor symptoms is inconclusive. A meta-analysis found an effect size of 0.3 of exercise on health-related quality of life (HRQOL) in breast cancer patients ${ }^{53}$.

- The effect of the $\mathrm{MCl}$ cannot last longer than the 5 years for which the symptoms normally are experienced. Moreover, the potential effect size becomes smaller throughout the years, as the symptoms diminish naturally.

It was estimated that the $\mathrm{MCl}$ is unlikely to reach the MRIE of 0.0129. The MRIE is almost the sum of the effects of PE and CBT, as no sub-additive effects for the costs occur. The main reason for the conclusion is that the symptom burden of the patients was relatively low. As the symptoms fade out by themselves and the single interventions PE and CBT do not result in effect sizes of that magnitude, the potential for reaching the high MRIE is small. CBT+PE is assumed to have a larger effect than one of them alone, as they 
have different effect-causing mechanisms. However, the intensity of following both interventions is assumed to be tiresome for some participants, which would further diminish the combined effect, so that it is unlikely to reach the sum of PE and CBT.

6. Compare the potential for cost-effectiveness of the $\mathrm{MCl}$ to that of the composite interventions

The single interventions CBT and PE are cost-effective. The $\mathrm{MCl}$ may add further effectiveness; however, it is estimated that the MRE of 0.0129 QALYs is unlikely to be attained. Thus, when aiming to choose a cost-effective intervention, one of the single interventions should be preferred.

\section{Discussion}

We developed and illustrated an approach that enables to estimate which intervention is likely to be more cost-effective, an $\mathrm{MCl}$ or its composite interventions, when empirical data on costs and effects of the $\mathrm{MCl}$ are incomplete. It is intended to be pragmatic and feasible to perform within a short time frame and without advanced health economic expertise, as this would limit its use by decision-makers. The approach builds on headroom analysis, which was extended in order to accommodate MCls. Given the costs of the $\mathrm{MCl}$ and the willingness-to-pay, the MRIE of the interventions in order to attain cost-effectiveness can be assessed. Subsequently, a qualitative yet systematic assessment of how likely the $\mathrm{MCl}$ is to achieve the MRIE can be made. Depending on whether the single interventions are cost-effective, it can be assessed whether the $\mathrm{MCl}$ is likely to be more cost-effective.

The literature review showed that methodology concerning this specific decisionproblem is rather scarce. Reasons for this gap are that guideline developers traditionally have been more concerned with effectiveness than cost-effectiveness, that including economic evidence into guidelines makes the process of developing them even lengthier and more resource intensive ${ }^{54}$, and that clear criteria of when an intervention is considered cost-effective are lacking. A framework to overcome this was developed by Gandjour and Lauterbach ${ }^{23}$ for assessing the break-even point of guidelines. Our approach adds the option to estimate the potential for cost-effectiveness of an $\mathrm{MCl}$ in the absence of full data and in a pragmatic way that can be conducted by decision makers. 
The approach presented here is developed for national decision making, but with little adaptation it can also support local decision makers. Hospitals or health care providers can use it to decide how to implement a comprehensive guideline advice by replacing the WTP by their budget or the reimbursement, in order to analyse how to achieve the best use of the available resources. This would form a beneficial addition to the current mini-HTAs, which are used e.g. for making decisions on local budgets ${ }^{17}$. Another variant of the approach is to not analyse the MRIE and then decide if the intervention potentially can attain this, but to first estimate the range of the effect that the intervention is thought to attain, and to then determine the range of ICERs that this corresponds to. Subsequently, the intervention with the most favourable ICER range can be chosen.

As the key missing information in the puzzle of the cost-effectiveness is the effect of the $\mathrm{MCl}$, research should focus on how to assess the additivity of the health benefits of interventions when they are combined into an $\mathrm{MCl}$, as this so far is seen as a "black box". One direction that could be taken is to use the various approaches that sensitivity analysis offers, which also take the already existing information and clinical expertise into account $^{55}$. Another direction is the approach by Basu et al. in which prediction models are used that analyse the utility of a joint health state, i.e. a patient experiencing several symptoms, from the utility of single health states, i.e. from patients having only one symptom ${ }^{56}$.

Moreover, to evaluate the benefit of the developed approach in practice, future research is needed. Comparisons should be made of the results of this approach versus those of an economic evaluation alongside an RCT, in order to gain more insight into the validity of the results of headroom analysis for multicomponent interventions.

\section{Conclusion}

We developed a systematic approach to estimate, in the absence of suitable data on costs and effects, if an $\mathrm{MCl}$ can be more cost-effective than its composite, single interventions. The purpose of this method is to support the decision of which interventions to recommend in guidelines based on cost-effectiveness considerations, in the absence of full (and timely) data. We illustrated the use of this method in the field of cancer survivorship. Further research is needed in which headroom analysis for $\mathrm{MCls}$ is applied to multicomponent guidelines, to test the method's practical use and impact. 


\section{References}

1. The Netherlands Comprehensive Cancer Organisation (IKNL). Cancer rehabilitation - nation-wide guideline. Utrecht: IKNL, 2011.

2. Balinsky W, Muennig P. The costs and outcomes of multifaceted interventions designed to improve the care of congestive heart failure in the inpatient setting: a review of the literature. Medical Care Research and Review 2003; 60(3): 275-93.

3. Chou R, Loeser JD, Owens DK, et al. Interventional therapies, surgery, and interdisciplinary rehabilitation for low back pain. Spine 2009; 34(10): 1066-77.

4. Prvu Bettger JA, Stineman MG. Effectiveness of multidisciplinary rehabilitation services in postacute care: state-of-the-science. A review. Archives of Physical Medicine and Rehabilitation 2007; 88(11): 1526-34.

5. Smeets RJ, Severens JL, Beelen S, Vlaeyen JW, Knottnerus JA. More is not always better: cost-effectiveness analysis of combined, single behavioral and single physical rehabilitation programs for chronic low back pain. European Journal of Pain 2009; 13(1): 71-81.

6. IOM (Institute of Medicine). Cognitive rehabilitation therapy for traumatic brain injury: evaluating the evidence. Washington, DC: The National Academies Press, 2011.

7. Ollendorf DA, Silverstein MD, Andry A, Pearson SD. Management options for patients with low back disorders: final appraisal document. Boston: Institute for Clinical and Economic Review, 2011.

8. Saevarsson S, Halsband U, Kristjánsson Á. Designing rehabilitation programs for neglect: Could 2 be more than 1+1? Applied Neuropsychology 2011; 18: 95-106.

9. Ollenschlager G. Improving the quality of health care: using international collaboration to inform guideline programmes by founding the Guidelines International Network (G-I-N). Quality and Safety in Health Care 2004; 13(6): 45560.

10. Qaseem A, Forland F, Macbeth F, et al. Guidelines International Network: toward international standards for clinical practice guidelines. Annals of Internal Medicine 2012; 156: 525-31.

11. Mason J, Eccles M, Freemantle N, Drummond M. A framework for incorporating cost-effectiveness in evidence-based clinical practice guidelines. Health Policy 1999; 47: 37-52.

12. Rickles D, Hawe P, Shiell A. A simple guide to chaos and complexity. Journal of Epidemiology and Community Health 2007; 61(11): 933-7. 
13. Lovemen E, Frampton GK, Shepherd J, et al. The clinical effectiveness and costeffectiveness of long-term weight management schemes for adults: a systematic review. Health Technology Assessment. 2011: 1-184.

14. Ramsey SD, Willke RJ, Glick H, et al. Cost-effectiveness analysis alongside clinical trials II-an ISPOR Good Research Practices Task Force report. Value in Health 2015; 18(2): 161-72.

15. Hay J, Smeeding J, Carroll N, et al. Good research practices for measuring drug costs in cost effectiveness analyses: issues and recommendations: The ISPOR Drug Cost Task Force Report-part 1. Value in Health 2010; 13(1): 3-7.

16. Guyatt G, Oxman A, Vist G, Kunz R, Falck-Ytter Y, Schünemann H. GRADE: What is "quality of evidence" and why is it important to clinicans? British Medical Journal 2008; 336(7651): 995-8.

17. Danish Centre for Evaluation and Health Technology Assessment (DACEHTA). Introduction to mini-HTA - a management and decision support tool for the hospital service. Copenhagen: DACEHTA, 2005.

18. Senn S. Cross-over trials in clinical research. Chichester: John Wiley \& Sons, 1993.

19. Barasa EW, Ayieko P, Cleary S, English M. A multifaceted intervention to improve the quality of care of children in district hospitals in Kenya: a cost-effectiveness analysis. PLoS Medicine 2012; 9(6): e1001238.

20. Lee CC, Czaja SJ, Schulz R. The moderating influence of demographic characteristics, social support, and religious coping on the effectiveness of a multicomponent psychosocial caregiver intervention in three racial ethnic groups. The Journals of Gerontology Series B: Psychological Sciences and Social Sciences 2010; 65B(2): 185-94.

21. Helgeson VS, Lepore SJ, Eton DT. Moderators of the benefits of psychoeducational interventions for men with prostate cancer. Health Psychology 2006; 25(3): 348-54.

22. Schootman M, Deshpande AD, Pruitt $S$, Aft R, Jeffe DB. Estimated effects of potential interventions to prevent decreases in self-rated health among breast cancer survivors. Annals of Epidemiology 2012; 22(2): 79-86.

23. Gandjour A, Lauterbach KW. A method for assessing the cost-effectiveness and the break-even point of clinical practice guidelines. International Journal of Technology Assessment in Health Care 2001; 17(4): 503-16.

24. Barasa EW, English M. Viewpoint: economic evaluation of package of care interventions employing clinical guidelines. Tropical Medicine and International Health 2011; 16(1): 97-104. 
25. Ahern J, Hubbard A, Galea S. Estimating the effects of potential public health interventions on population disease burden: a step-by-step illustration of causal inference methods. American Journal of Epidemiology 2009; 169(9): 1140-7.

26. Hardeman W. A causal modelling approach to the development of theory-based behaviour change programmes for trial evaluation. Health Education Research 2005; 20(6): 676-87.

27. Gandjour A. A model to predict the cost-effectiveness of disease management programs. Health Economics 2009; 19(6): 697-715.

28. Brooks JM, Fang G. Interpreting treatment-effect estimates with heterogeneity and choice: simulation model results. Clinical Therapeutics 2009; 31(4): 902-19.

29. Hersh AL, Black WC, Tosteson ANA. Estimating the population impact of an intervention: a decision-analytic approach Statistical Methods in Medical Research 1999; 8: 311-30.

30. Becker MG, Glass K, Barnes B, et al. Using mathematical models to assess response to an outbreak of an emerged viral repiratory disease. The Australian National University: National Centre for Epidemiology and Population Health, 2006.

31. Tappenden P, Chilcott J, Brennan A, Squires H, Stevenson M. Whole disease modeling to inform resource allocation decisions in cancer: a methodological framework. Value in Health 2012; 15(8): 1127-36.

32. Belle SH, Czaja SJ, Schulz R, et al. Using a new taxonomy to combine the uncombinable: integrating results across diverse interventions. Psychology and Aging 2003; 18(3): 396-405.

33. Schulz R, Czaja SJ, McKay JR, Ory MG, Belle SH. Intervention taxanomy (ITAX): describing essential features of interventions (HMC). American Journal of Health Behavior 2010; 34(6): 811-21.

34. Gitlin LN, Belle SH, Burgio LD, et al. Effect of multicomponent interventions on caregiver burden and depression: the REACH multisite initiative at 6-month follow-up. Psychology and Aging 2003; 18(3): 361-74.

35. Schouten LMT, Grol RPTM, Hulscher MEJL. Factors influencing success in qualityimprovement collaboratives: development and psychometric testing of an instrument. Implementation Science 2010; 5(1): 84.

36. Czaja SJ, Schulz R, Lee CC, Belle SH. A methodology for describing and decomposing complex psychosocial and behavioral interventions. Psychology and Aging 2003; 18(3): 385-95. 
37. Cobiac LJ, Vos T, Barendregt JJ. Cost-effectiveness of interventions to promote physical activity: a modelling study. PLoS Medicine 2009; 6(7): e1000110.

38. Gentry D, Herbers S, Shelton S, Mueller N, Luke D. What is it worth? Economic evaluation of the MFH Tobacco Initiative. St. Louis: Missouri Foundation for Health, 2009.

39. Hoaglin DC, Hawkins N, Jansen JP, et al. Conducting indirect treatmentcomparison and network-meta-analysis studies: report of the ISPOR Task Force on indirect treatment comparisons good research practices: part 2. Value in Health 2011; 14(4): 429-37.

40. Jansen JP, Fleurence $R$, Devine $B$, et al. Interpreting indirect treatment comparisons and network meta-analysis for health-care decision making: report of the ISPOR Task Force on indirect treatment comparisons good research practices: part 1. Value in Health 2011; 14: 417-28.

41. IJzerman MJ, Steuten LMG. Early assessment of medical technologies to inform product development and market access: a review of methods and applications. Applied Health Economics and Health Policy 2011; 9(5): 331-47.

42. Cosh E, Girling A, Lilford R, McAteer H, Young T. Investing in new medical technologies: a decision framework. Journal of Commercial Biotechnology 2007; 13(4): 263-71.

43. McAteer H, Cosh E, Freeman G, Pandit A, Wood P, Lilford R. Cost-effectiveness analysis at the development phase of a potential health technology: examples based on tissue engineering of bladder and urethra. Journal of Tissue Engineering and Regenerative Medicine 2007; 1(5): 343-9.

44. Geary N. Understanding synergy. American Journal of Physiology Endocrinology and Metabolism 2013; 304(3): E237-53.

45. Hollingsworth B, Peacock S. Efficiency measurement in health and health care. New York: Routledge; 2008.

46. Duijts SFA, Van Beurden M, Oldenburg HSA, et al. Efficacy of cognitive behavioral therapy and physical exercise in alleviating treatment-induced menopausal symptoms in patients with breast cancer: results of a randomized, controlled, multicenter trial. Journal of Clinical Oncology 2012; 30(33): 4124-33.

47. Mewes J, Steuten LD, SFA, Oldenburg $H$, et al. Cost-effectiveness of cognitive behavioral therapy and physical exercise for alleviating treatment-induced menopausal symptoms in breast cancer patients. Journal of Cancer Survivorship 2014; 9(1): 126-35. 
48. Duijts SFA, Oldenburg HSA, van Beurden M, Aaronson NK. Cognitive behavioral therapy and physical exercise for climacteric symptoms in breast cancer patients experiencing treatment-induced menopause: design of a multicenter trial. BMC Women's Health 2009; 6(9): 15.

49. Ivarsson T, Spetz AC, Hammar M. Physical exercise and vasomotor symptoms in postmenopausal women. Maturitas 1998; 29: 139-46.

50. Li C, Samsioe G, Borgfeldt C, Lidfeldt J, Agardh CD, Nerbrand C. Menopauserelated symptoms: What are the background factors? A prospective populationbased cohort study of Swedish women (The Women's Health in Lund Area study). American Journal of Obstetrics and Gynecology 2003; 189(6): 1646-53.

51. Hunter M. Cognitive behavioural interventions for premenstrual and menopausal symptoms. Journal of Reproductive and Infant Psychology 2003; 21(3): 183-93.

52. McKinlay SM, Brambilla DJ, Posner JG. Reprint of: The normal menopausal transition. Maturitas 2008; 61(1-2): 4-16.

53. Duijts SFA, Faber MM, Oldenburg HSA, van Beurden M, Aaronson NK. Effectiveness of behavioral techniques and physical exercise on psychosocial functioning and health-related quality of life in breast cancer patients and survivors-a meta-analysis. Psycho-Oncology 2011; 20(2): 115-26.

54. Eccles M, Mason J. How to develop cost-conscious guidelines. Health Technology Assessement 2001; 5(16): 1-78.

55. Liu W, Kuramoto SJ, Stuart EA. An introduction to sensitivity analysis for unobserved confounding in nonexperimental prevention research. Prevention Science 2013; 14(6): 570-80.

56. Basu A, Dale W, Elstein A, Meltzer D. A linear index for predicting joint healthstates utilities from single health-states utilities. Health Economics 2009; 18(4): 403-19. 


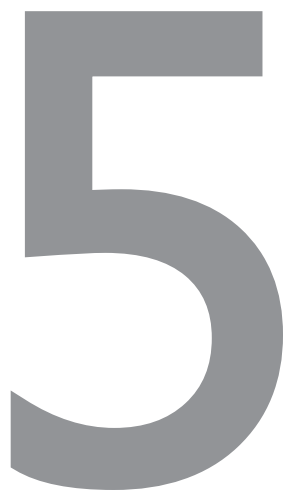

\section{Return-to-work intervention for cancer survivors: Budget impact and allocation of costs and returns in the Netherlands and six major EU-countries}

Janne C. Mewes

Lotte M.G. Steuten

Iris F. Groeneveld

Angela G.E.M. de Boer

Monique H.W. Frings-Dresen

Maarten J. IJzerman

Wim H. van Harten

BMC Cancer 15: 899, 2015 



\title{
Return-to-work intervention for cancer survivors: Budget impact and allocation of costs and returns in the Netherlands and six major EU-countries
}

\begin{abstract}
Introduction: Return-to-work (RTW)-interventions support cancer survivors in resuming work, but come at additional healthcare costs. The objective of this study was to assess the budget impact of a RTW-intervention, consisting of counselling sessions with an occupational physician and an exercise-programme. The secondary objective was to explore how the costs of RTW-interventions and its financial revenues are allocated among the involved stakeholders in several EU-countries.

Methods: The budget impact (BI) of a RTW-intervention versus usual care was analysed yearly for 2015-2020 from a Dutch societal- and from the perspective of a large cancer centre. The allocation of the expected costs and financial benefits for each of the stakeholders involved was compared between the Netherlands, Belgium, England, France, Germany, Italy, and Sweden.

Results: The average intervention costs in this case were $€ 1,519 /$ patient. The Bl for the Netherlands was $€-14.7 \mathrm{~m}$ in 2015 , rising to $€-71.1 \mathrm{~m}$ in 2020, thus the intervention is costsaving as the productivity benefits outweigh the intervention costs. For cancer centres the $\mathrm{Bl}$ amounts to $€ 293 \mathrm{k}$ in 2015, increasing to $€ 1.1 \mathrm{~m}$ in 2020. Across European countries, we observed differences regarding the extent to which stakeholders either invest or receive a share of the benefits from offering a RTW-intervention.

Conclusion: The RTW-intervention is cost-saving from a societal perspective. Yet, the total intervention costs are considerable and, in many European countries, mainly covered by care providers that are not sufficiently reimbursed.
\end{abstract}




\section{Background}

Many cancer survivors experience difficulties in returning to work. Approximately 40\% have not resumed work 24 months post treatment. Furthermore, cancer survivors have an increased risk for unemployment compared to the general population ${ }^{2,3}$. Supporting patients in returning to the workplace may improve health and quality of life, and avoid high societal costs associated with unemployment and long-term inability to work ${ }^{4-6}$. When successful, RTW-interventions can increase productivity through reducing sick leave and might save costs to society. However, RTW is not or only partly reimbursed by health insurers in most European countries, including the Netherlands. The main reason is that the interventions are expected to be expensive and unaffordable. However, when they are effective, return-to-work interventions can produce financial benefits, although their size is unknown. To date, no budget impact analysis of these interventions or of any other cancer rehabilitation intervention has been published. Evidence on the budget impact would quantify to what extent return-to-work interventions are beneficial from a financial point of view or if these intervention would add costs to the system. Therefore, the primary aim of this study was to evaluate the expected budget impact (BI) of RTW interventions for cancer survivors. In a budget impact analysis, the expected financial impact of an intervention on the budget of a health system is analysed ${ }^{7}$.

Return-to-work interventions typically consist of counselling by an occupational physician directed on return-to-work possibilities. We considered an intervention that combines counselling with physical exercise, as a Cochrane review showed that multidisciplinary RTW-interventions are most effective. Moreover, physical exercise is strongly recommended for cancer patients in several organisations' guidelines ${ }^{8-12}$. The analysis was conducted from the Dutch societal perspective and from the perspective of a cancer centre over the time period 2015 to 2020. The latter perspective serves to estimate the BI for cancer centres that plan to introduce RTW and want to investigate its year-by-year financial impact. The secondary objective was to identify the allocation of costs and financial returns of providing RTW for cancer survivors for several European countries. This provides insights in financial incentives for and against RTWimplementation. 


\section{Methods}

\section{Budget impact analysis}

The budget impact of a multidisciplinary RTW-intervention was assessed following the International Society for Pharmaco-economics and Outcome Research-guidelines over a time horizon of 5 years. We compared the situation in which the intervention gradually is implemented to current practice, where only $5 \%$ of the eligible patients can follow the intervention. We considered a Dutch societal perspective and that of a cancer centre serving a population of $1 \mathrm{~m}$ inhabitants, which equals the catchment area of large European cancer centres ${ }^{7,13}$. All input parameters are presented in Table 1. 


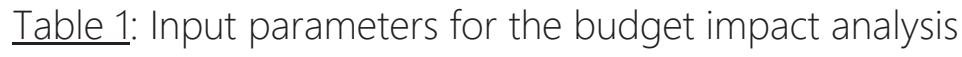

\begin{tabular}{|c|c|c|c|}
\hline Parameter & $\begin{array}{l}\text { Value for } \\
\text { the Nether- } \\
\text { lands }\end{array}$ & $\begin{array}{l}\text { Value for a } \\
\text { hypothetical } \\
\text { cancer centre }\end{array}$ & Source \\
\hline $\begin{array}{l}\text { Cancer incidence in the Netherlands: } \\
2015 \\
2016 \\
2017 \\
2018 \\
2019 \\
2020\end{array}$ & $\begin{array}{l}110,215 \\
112,776 \\
115,337 \\
117,899 \\
120,460 \\
123,021 \\
\end{array}$ & $\begin{array}{l}6,533 \\
6,675 \\
6,816 \\
6,805 \\
7,097 \\
6,237\end{array}$ & $\begin{array}{l}\text { Signaleringscommissie } \\
\text { Kanker of the Dutch } \\
\text { Cancer Society, } 2011^{4}\end{array}$ \\
\hline $\begin{array}{l}\text { Percentage of eligible patients: } \\
\% \text { with } 5 \text {-year survival } \\
\% \text { aged } 25-64 \\
\% \text { with treatment outcome that } \\
\text { allows RTW } \\
\% \text { who want to resume work } \\
\% \text { who wish to follow intervention }\end{array}$ & & $\begin{array}{l}6 \\
6 \\
6\end{array}$ & $\begin{array}{l}\text { Dutch Cancer Registry }{ }^{15} \\
\text { Dutch Cancer Registry } \\
\text { Assumption } \\
\text { Assumption } \\
\text { Assumption }\end{array}$ \\
\hline \% eligible for intervention & \multicolumn{2}{|c|}{$\begin{array}{c}12 \% \\
(=0.32 * 0.80 * 0.85 * 0.70) \\
\end{array}$} & Product of the above \\
\hline \multicolumn{4}{|l|}{ Capacity in current practice: } \\
\hline 2015-2020, yearly & $5 \%$ & $5 \%$ & Assumptions \\
\hline $\begin{array}{l}\text { Capacity in new situation: } \\
2015 \\
2016 \\
2017 \\
2018 \\
2019 \\
2020\end{array}$ & $\begin{array}{l}20 \% \\
30 \% \\
40 \% \\
50 \% \\
60 \% \\
70 \% \\
\end{array}$ & $\begin{array}{l}30 \% \\
60 \% \\
90 \% \\
90 \% \\
90 \% \\
90 \% \\
\end{array}$ & Assumptions \\
\hline $\begin{array}{l}\text { Percentage of patients for whom the } \\
\text { intervention is reimbursed in current } \\
\text { situation: }\end{array}$ & \multicolumn{2}{|c|}{$100 \%$} & \\
\hline $\begin{array}{l}\text { Percentage of patients for whom the } \\
\text { intervention is reimbursed in new } \\
\text { situation: }\end{array}$ & \multicolumn{2}{|c|}{$10 \%$} & Assumption \\
\hline Intervention costs & \multicolumn{2}{|c|}{$€ 1,517$} & $\begin{array}{l}\text { Assessment of the costs } \\
\text { based on intervention } \\
\text { description }{ }^{13} \text { and } \\
\text { information provided from } \\
\text { the staff who delivered the } \\
\text { intervention. }\end{array}$ \\
\hline $\begin{array}{l}\text { Additional weekly working hours in } \\
\text { the new situation }\end{array}$ & \multicolumn{2}{|c|}{$5.8 \mathrm{~h}$} & Thijs et al., $2011^{17}$ \\
\hline
\end{tabular}

Approval of an ethics committee and the participants' consent were not required for this research, as the data were derived from the literature and from health professionals. 
Dutch law does not require medical or ethical reviews for interviews with health care professionals. Confidentiality was ensured by not disclosing the names or hospitals of the interviewees and only referring to them by country. The study on which the cost calculation is based had received approval from the respective ethics committee ${ }^{12}$.

\section{Intervention description and uptake of the intervention}

The RTW-intervention, including counselling and exercise, is prescribed at the start of cancer treatment to all cancer patients who potentially can and wish to resume work. The counselling includes two one-hour sessions with an occupational physician specialised in oncology. The exercise component consists of 24 group sessions of moderate to high-intensity physiotherapy in groups of five. The duration of the exercise programme is 12 weeks, starting at the onset of chemotherapy. Some hospitals also provide a sports medical capacity-assessment before and after the programme. A more detailed description of the intervention was published previously ${ }^{12,14}$.

\section{Eligible Population}

Patients with any type of cancer are eligible when they are; a) of working age, i.e. between 25 and 64 years, b) treated with curative intent ${ }^{4,15,16}$, c) expected to have a treatment outcome that allows returning to work, d) wishing to return to work, and e) willing to follow the intervention. For each criterion, the percentage of all cancer patients to whom this applies was analysed and is given in Table 1. The percentage of patients who are eligible was calculated by multiplying $100 \%$ with the percentages of all criteria. This resulted in an eligibility percentage of $12 \%$ of all cancer patients that are diagnosed yearly (see Table 1).

\section{Capacity}

As there currently is insufficient capacity for providing the intervention, not all patients eligible for a multidisciplinary return-to-work intervention can follow it. Reasons for the limited capacity are that the implementation in general is still in the starting phase and that many health professionals are not fully aware of the possibilities that cancer rehabilitation offers. In order to offer the intervention to all eligible patients and provide the intervention on a larger scale, hospitals would, e.g., first need to employ more physical therapists and occupational physicians, and create the appropriate organisational structures for providing the intervention on a larger scale.

As a result of the above, currently only a small (i.e. 5\%) subgroup of survivors is prioritized to receive multidisciplinary rehabilitation treatment. Thus, of the $12 \%$ of the 
cancer patients who are eligible, 5\% can follow the intervention. This capacity is assumed to remain at that 5\% level throughout the analysis' time horizon for current practice. This is compared to the situation in which hospitals start to implement the intervention and gradually increase the capacity to enrol patients, starting with $30 \%$ of eligible patients in 2015 to $70 \%$ in 2020. Thus, in 2015, 30\% of the 12\% eligible survivors follow the intervention. Finally it is expected that in 2017 most of the eligible survivors (70\%) can participate in multidisciplinary return-to-work interventions.

The capacity in a single cancer centre that is used for the analysis from the perspective of a hypothetical cancer centre rises much faster, from 30\% in 2015 to 90\% in 2020. It is assumed that once a cancer centre decides to offer the intervention it would take measures to relatively quickly provide it to all eligible patients. However, they would also be faced by shortages of staff, especially for occupational physicians. The percentage from the Dutch societal perspective remains lower at 70\%, because it is assumed that not every hospital will offer the intervention. Thus, some hospitals will not offer returnto-work interventions at all, whereas some offer it to $90 \%$ of the eligible patients, leading to an overall percentage of $70 \%$.

Costs of the intervention and impact on other costs

Intervention costs include staff costs, administration, materials, and 42\% overhead, according to the Dutch manual for cost research ${ }^{17}$. Volumes of resource use were obtained from the intervention protocol and health professionals participating in a feasibility study of the intervention ${ }^{12,14}$. Unit costs were determined following Dutch guidelines for pharma-economic research ${ }^{17}$. Staff training costs of $€ 335$ were considered as part of the overhead. Hospitals receive reimbursement for providing RTWinterventions to patients formally indicated for multidisciplinary rehabilitation. This is circa $10 \%$ of the eligible population. In current practice, all patients who receive the RTW-interventions are indicated for multidisciplinary rehabilitation and thus receive reimbursement.

An impact on other costs occurs through changes in the patients' productivity. The effect of RTW on resuming work was taken from a Dutch trial. In the intervention group the participants followed an 18-weeks exercise programme, consisting of a high intensity resistance and endurance training. This was compared to standard medical care that was received by an age-matched control group. Patients with any type of cancer of 1865 years of age were included who were treated with curative intend and were in paid employment at the time of diagnosis. 110 patients were included in the analysis, 72 in the intervention group and 38 in the control group. The adherence of the participants 
was very high with $96 \%$ and thus slightly higher than for the multidisciplinary return-towork intervention where it was $86 \%$. A significant difference in the time to resume work was not found. However, the intervention was found to increase productivity significantly by 5.8 hours/week for one year ${ }^{18}$. Thus, the participants in the intervention group were able to work more in the long-term. This 5.8hours/week that are worked more than in current practice was used for the productivity benefit in this analysis and was valued at €30.02/hour, according to the Dutch manual for cost research ${ }^{17}$.

\section{Analysis}

For analysing the budget impact, a spreadsheet model (Figure 1) was created in Microsoft Excel (Redmond, WA). The budget impact equals the total cost of the RTWintervention minus the productivity gains that accrue from RTW, in the new situation vs. current practice ${ }^{7}$. In the model, the number of patients following the intervention was identified by multiplying cancer incidence with the percentage of eligible patients and the capacity of hospitals to provide the intervention. The number of patients was then multiplied with the intervention costs, which resulted in the total costs of the RTWintervention. For the Dutch societal perspective, the productivity gains equal the number of patients who follow the intervention multiplied with the additional yearly working time generated and with the hourly productivity costs. For the cancer centre's perspective, the benefit consists of receiving reimbursement from the health insurer for delivering RTW to the $10 \%$ of the patients indicated for multidisciplinary rehabilitation. 


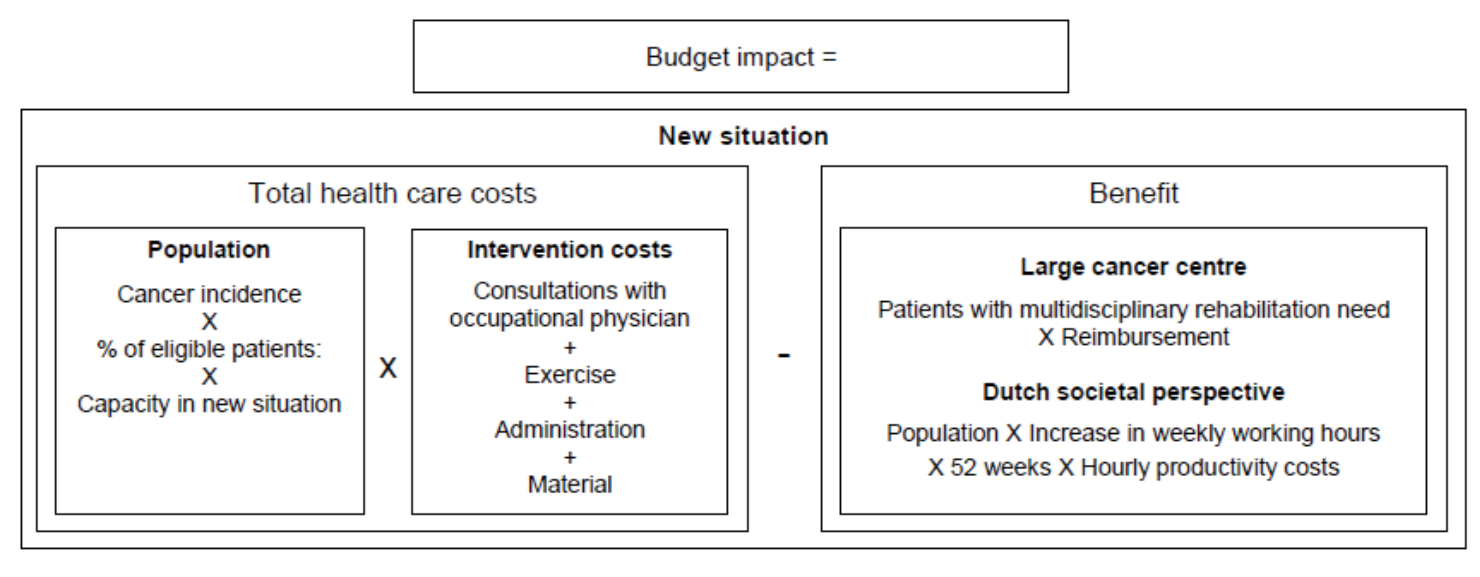

minus

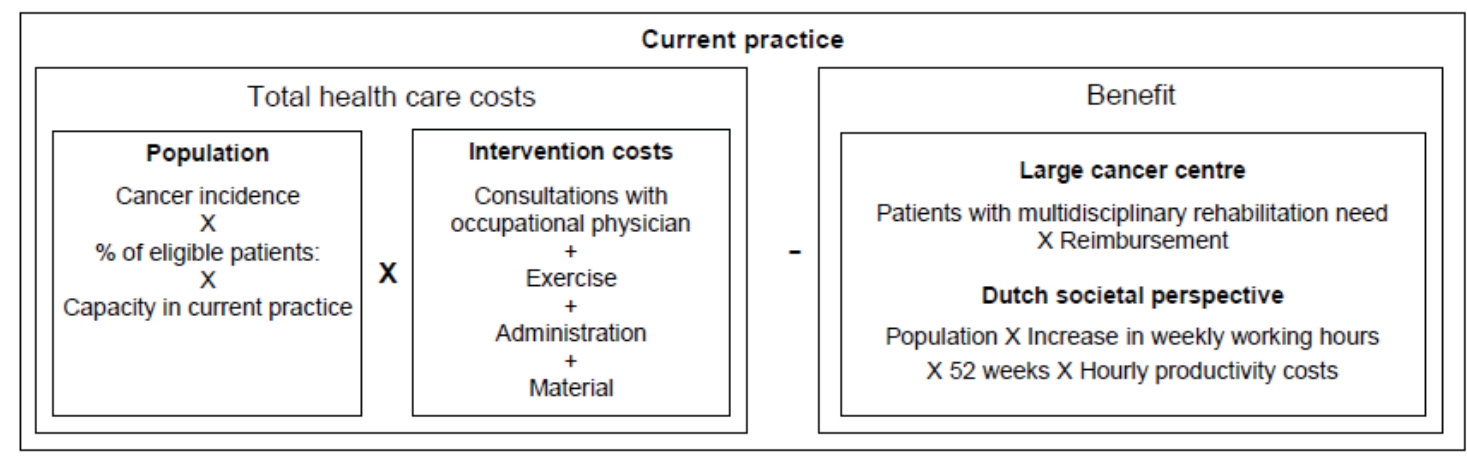

Figure 1: Structure of the budget impact model

\section{Sensitivity analysis}

The influence on the budget impact of the effectiveness of the intervention was analysed, in order to test the robustness of the model outcomes. For this purpose, the effect in a range of 0 to 5.8 additional weekly working hours, which corresponds to 0 to 302 hours a year, was used to display its effect on the budget impact graphically. This also allowed analyzing where the budget impact changes from being cost-saving to adding costs, i.e. where the line of the budget impact crosses the $x$-axis from being cost-saving to adding costs.

Analysis of the incentive structure to implement RTW in the Netherlands and in several EU-countries

The allocation of costs and financial returns across stakeholders involved in RTW was analysed, to identify potential (dis)incentives for implementing RTW-interventions. For this purpose, an email survey was conducted among comprehensive cancer centres that are members of the Organisation of European Cancer Institutes $(n=40)$ from the Netherlands, Belgium, England, France, Germany, Italy, and Sweden. At least one 
respondent from each country was required. In the survey each cancer centrerepresentative with professional knowledge about the healthcare and welfare system in their respective country, was asked to tick in a list of stakeholders which of these (1) bear the costs of sick leave of cancer patients, (2) are responsible for the reintegration of cancer patients into the workplace, (3) bear the costs for offering an RTW-intervention, and (4) benefit financially from cancer patients following a RTW intervention. The list of stakeholders included health insurers, hospitals, patients, employers, pension insurance schemes, and the state. The nature of the financial benefits depends on the stakeholder and includes, e.g., for a hospital reimbursement by the patients' health insurers, for health insurers a reduction in the patients' future health care needs, for patients the ability to continue working and receive an income, or for employers the prevention of sick leave and subsequent production losses.

For the analysis, the results of the survey were assessed in $2 * 2$ tables showing how many and which stakeholders both pay and gain from RTW, how many only pay or only gain, and how many do not pay or gain.

\section{Results}

\section{Budget impact analysis}

Base case results

The number of patients following the intervention under current (Dutch) practice on national level was estimated to be 651 in 2015 and increase to 726 patients in 2020. This increase only reflects the rising cancer incidence, while the percentage of patients who are eligible for the interventions remains stable in this model. In the new situation in which RTW-interventions are rolled out more widely, 2,602 patients would participate in the intervention in 2015. As cancer incidence and the capacity both rose, it is estimated that 10,166 patients would follow the intervention in 2020.

The same reasoning as described above was applied to estimate the number of patients receiving a $\mathrm{RTW}$-intervention in a large cancer centre. In current practice this number would rise from 39 to 43 in the 5-year period in our model, due to the growth in cancer incidence. After implementing RTW, the number could increase from 231 in 2015 to 769 in 2020, as the capacity for treating the eligible patients is assumed to grow.

The average costs of the RTW-intervention are estimated at €1,517 per patient, of which $€ 567$ (37\%) are for consultations with the occupational physician, €879 (59\%) for the exercise part, and $€ 46$ for administration and printed materials. 
The total health care costs when implementing RTW for the Netherlands are $€ 4.0 \mathrm{~m}$ to $€ 15.4 \mathrm{~m}$ from 2015 to 2020. The benefits in terms of productivity gains are $€ 23.6 \mathrm{~m}$ to $€ 92.0 \mathrm{~m}$ in 2015 to 2020. The BI for the Netherlands is $€-14.7 \mathrm{~m}$ in 2015, rising to $€-71.1 \mathrm{~m}$ in 2020, meaning that from a societal perspective RTW for cancer survivors in the Netherlands would be cost-saving. The productivity gains are large and outweigh the intervention costs by far. In fact, with rising incidence and a growing proportion of patients following RTW, cost savings further increase year-by-year. However, the intervention is rather expensive to its providers and the initial health care costs are considerable.

For a large cancer centre, the costs for the intervention compared to current practice, from 2015 to 2020 increase from $€ 351 \mathrm{k}$ to $€ 1.2 \mathrm{~m}$. The financial benefit in terms of reimbursement from 2015 to 2020 is only $€ 58$.6k to $€ 116.8 \mathrm{k}$. The BI for a cancer centre is $€ 292.8 \mathrm{~K}$ in 2015 and rises to $€ 1.1 \mathrm{~m}$ in 2020. Thus, for a cancer centre providing this service, the high intervention costs cause RTW to be an expensive intervention to offer, as they get only reimbursed for $10 \%$ of the patient population. Table 2 shows the base case results. 
Table 2: Results of the budget impact analysis

\begin{tabular}{|c|c|c|c|c|c|c|}
\hline & 2015 & 2016 & 2017 & 2018 & 2019 & 2020 \\
\hline \multicolumn{7}{|c|}{ DUTCH SOCIETAL PERSPECTIVE } \\
\hline \multicolumn{7}{|c|}{ Current practice: } \\
\hline $\begin{array}{l}\text { Number of } \\
\text { patients }\end{array}$ & 651 & 666 & 681 & 696 & 711 & 726 \\
\hline $\begin{array}{l}\text { Health care } \\
\text { costs [in } €]\end{array}$ & 987,901 & $1,010,858$ & $1,033,815$ & $1,056,772$ & $1,079,729$ & $1,102,686$ \\
\hline $\begin{array}{l}\text { Productivity } \\
\text { benefits [in } \\
€ \text { ] }\end{array}$ & $5,889,947$ & $6,026,819$ & $6,163,690$ & $6,300,562$ & $6,437,434$ & $6,574,306$ \\
\hline \multicolumn{7}{|l|}{$\begin{array}{l}\text { New } \\
\text { situation: }\end{array}$} \\
\hline $\begin{array}{l}\text { Number of } \\
\text { patients }\end{array}$ & 2,602 & 3,994 & 5,446 & 6,959 & 8,532 & 10,166 \\
\hline $\begin{array}{l}\text { Health care } \\
\text { costs [in } €]\end{array}$ & $3,951,605$ & $6,065,149$ & $8,270,522$ & $10,567,724$ & $12,956,753$ & $15,437,611$ \\
\hline $\begin{array}{l}\text { Productivity } \\
\text { benefit [in } € \text { ] }\end{array}$ & $23,559,787$ & $36,160,912$ & $49,309,524$ & $63,005,623$ & $77,249,210$ & $92,040,284$ \\
\hline $\begin{array}{l}\text { Budget } \\
\text { impact [€] }\end{array}$ & $\begin{array}{c}\text { Negative } \\
14,706,137 \\
\end{array}$ & $\begin{array}{c}\text { Negative } \\
25,079,802\end{array}$ & $\begin{array}{c}\text { Negative } \\
35,909,126\end{array}$ & $\begin{array}{c}\text { Negative } \\
47,194,109 \\
\end{array}$ & $\begin{array}{c}\text { Negative } \\
58,934,752\end{array}$ & $\begin{array}{c}\text { Negative } \\
71,131,054 \\
\end{array}$ \\
\hline \multicolumn{7}{|c|}{ PERSPECTIVE OF A REFERENCE CANCER CENTRE } \\
\hline \multicolumn{7}{|c|}{ Current practice: } \\
\hline $\begin{array}{l}\text { Number of } \\
\text { patients }\end{array}$ & 39 & 39 & 40 & 40 & 42 & 43 \\
\hline $\begin{array}{l}\text { Health care } \\
\text { costs [in } €]\end{array}$ & 58,560 & 59,828 & 61,093 & $60,999 €$ & $63,611 €$ & $64,864 €$ \\
\hline $\begin{array}{l}\text { Benefits } \\
\text { (reimbursem } \\
\text { ent) [in } €]\end{array}$ & 58,560 & 59,828 & 61,093 & $60,999 €$ & $63,611 €$ & $64,864 €$ \\
\hline \multicolumn{7}{|l|}{$\begin{array}{l}\text { New } \\
\text { situation: }\end{array}$} \\
\hline $\begin{array}{l}\text { Number of } \\
\text { patients }\end{array}$ & 231 & 473 & 724 & 723 & 754 & 769 \\
\hline $\begin{array}{l}\text { Health care } \\
\text { costs [in €] }\end{array}$ & 351,358 & 717,939 & $1,099,674$ & $1,097,987$ & $1,144,994$ & $1,167,550$ \\
\hline $\begin{array}{l}\text { Benefit } \\
\text { (reimbursem } \\
\text { ent) [in } €]\end{array}$ & $58,560 *$ & 71,794 & 109,967 & 109,799 & 114,499 & 116,755 \\
\hline $\begin{array}{l}\text { Budget } \\
\text { impact [€] }\end{array}$ & 292,798 & 646,145 & 989,706 & 988,188 & $1,030,495$ & $1,050,795$ \\
\hline
\end{tabular}

*) According to the model, this would be $€ 35,136$, assuming that hospitals receive reimbursement for $10 \%$ of the patients. As this is lower than the benefit in the current situation, it is expected that as long as in the new situation there still are patients with a multidisciplinary rehabilitation need (for whom the costs are reimbursed by 
insurance), these would be treated preferentially to patients for whom the costs are not reimbursed.

\section{Sensitivity analysis}

Figure 3 shows that even when the benefit of the RTW-intervention was much smaller than expected based on current data it would still be cost-saving. The health care costs equal the productivity benefits, i.e. the $\mathrm{BI}$ is zero, when the RTW-intervention enables patients to return to work 50.6 hours earlier in 2020 compared to usual care. This value corresponds to an increased weekly working time of approximately 1h/week, which is more than five times lower than the value used in the base case analysis (5.8h/week).

Figure 3: The impact of earlier RTW on the budget impact in 2020. From 2020 on a steady state is assumed.

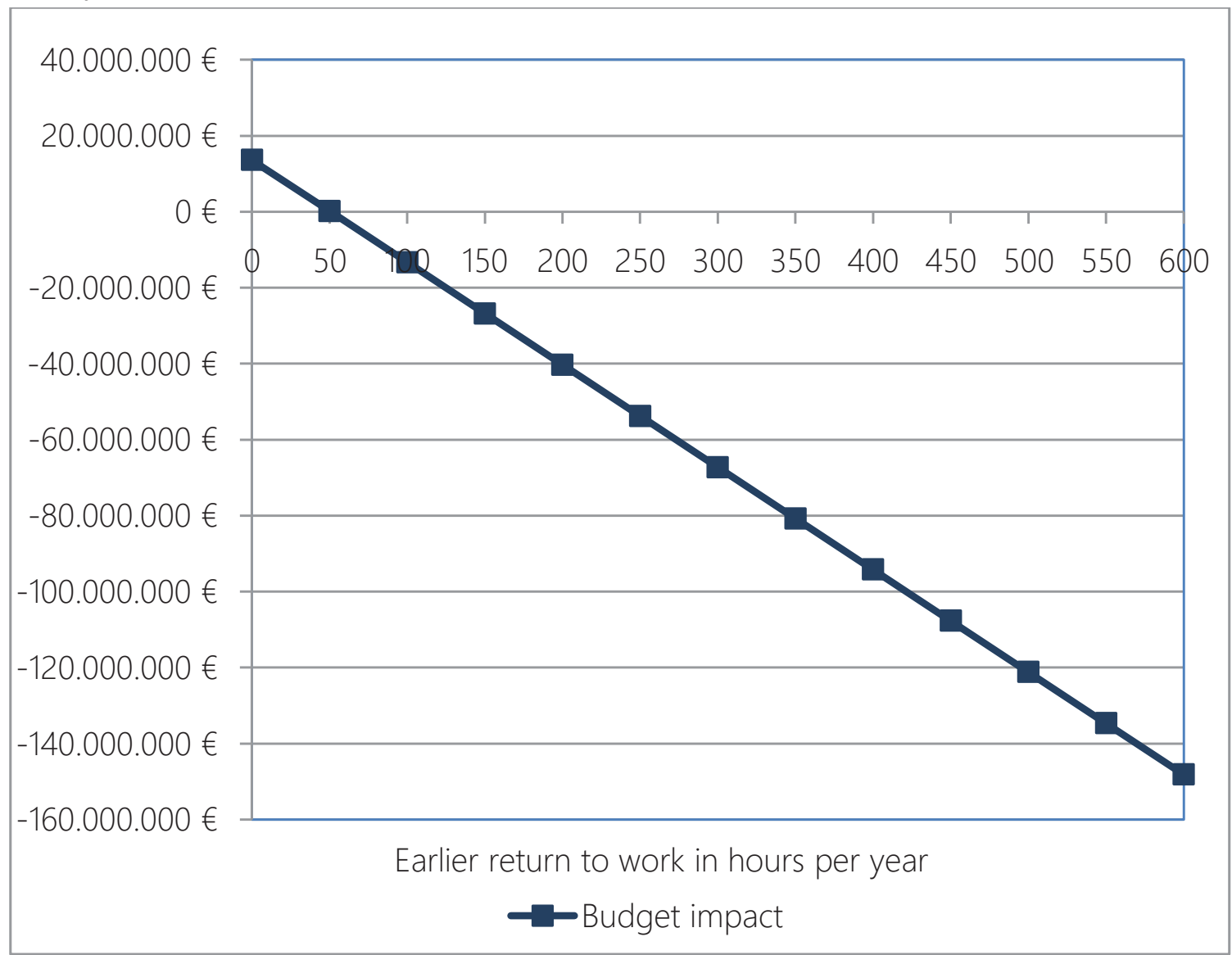




\section{Analysis of the incentive structure for implementing RTW}

The Netherlands

Health care providers that offer RTW-interventions carry their costs themselves, apart from the health insurances' reimbursement for about 10\% of patients with a multidisciplinary rehabilitation need. The financial returns from earlier RTW are received by employers, the patients, and pension funds. Thus, a misalignment exists between the stakeholders that pay for RTW and those that receive the financial benefits in terms of increased productivity or in preventing invalidity pension. As this situation discourages to offer RTW on a large scale, its substantial cost-savings to society are forgone. A cancer centre or hospital would need to highly value the intangible benefits, such as being a provider of high-quality care, attractiveness for patients, or being a leading cancer centre, in order to make up for the costs. See Table 3 for the results of this analysis. 
Table 3: Distribution of RTW intervention costs and financial returns across the stakeholders for the Netherlands

\begin{tabular}{|c|c|c|c|c|c|c|}
\hline & $\begin{array}{l}\text { Health } \\
\text { insurance }\end{array}$ & $\begin{array}{l}\text { Hospitals/ } \\
\text { Healthcare } \\
\text { providers }\end{array}$ & Employers & $\begin{array}{l}\text { Patients/ } \\
\text { Employees }\end{array}$ & The state & $\begin{array}{l}\text { Pension } \\
\text { insurance } \\
\text { scheme }\end{array}$ \\
\hline $\begin{array}{l}\text { Responsibi- } \\
\text { lities in RTW }\end{array}$ & $\begin{array}{l}\text { General } \\
\text { responsibi- } \\
\text { lity for } \\
\text { reimbur- } \\
\text { sing } \\
\text { necessary } \\
\text { health care }\end{array}$ & & $\begin{array}{l}\text { Sick pay } \\
\text { for first } 2 \\
\text { years, } \\
\text { reintegra- } \\
\text { tion of sick } \\
\text { employees } \\
\text { into the } \\
\text { workplace }\end{array}$ & & $\begin{array}{l}\text { Sick pay } \\
\text { after } 2 \\
\text { years of } \\
\text { inability to } \\
\text { work }\end{array}$ & \\
\hline $\begin{array}{l}\text { Carrying the } \\
\text { costs of } \\
\text { RTW } \\
\text { interven- } \\
\text { tions }\end{array}$ & $\begin{array}{l}\text { Reimburse } \\
\text { ment for } \\
\text { patients } \\
\text { with } \\
\text { multidisci- } \\
\text { plinary } \\
\text { rehabilita- } \\
\text { tion need }\end{array}$ & $\begin{array}{l}\text { Interven- } \\
\text { tion costs }\end{array}$ & & & & \\
\hline $\begin{array}{l}\text { Receiving } \\
\text { the financial } \\
\text { returns of } \\
\text { RTW }\end{array}$ & $\begin{array}{l}\text { Lower } \\
\text { future } \\
\text { health care } \\
\text { costs, } \\
\text { however, } \\
\text { high } \\
\text { budget } \\
\text { impact }\end{array}$ & & $\begin{array}{l}\text { Fewer } \\
\text { productivi- } \\
\text { ty losses, } \\
\text { no } \\
\text { replaceme } \\
\text { nt for } \\
\text { employee } \\
\text { needed }\end{array}$ & $\begin{array}{l}\text { Ability to } \\
\text { generate } \\
\text { an income }\end{array}$ & & $\begin{array}{l}\text { Less early- } \\
\text { retirement- } \\
\text { pension } \\
\text { payments }\end{array}$ \\
\hline $\begin{array}{l}\text { Incentive for } \\
\text { financing } \\
\text { RTW for } \\
\text { cancer } \\
\text { patients * }\end{array}$ & $\begin{array}{l}\text { - } \\
\text { Lower future } \\
\text { health care } \\
\text { costs in the } \\
\text { long-run, } \\
\text { considerable } \\
\text { budget impact }\end{array}$ & $\begin{array}{l}\text {-- } \\
\text { Carrying the } \\
\text { costs, but } \\
\text { hardly receiving } \\
\text { financial } \\
\text { returns. }\end{array}$ & $\begin{array}{l}\text { - } \\
\text { Status quo is } \\
\text { financially } \\
\text { gbeneficial for } \\
\text { employers. }\end{array}$ & $\begin{array}{l}+ \\
\text { Incentive } \\
\text { for an } \\
\text { acceptable } \\
\text { out-of- } \\
\text { pocket } \\
\text { payment }\end{array}$ & $\begin{array}{l}\text {-- } \\
\text { Not receiving } \\
\text { any financial } \\
\text { returns }\end{array}$ & $\begin{array}{l}\text { - } \\
\text { Status quo } \\
\text { is } \\
\text { financially } \\
\text { beneficial. }\end{array}$ \\
\hline
\end{tabular}

*) The distribution of costs and financial benefits in which the costs as well as the financial returns are incurred by the same stakeholder incentivizes the financing and implementation of RTW. For stakeholders who receive financial benefits, but do not need to carry the costs, the current financing arrangement is very attractive. Thus, they do not have an interest in changing the financial structure. However, if they would need to take over (a part of) the financing, this would be acceptable. For stakeholders who need to carry the costs, but do not receive financial returns, an incentive to finance RTW does not exist, as they it will only cost them. 


\section{$\underline{\text { EU-countries }}$}

Eleven of the 40 questionnaires (28\%) that were sent to cancer centres were returned (Belgium=1, England=2, France=1, Germany=2, Italy=3, Sweden=1, The Netherlands=1). Respondents included researchers, scientific directors, medical directors, a director of the psychosocial service, an HR-manager, and a social worker. In four of thesix EUcountries included in this analysis, similar misalignments of costs and financial benefits as in the Netherlands were observed, as shown in Figure 4. The most beneficial situation for implementation of RTW-interventions is found in Germany and France. In Germany, the employers, health insurance, and pension insurance have financial incentives to support RTW, by being both responsible for financing RTW and receiving its financial benefits. In France this applies to employers and health insurers. In Belgium, the National Health Service in England, and the Netherlands patients/employees and one other stakeholder pay for and gain from RTW, while in Italy and Sweden the patients are the only stakeholders mentioned in both categories. 


\section{Belgium}

Stakeholders, who:

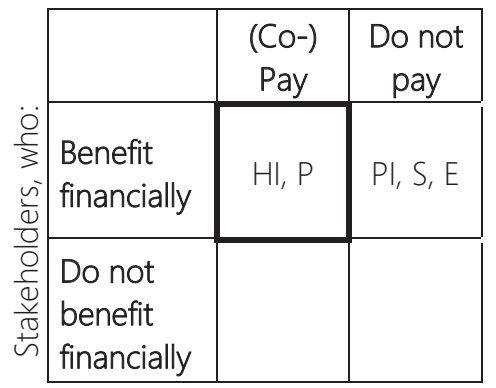

Germany

Stakeholders, who:

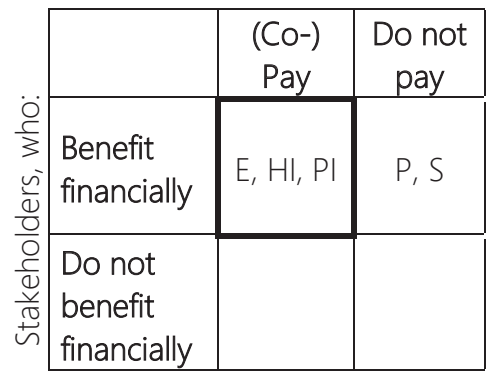

\section{England}

Stakeholders, who:

\begin{tabular}{|c|c|c|}
\hline & $\begin{array}{c}\text { (Co-) } \\
\text { Pay }\end{array}$ & $\begin{array}{c}\text { Do not } \\
\text { pay }\end{array}$ \\
\hline $\begin{array}{l}\text { Benefit } \\
\text { financially }\end{array}$ & $P, E$ & $\mathrm{HI}, \mathrm{Pl}, \mathrm{S}$ \\
\hline $\begin{array}{l}\text { Do not } \\
\text { benefit } \\
\text { financially }\end{array}$ & $\mathrm{HO}$ & \\
\hline
\end{tabular}

Italy

Stakeholders, who:

\begin{tabular}{|c|c|c|}
\hline & $\begin{array}{l}\text { (Co-) } \\
\text { Pay }\end{array}$ & $\begin{array}{l}\text { Do not } \\
\text { pay }\end{array}$ \\
\hline $\begin{array}{l}\text { Benefit } \\
\text { financially }\end{array}$ & P & $\mathrm{Pl}, \mathrm{S}$ \\
\hline $\begin{array}{l}\text { Do not } \\
\text { benefit } \\
\text { financially }\end{array}$ & $\mathrm{HO}$ & \\
\hline
\end{tabular}

France

Stakeholders, who:

\begin{tabular}{|c|c|c|}
\hline & $\begin{array}{c}\text { (Co-) } \\
\text { Pay }\end{array}$ & $\begin{array}{c}\text { Do not } \\
\text { pay }\end{array}$ \\
\hline $\begin{array}{l}\text { Benefit } \\
\text { financially }\end{array}$ & $H I, P, E$ & $\mathrm{Pl}, \mathrm{S}$ \\
\hline $\begin{array}{l}\text { Do not } \\
\text { benefit } \\
\text { financially }\end{array}$ & & \\
\hline
\end{tabular}

The Netherlands

Stakeholders, who:

\begin{tabular}{|c|c|c|}
\hline & $\begin{array}{c}\text { (Co-) } \\
\text { Pay }\end{array}$ & $\begin{array}{c}\text { Do not } \\
\text { pay }\end{array}$ \\
\hline $\begin{array}{l}\text { Benefit } \\
\text { financially }\end{array}$ & $\mathrm{HI}, \mathrm{P}$ & $\mathrm{E}, \mathrm{S}, \mathrm{Pl}$ \\
\hline $\begin{array}{l}\text { Do not } \\
\text { benefit } \\
\text { financially }\end{array}$ & $\mathrm{HO}$ & \\
\hline
\end{tabular}

Figure 4: Incentive in EU-countries for financing RTW for cancer patients.

$\mathrm{HI}=$ Health insurance, $\mathrm{HO}=$ Hospital or health care provider, $\mathrm{E}=$ Employer, $\mathrm{S}=$ State, $\mathrm{Pl}=$ Pension insurance scheme, $\mathrm{P}=$ Patient / employee

The stakeholders placed in the framed square have a financial incentive for financing RTW interventions. The more stakeholders are placed in the framed square, the greater the incentives for implementing RTW are. If this is the patient / the employee, this is less 
beneficial than when this is another stakeholder, as it is not feasible that the patients carry the costs for the intervention alone.

\section{Discussion}

From the Dutch societal perspective, the BI of the RTW-intervention for cancer survivors is negative, i.e. the RTW-intervention yields more financial benefits than it costs. The BI for cancer centres is high, as these mainly shoulder the costs of providing the intervention. The way in which costs and financial benefits in the Netherlands are allocated, leads to a disincentive to offer RTW-interventions for cancer survivors. Of the six countries included in the European comparison, only Germany and France provide a payment structure that rewards the provision of RTW by health care providers.

In order to reduce the misalignment of costs and financial benefits in and outside the healthcare system and facilitate larger scale patient access, the payment and reimbursement structures need adjustment. For many countries, a more sustainable way of financing RTW may include shifting a larger share of the costs to employers or pension schemes, which primarily benefit financially from RTW-interventions. Alternatively within the current financing system, the intervention could be prescribed

more selectively to patients at highest risk of not returning to work ${ }^{18-24}$. In addition, the counselling by the occupational physician could possibly be prescribed as a monodimensional intervention, when this matches with the individual patient's need. As the costs for the counselling make up 37\% of the intervention costs, this would decrease the health care costs considerably for all stakeholders involved.

This study has some limitations; first, the potential overall health benefits of exercise programs, beyond returning to work, that may lead to lower future health care resource use are not included in the analysis ${ }^{19}$. Thus, the cost savings of RTW-interventions are probably underestimated. Welfare benefits that are influenced by RTW, such as sick pay, and invalidity and retirement pension, have not been included due to a lack of data. This might also lead to an underestimation of the potential cost savings and precludes a quantification of the financial benefits of RTW to the state. Finally, while a healthcare system perspective is recommended for $\mathrm{Bl}$ analysis ${ }^{7}$, we deviated from this recommendation to show the relation between the intervention costs and the productivity gains that extend beyond the health care system.

Regarding transferability of the costs of the Netherlands to other countries, it can be noted that the intervention costs mainly consist of labor costs and thus depend on the 
income level in the respective country. The number of patients who follow the intervention is a product of cancer incidence, the percentage of eligible patients, and capacity for treating patients. These would need to be adjusted to the respective country as well.

Moreover, the limitations of the data that was used for the productivity benefits which were derived from the study by Thijs et al. ${ }^{18}$ need to be mentioned. First, given the evidence for the effectiveness of exercise it was considered unethical to randomize patients. Thus, instead, an age-matched control group recruited in another hospital was used. Still, the baseline characteristics of both groups were comparable. Second, most of the participants, around 70\%, were breast cancer patients and around $80 \%$ were female. This is an issue in cancer survivorship research in general ${ }^{20}$ but yields questions about the generalizability of the outcome. As breast cancer patients often are relatively young and have good treatment outcomes, they participate in intervention research more often than other groups. However, the criteria for being eligible for the intervention included treatment with curative intent and a treatment outcome that is sufficient for being able to return to work. Thus, this also is a selected group of cancer survivors, of which many might be breast cancer survivors, as these patients would fulfil these criteria more often than e.g. lung cancer patients. Therefore, and given the robustness of our findings against alternative effectiveness inputs (i.e. 5 times smaller), we consider it safe to conclude that the intervention is cost-saving for the general group of cancer survivors who are eligible for multidisciplinary return-to-work interventions.

In order to increase patient access to RTW-interventions, a consensus among stakeholders on how to arrange the financing of RTW-interventions needs to be found when the value of RTW-interventions is sufficiently demonstrated. For this purpose, more research is needed that assesses the effectiveness of RTW, and on the subgroups of patients who would benefit the most. Moreover, the value of the intangible benefits for the stakeholders and the intervention's indirect benefits would need to be investigated to support this process.

\section{Conclusions}

This study analysed the BI of a multidisciplinary RTW-intervention for cancer survivors and explored the allocation of the costs and financial benefits of RTW across the stakeholders involved in six EU-countries. From the Dutch societal perspective, the productivity gains of the RTW-intervention outweigh the intervention costs by far. 
However, the total healthcare costs are considerable and shouldered almost exclusively by health care providers. Therefore, the BI of RTW for cancer centres is very high and the current financing system does not provide the appropriate incentives for implementing RTW on a larger scale. A similar misalignment of financial incentives exists in other EU-countries, with only Germany and France providing an incentive for stakeholders to pay for RTW. To ensure patient access to RTW-programs, future investigations into the real-world effectiveness and societal impact of RTW-programs for cancer survivors are needed, as well as a consensus on how to fix the current financial misalignment. 


\section{References}

1. Mehnert A. Employment and work-related issues in cancer survivors. Critical Reviews in Oncology \& Hematolology 2011; 77: 109-30.

2. de Boer AGEM, Taskila T, Ojajärvi A, et al. Cancer survivors and unemployment: a meta-analysis and meta-regression. Journal of the American Medical Association 2009; 301: 753-62.

3. Amir Z, Wynn P, Whitaker S, et al. Cancer survivorship and return to work: UK occupational physician experience. Occupational Medicine 2008; 59: 390-96.

4. Signaleringscommissie Kanker van KWF Kankerbestrijding. Kanker in Nederland tot 2020 - trends en prognoses. Amsterdam: Dutch Cancer Society, 2011.

5. Lilliehorn S, Hamberg K, Kero A, et al. Meaning of work and the returning process after breast cancer: a longitudinal study of 56 women. Scandinavian Journal of Caring Sciences 2013; 27: 267-74.

6. Mehnert A, Koch U. Predictors of employment among cancer survivors after medical rehabilitation-a prospective study. Scandinavian Journal of Work, Environment and Health 2013; 39: 76-87.

7. Sullivan S, Mauskopf J, Augustovski F, et al. Budget impact analysis-principles of good practice: report of the ISPOR 2012 Budget Impact Analysis Good Practive II Task Force. Value in Health 2014; 17: 5-14.

8. de Boer AGEM, Taskila TK, Frings-Dresen MHW, et al. Interventions to enhance return-to-work for cancer patients. Cochrane Database of Systematic Reviews 2011; (2).

9. The Netherlands Comprehensive Cancer Organisation (IKNL). Cancer rehabilitation - nation-wide guideline. Utrecht, 2011.

10. Schmitz KH, Courneya KS, Matthews C, et al. American College of Sports Medicine Roundtable on Exercise Guidelines for Cancer Survivors. Medicine \& Science in Sports \& Exercise 2010; 42: 1409-26.

11. Harris SR, Schmitz KH, Campbell KL, et al. Clinical practice guidelines for breast cancer rehabilitation: syntheses of guideline recommendations and qualitative appraisals. Cancer 2012; 118: 2312-24.

12. Groeneveld IF, de Boer AGEM, Frings-Dresen MHW. A multidisciplinary intervention to facilitate return to work in cancer patients: intervention protocol and design of a feasibility study. BMJ Open 2012; 2: e001321-e21. 
13. Mauskopf J, Sullivan S, al. Annemans L et al. Principles of Good Practice for budget impact analysis: report of the ISPOR Task Force on Good Research Practices-budget impact analysis. Value in Health 2007; 10: 336-47.

14. Groeneveld I, de Boer A, Frings-Dresen M. Physical exercise and return to work: cancer survivors' experiences. Journal of Cancer Survivorship 2013; 7: 237-46.

15. The Netherlands Comprehensive Cancer Organisation. Incidence. Utrecht: IKNL 2015.

16. The Netherlands Comprehensive Cancer Organisation. Survival. Utrecht: IKNL 2015.

17. Hakkaart-Van Roijen L, Tan SS, Bouwmans CAM. Manual for cost research: methods and standard cost prices for economic evaluations in health care. Diemen: Health Care Insurance Board, 2010.

18. Thijs $K M$, de Boer AG, Vreugdenhil $G$, et al. Rehabilitation using high-intensity physical training and long-term return-to-work in cancer survivors. Journal of Occupational Rehabilitation 2012; 22: 220-9.

19. Jones LW, Alfano CM. Exercise-oncology research: past, present, and future. Acta Oncologica 2012: 1-21.

20. Rowland JH, Kent EF, LP, Havard Loge J, et al. Cancer survivorship research in Europe and the United States: Where have we been, where are we going, and what can we learn from each other? Cancer 2013; 19: 2094-108. 
Budget impact analysis of return-to-work interventions 


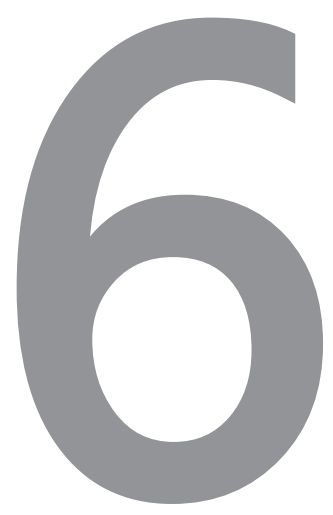

\section{Value of implementation analysis of strategies to increase the adherence of health professionals and patients to (the guidelines for) physical exercise for cancer survivors}

Janne C. Mewes

Lotte M.G. Steuten

Charlotte IJsbrandy

Maarten J. IJzerman

Wim H. van Harten

Submitted 



\title{
Value of implementation analysis of strategies to increase the adherence of health professionals and patients to (the guidelines for) physical exercise for cancer survivors
}

\begin{abstract}
Background: In order to increase the adherence of health professionals and cancer survivors to guideline-recommended physical exercise, effective implementation strategies (ISTS) are required. As these have costs, it needs to be examined if these provide value for money and which has the highest value.

Methods: The net-benefit framework of health economic evaluations is used to conduct a value-of-information analysis of nine ISTs. Seven are directed on health professionals and two on cancer survivors. The analysis consists of four steps; (1) analysing the expected value of perfect implementation (EVPIM), which represents the maximum cost an implementation strategy may have in order to be cost-effective, (2) assessing the estimated costs of the various ISTS, (3) comparing the ISTs' costs to the EVPIM to decide which of these are considered cost-effective, and (4) assessing the total net benefit of the ISTS, to identify which strategy has the greatest value.

Results: The EVPIM for physical exercise in the Netherlands is $€ 293 \mathrm{~m}$. The total costs for the ISTs range from $€ 34 \mathrm{k}$ for printed educational materials for professionals to $€ 120.0 \mathrm{~m}$ for financial incentives for patients, and thus all are well below the EVPIM. The total net benefit of the ISTs that are directed on professionals ranges from $€ 5.7 \mathrm{~m}$ for printed educational materials to $€ 30.9 \mathrm{~m}$ for reminder systems. Of the strategies that are directed on patients, only the motivational programme had a positive net benefit of $€ 100.4 \mathrm{~m}$.
\end{abstract}

Conclusion: All but one IST have a positive total net benefit. The largest improvements in adherence were created by a motivational programme for patients, followed by a reminder system for professionals. Most ISTs that are directed at professionals lead to very small increases in adherence and thus only contribute partially to achieving the highest possible total net benefit. This suggests that it is most valuable to invest in increasing the adherence of patients by one of the most effective ISTs and to conduct further research into making the ISTs that are directed at professionals more effective. 


\section{Introduction}

The evidence base on the effectiveness of physical exercise for cancer survivors (PE) is growing. It has been shown that exercise interventions are an effective way to alleviate late and long-term effects of cancer treatment, such as fatigue and health-related quality of life (hrqol) $)^{1-5}$. Subsequently, PE is recommended for cancer survivors by professional organisations in various countries ${ }^{1-5}$. However, the fact that a clinical guideline is developed and published does not mean that the adherence of professionals and patients to the recommendations is sufficient $t^{6-9}$. In the Netherlands, a guideline on cancer rehabilitation was published in 2011 and recommends that all cancer survivors who have completed active curative treatment and are physically able should exercise, ideally by following an exercise intervention of at least moderate intensity ${ }^{2}$. Still, only very few of the eligible cancer survivors are referred to PE. One of the reasons might be that the guideline is relatively new and not all professionals are yet aware of the possibilities. Of the survivors who are prescribed PE, only slightly more than half take part in at least three quarters of the sessions ${ }^{7,10,11}$. Thus, efforts should be undertaken to increase the adherence of professionals to the guideline and of cancer survivors to the prescribed interventions, next to the general implementation of the guideline.

As costs are attached to implementation strategies (ISTs), it is worth to evaluate them on their cost-effectiveness before choosing which one to use. Although it is already relatively common to evaluate interventions on their cost-effectiveness, less so this is the case for efforts to enhance the implementation of clinical guidelines ${ }^{8}$. However, as the ISTs, just like the intervention itself, require financial resources that could also be spent elsewhere, it should be evaluated if it is worthwhile to perform them ${ }^{9,12,13}$. Therefore, the aim of this study is to analyse the total net benefit (TNB) of various ISTs for increasing adherence of health professionals to the exercise-recommendations of the rehabilitation guideline and of cancer survivors to their prescribed intervention, and to identify which IST is the most beneficial.

\section{Methods}

The analysis is based on the value-of-implementation framework of Fenwick et al. ${ }^{6}$ and Hoomans et al. ${ }^{8,14}$ and consisted of the following steps:

(1) Analysing the expected value of perfect implementation (EVPIM). 
(2) Assessing the costs of the ISTs under comparison.

(3) Comparing the ISTs' costs to the EVPIM, in order to decide which of these forms a cost-effective way of spending implementation resources.

(4) Evaluating the ISTs that are cost-effective on their TNB, to identify which IST has the greatest value.

The methodology is described in detail elsewhere ${ }^{6,8,13,14}$.

\section{Intervention and patient description}

In this study, a standard exercise intervention used in cancer rehabilitation is evaluated. A typical average intervention duration is 12 weeks $^{15}$, with two weekly sessions of 90 minutes delivered by a physiotherapist to groups of six patients. The physiotherapist also conducts a 20-minute intake session and in-between consultation. The patients are adult cancer survivors, diagnosed with any type of cancer, who have completed active treatment. They experience at least one late or long-term symptom through cancer or cancer treatment that can be alleviated through exercising, such as fatigue, low quality of life, reduced physical fitness, or reduced physical functioning. The mean age is $58^{16-19}$.

\section{Analysis of the expected value of perfect implementation (EVPIM)}

\subsection{Analysis}

The EVPIM is analysed using the net-benefit framework of health economic evaluation. The net benefit is deducted from the decision-rule for analysing whether an intervention is considered cost-effective based on the incremental cost-effectiveness ratio (ICER). The ICER expresses the additional cost of an intervention for gaining one additional unit of effectiveness, in comparison to usual care ${ }^{20}$ :

(1) $\quad$ ICER $=\Delta C \div \Delta E$,

with $\Delta C$ being the incremental costs and $\Delta E$ being the incremental effectiveness of the intervention.

An intervention is considered cost-effective when its ICER is lower than the willingnessto-pay, which is the maximum amount society is willing to spend for one additional quality-adjusted life year (QALY):

(2) $\quad \Delta C \div \Delta E<W T P$

Another way for deciding if an intervention is cost-effective given the willingness-to-pay is to analyse the intervention's net benefit (NB). The net benefit expresses the value of the additional health benefit in monetary terms. To do so, the incremental effect is multiplied with the willingness-to-pay and the incremental costs are deducted. An 
intervention is cost-effective at the chosen willingness-to-pay when the NB is at least zero $^{21}$.

$$
N B=W T P \times \Delta E-\Delta C
$$

(4) $\quad N B \geq 0$

The NB in health economic evaluation thus is similar to a NB in business administration, where it represents a monetary profit after all costs have been deducted from the revenue. However, as health does not have a market price or a price tag attached, in health economics the willingness-to-pay is used to determine what a QALY is worth.

Based on the NB, the EVPIM can be analysed. It represents the difference between the NB of the exercise intervention being implemented perfectly with $100 \%$ adherence and with adherence on the current level ${ }^{6}$. The total net benefit of the guideline in perfect use represents the NB of the clinical guideline extended over the yearly patient population for the time period in which it is used ${ }^{14}$.

(5) Net benefit of the clinical guideline

$$
N B_{c g}=\Delta E_{c g} * \lambda-\Delta C_{c g}
$$

(6) Total net benefit of the guideline in perfect use

$$
\mathrm{TNB}_{\text {cg_perfect }}=N B_{\mathrm{cg}} \text { * } \mathrm{d}_{\mathrm{cg}} \text { * } \mathrm{s}_{\mathrm{pp}}
$$

(7) Total adherence

$$
A d r=a d r_{h p} \text { * } a d r_{p t}
$$

(8) Total net benefit of the guideline in current use

$$
\mathrm{TNB}_{\text {cg_current }}=\mathrm{TNB}_{\text {cg_perfect }} \text { * } \mathrm{adr}
$$

(9) Expected value of perfect implementation

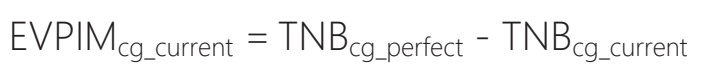

With:

$\Delta \mathrm{E}_{\mathrm{cg}}=$ Incremental effectiveness of the clinical guideline

$\lambda=$ Willingness-to-pay

$\Delta C_{c g}=$ Incremental costs of the clinical guideline

$N B_{c g}=$ Net benefit of the clinical guideline

$\mathrm{TNB}_{\text {cq_perfect }}=$ Total net benefit of the clinical guideline in perfect use

$\mathrm{d}_{\mathrm{cg}}=$ Duration of guideline usage 
$S_{\mathrm{pp}}=$ Size of the patient population served

$\mathrm{adr}=$ Total adherence

$\mathrm{adr}_{\mathrm{hp}}=$ Adherence by health professionals

$\operatorname{adr}_{\mathrm{pt}}=$ Adherence by patients

$\mathrm{TNB}_{\text {cg_current }}=$ Total net benefit of the clinical guideline in current use

EVPIM $_{\text {cg_current }}=$ Expected value of perfect implementation

If the EVPIM has a positive value it is cost-effective to use this amount to invest in implementation strategies that aim at improving the current level of implementation ${ }^{14}$.

\subsection{Data}

The incremental effectiveness of PE for cancer survivors is based on the meta-analyses of Fong et al. ${ }^{22}$ and Mishra et al. ${ }^{15}$ These meta-analyses have included 34 and 33 randomized controlled trials, respectively, and found that physical exercise had a significant impact on health-related quality of life. From these, the studies in which the SF-36 questionnaire was used were identified ${ }^{16-19,23,24}$, from which the corresponding EQ-5D-value can be deducted. This is done by first computing the mental and physical component scales (if not already stated in the paper) for the baseline and last follow-up measurement in the intervention and control groups, using the SF-36 manual and the Dutch reference scores ${ }^{25}$. The algorithm by Ara and Brazier was used to derive the corresponding EQ-5D utility values ${ }^{26}$. Then, the difference in EQ-5D score from baseline to the follow-up measurement is analysed per study for the intervention and control group. Afterwards, the difference in improvement between the intervention and control group is calculated per study. From these values, the weighed mean difference in the EQ-5D-value from baseline to follow-up is generated. To analyse the QALY-gain, this difference is multiplied by 5 years, as studies on the effect duration of PE with a long follow-up period found the effectiveness to last this long ${ }^{27-29}$.

The intervention costs consist of costs for the physiotherapist for preparing and conducting all sessions and consultations, as well as of administrative costs. The intervention costs are assessed based on the intervention description and on previous research into the required time for the tasks ${ }^{30}$. Health care costs include consultations and medication, and are based on previous research ${ }^{30}$. The WTP is set at $€ 30,000$ for one additional QALY ${ }^{31}$ and the guideline's duration is 5 years. The size of the patient population is assessed using the projections for 2015-2020 of cancer incidence in the Netherlands of the Dutch Cancer Society ${ }^{32}$. It is assumed that $42 \%$ of all cancer survivors are eligible for PE. This percentage is based on the number of cancer patients who are 
aged 20 and older $\left(99 \%{ }^{33}\right)$, an estimated percentage of patients that is able to follow an exercise intervention of $60 \%$, and on $70 \%$ of these patients being willing to participate in the intervention.

The adherence of patients who have completed at least $75 \%$ of the prescribed exercise programme is $53 \%{ }^{10}$. The adherence of professionals to the guideline is assumed to be $5 \%$. After the full implementation of the guideline, the adherence of health professionals is expected to rise to $85 \%$. All data are given in Table 1 . 
Table 1: Data used in the analysis and results that are valid for all implementation strategies (up to equation 5)

\begin{tabular}{|c|c|c|c|}
\hline Parameter & Variable name & Value & Source \\
\hline $\begin{array}{l}\text { Incremental effectiveness of the clinical } \\
\text { guideline (additional quality-adjusted } \\
\text { life years over the } 5 \text {-year time horizon) }\end{array}$ & $\Delta \mathrm{E}_{\mathrm{cg}}$ & 0.0774 QALYS & $\begin{array}{l}\text { Analysis based on } \\
\text { Fong et al. }{ }^{22} \text { and } \\
\text { Mishra et al. }\end{array}$ \\
\hline Willingness-to-pay & $\lambda$ & $€ 30,000$ & Assumption \\
\hline $\begin{array}{l}\text { Incremental costs of the clinical } \\
\text { guideline (average per patient) }\end{array}$ & $\Delta C_{c g}$ & $€ 167$ & $\begin{array}{l}\text { Calculated as } \\
\text { described in the } \\
\text { methods section }\end{array}$ \\
\hline Net benefit of the clinical guideline & $\mathrm{NB}_{\mathrm{cg}}$ & $€ 2,155$ & $\begin{array}{l}\text { Result of the } \\
\text { analysis }\end{array}$ \\
\hline Size of the patient population served & Spp & 49,767 patients & $\begin{array}{l}\text { Calculated as } \\
\text { described in the } \\
\text { methods section }\end{array}$ \\
\hline Duration of guideline usage & $\mathrm{d}_{\mathrm{cg}}$ & 5 years & Assumption \\
\hline $\begin{array}{l}\text { Total net benefit of perfect use of the } \\
\text { clinical guideline }\end{array}$ & $\mathrm{TNB}_{\text {cg_perfect }}$ & $€ 536,273,407$ & $\begin{array}{l}\text { Result of the } \\
\text { analysis }\end{array}$ \\
\hline Adherence by professionals & $a d r_{h p}$ & $85 \%$ & Assumption \\
\hline Adherence by patients & $a d r_{p t}$ & $53 \%$ & $\begin{array}{l}\text { Adams et al., } \\
2015^{10}\end{array}$ \\
\hline Adherence & Adr & $45 \%$ & $\begin{array}{l}\text { Result of the } \\
\text { analysis }\end{array}$ \\
\hline $\begin{array}{l}\text { Total net benefit of current (or future) } \\
\text { use of clinical guidance }\end{array}$ & $\mathrm{TNB}_{\text {cg_current }}$ & $243,414,499 €$ & $\begin{array}{l}\text { Result of the } \\
\text { analysis }\end{array}$ \\
\hline $\begin{array}{l}\text { Expected value of perfect } \\
\text { implementation }\end{array}$ & EVPIM cg_current & $292,858,907 €$ & $\begin{array}{l}\text { Result of the } \\
\text { analysis }\end{array}$ \\
\hline $\begin{array}{l}\text { Number of health professionals } \\
\text { targeted per year }\end{array}$ & $N_{h p}$ & $\begin{array}{l}650 \\
\text { professionals }\end{array}$ & $\begin{array}{l}\text { Dutch Oncology } \\
\text { Association }^{34}\end{array}$ \\
\hline Number of patients targeted per year & $N_{p t}$ & 49,767 patients & $\begin{array}{l}\text { Calculated as } \\
\text { described in the } \\
\text { methods section }\end{array}$ \\
\hline
\end{tabular}




\section{Cost-assessment of the ISTs}

\subsection{The ISTS}

The following strategies for further increasing adherence after the general implementation of the guideline are evaluated:

Directed at health professionals:

a) Continuing education meetings and workshops (CME)

b) Educational outreach visits (EOV)

c) Printed educational materials (PEM)

d) Local opinion leaders (LOPL)

e) Audit and feedback (AF)

f) Reminder systems (RS)

g) A multifaceted strategy (MF) consisting of CME and AF

The multifaceted interventions for changing professional practice often are assumed to be more effective than single interventions ${ }^{35}$, although more recent reviews did not find evidence for this being the case ${ }^{36,37}$. We included a multifaceted strategy in order to demonstrate the impact of combining two ISTs on the total net benefit.

Directed at patients:

h) Motivational programme (MP)

i) Financial incentives (FI)

See Table 2.

Table 2: Description and effectiveness of the implementation strategies

\begin{tabular}{|c|c|c|}
\hline Strategy & Description of the strategy & $\begin{array}{l}\text { Effectiveness (source, type of evidence, } \\
\text { influence on adherence) }\end{array}$ \\
\hline \multicolumn{3}{|c|}{ Directed at health professionals } \\
\hline $\begin{array}{l}\text { A. } \\
\text { Continuing } \\
\text { education } \\
\text { meetings and } \\
\text { workshops }\end{array}$ & $\begin{array}{l}\text { The most common form is an educational } \\
\text { meeting, which includes various forms of courses } \\
\text { and workshops. These meetings vary in their } \\
\text { length, intensity, the number of participants, and } \\
\text { its degree of interaction }{ }^{36} \text {. } \\
\text { Used for the cost calculation: } \\
\text { Two workshops of four hours length are provided } \\
\text { to health professionals in their location by two } \\
\text { staff. The average group size is ten participants. }\end{array}$ & $\begin{array}{l}\text { Forsetlund et al., } 2009^{36} \\
\text { Cochrance review, } \\
6 \% \text { RD (IQR 2.9\% to 15.3\%) (for } \\
\text { dichotomous outcomes), } \\
19 \text { studies included, } \\
21 \text { comparisons }\end{array}$ \\
\hline $\begin{array}{l}\text { B. } \\
\text { Educational } \\
\text { outreach visits }\end{array}$ & $\begin{array}{l}\text { Health professionals are visited in their own } \\
\text { premises by a trained person. Aim of the visit is to } \\
\text { inform health professionals with the objective of } \\
\text { improving their behaviour }{ }^{38} \text {. }\end{array}$ & $\begin{array}{l}\text { O’Brien et al., } 2007^{38} \\
\text { Cochrane review, }\end{array}$ \\
\hline
\end{tabular}




\begin{tabular}{|c|c|c|}
\hline & $\begin{array}{l}\text { Used for the cost calculation: } \\
\text { Health professionals were visited individually } 4 \\
\text { times for } 20 \text { minutes by an experienced physician } \\
\text { who is the EOV-facilitator. }\end{array}$ & $\begin{array}{l}5 \% \text { RD (IQR 3\% to 6.2\%) (for dichotomous } \\
\text { outcomes), } \\
34 \text { studies included, } \\
37 \text { comparisons }\end{array}$ \\
\hline $\begin{array}{l}\text { C. } \\
\text { Printed } \\
\text { educational } \\
\text { materials }\end{array}$ & $\begin{array}{l}\text { Printed educational materials are information } \\
\text { provided in paper format, including articles } \\
\text { published in journals, guidelines, and } \\
\text { monographs. These can be send by post or mail, } \\
\text { be delivered in person, or made available in } \\
\text { public, e.g. on the internet. } \\
\text { Used for the cost calculation: } \\
\text { Three information mailings about the guideline } \\
\text { are developed by a clinical researcher and sent in } \\
\text { three mass mailings. }\end{array}$ & $\begin{array}{l}\text { Giguère et al., } 2012^{39} \\
\text { Cochrance review, } \\
\text { Categorial practice outcomes: } 2 \% \text { RD } \\
\text { (Range } 0 \text { to } 0.11 \text { ), } \\
7 \text { studies included, } \\
69 \text { outcomes }\end{array}$ \\
\hline $\begin{array}{l}\text { D. } \\
\text { Local opinion } \\
\text { leader }\end{array}$ & $\begin{array}{l}\text { A local opinion leader is a person who is able to } \\
\text { positively influence the behaviour of others. The } \\
\text { local opinion leader is able to do so through } \\
\text { being perceived as a credible person with } \\
\text { authority, being very interconnect, and having a } \\
\text { very influential position within a network }{ }^{40} \text {. } \\
\text { Used for the cost calculation: } \\
\text { The local opinion leaders conduct three tutorials } \\
\text { of one hour length in groups of three at the } \\
\text { premises of the health professionals. }\end{array}$ & $\begin{array}{l}\text { Flodgren et al., } 2011^{40} \\
\text { Cochrane review, } \\
\text { Dichotomous outcomes: 9\% RD (IQR 3\% to } \\
6.2 \%), \\
5 \text { studies included, } \\
37 \text { outcomes }\end{array}$ \\
\hline $\begin{array}{l}\text { E. } \\
\text { Audit and } \\
\text { feedback }\end{array}$ & $\begin{array}{l}\text { It is measured how well health professionals } \\
\text { adhere to a clinical guideline. Subsequently, they } \\
\text { receive feedback on their level of compliance and } \\
\text { it is assumed that they adapt their behaviour }{ }^{41} \text {. } \\
\text { Used for the cost calculation: } \\
\text { The audit and feedback is conducted individually } \\
\text { with every oncologist. The intervention is } \\
\text { delivered by a senior colleague. The audit } \\
\text { sessions last } 1.5 \text { hours. Feedback is provided } \\
\text { verbally in a one-hour session and an action plan } \\
\text { is provided }\end{array}$ & $\begin{array}{l}\text { Yvers et al, } 2012^{41} \\
\text { Cochrane review, } \\
\text { Dichotomous outcomes: 3\% RD (IQR 1.8\% } \\
\text { to } 7.7 \%) \text {, } \\
26 \text { studies included, } \\
32 \text { comparisons }\end{array}$ \\
\hline $\begin{array}{l}\text { F. } \\
\text { Reminder } \\
\text { systems }\end{array}$ & $\begin{array}{l}\text { Reminders systems are measures to support the } \\
\text { memory of health professionals. The reminders } \\
\text { can be delivered via computer software, in } \\
\text { printed form, or by telephone. }\end{array}$ & $\begin{array}{l}\text { Arditi et al, } 2012^{42} \\
\text { Cochrance review } \\
11.2 \% \text { (IQR } 6.5 \% \text { to } 19.6 \%) \text {, } \\
\text { Not stated }\end{array}$ \\
\hline $\begin{array}{l}\text { G. } \\
\text { Multifaceted }\end{array}$ & $\begin{array}{l}\text { This strategy consists of continuing medical } \\
\text { education and audit and feedback combined. }\end{array}$ & Assumptions \\
\hline
\end{tabular}


strategy

Directed at patients

H. The motivation programme consists of 5 steps: (1) Friedrich et al., $1999^{43}$

Motivational Extensive counselling and information provision,

programme (2) reinforcement techniques that pronounce the patients' efforts, (3) setting up a "treatment low back pain patients, $N=93$,

contract" between the therapist and the patient,

(4) asking patients to place the treatment contract $81.8 \%$ versus $51 \%$ of the sessions were

in a prominent place in their home, (5) patients attended in the motivation + exercise

filling in an exercise diary. group versus exercise only group.

Used for the cost-calculation:

Three individual counselling sessions with a

physiotherapist are provided. The treatment

contract and exercise diary are discussed during

these sessions. The reinforcement techniques are

used during the exercise sessions and do not result in additional costs.

\begin{tabular}{lll}
\hline $\begin{array}{l}\text { I. Financial } \\
\text { incentives }\end{array}$ & $\begin{array}{l}\text { Financial incentives (cash or another reward that } \\
\text { has a monetary value) are given to patients based }\end{array}$ & \multicolumn{2}{l}{ Mitchell et al., $2013^{44}$} \\
& on specified exercise behaviour. & Meta-analysis with healthy adults, N=554 \\
& $\begin{array}{l}\text { Used for the cost-calculation: } \\
\text { Patients receive } € 30 / \text { week when they attend all } \\
\text { scheduled exercise sessions in a given week. }\end{array}$ & $\begin{array}{l}\text { The adherence in the intervention groups } \\
\text { groups. }\end{array}$ \\
\hline
\end{tabular}

$\mathrm{RD}=$ risk difference, $\mathrm{IQR}=$ interquartile range

\subsection{Analysis}

The costs of the ISTs are calculated as follows:

$$
\begin{aligned}
& \text { Total cost of implementation strategy } \\
& T C_{\text {IST }}=C_{\text {dev }}+\left(C_{\text {per_pat }} * N_{p} * D_{\text {a_impl }}\right)+\left(C_{\text {per_hp }} * N_{h p} * D_{\text {a_impl }}\right)
\end{aligned}
$$

With:

$\mathrm{TC}_{\text {IST }}=$ Total cost of implementation strategy

$\mathrm{C}_{\mathrm{dev}}=$ Costs of developing an implementation strategy

$\mathrm{C}_{\text {per_par }}=$ Per patient costs of executing the implementation strategy targeted at patients

$N_{p}=$ Number of patients targeted per year

$D_{\text {a_impl }}=$ Duration of active implementation

$C_{\text {per_hp }}=$ Per patient costs of executing the implementation strategy targeted at health professionals

$N_{h p}=$ Number of health professionals targeted per year 


\subsection{Data}

For the general implementation of the clinical guideline, a national project was required by the organisation that developed the guideline, which would costs $€ 3.78 \mathrm{~m}$. The ISTs' development costs include the costs for the researchers who are assigned with this task. For every IST it is analysed which actions are required to develop and execute the strategy. It is then assessed how much time is required by which type of staff for training and for executing the strategy, and which material, services, and/or travel and meeting costs are needed. Subsequently, the costs are assessed according to the Dutch manual for cost research ${ }^{45}$.

\section{Analysing if the ISTs are cost-effective}

The total costs of the ISTS, as analysed in step 2, are compared to the EVPIM, which was analysed in step 1. If the total costs are lower than the EVPIM, the IST is considered costeffective.

\section{Analysis of the total net benefit of the ISTS}

\subsection{Analysis}

The TNB of perfect use of the guideline is the value of the amount of health that is realised in the hypothetical situation that professionals and patients are 100\% adherent. However, in the current situation the adherence is only $45 \%$. The health gain produced by the guideline when the adherence is $45 \%$ expressed in monetary terms is the TNB of current guideline use. The potential TNB that can be realised by increasing adherence from $45 \%$ to $100 \%$ is expressed as the EVPIM. When an IST is effective in further increasing adherence up from 45\%, it realises a part of the EVPIM; this part is the TNB of the IST. It is analysed using the following equations, which are adapted from Hoomans et al. ${ }^{13}$.

For ISTs directed at professionals:

$$
\mathrm{TNB}_{\text {IST }}=\mathrm{TNB}_{\text {cg_perfect }} *\left(\Delta \mathrm{adr} \mathrm{r}_{\text {IST }} * \mathrm{adr} \mathrm{r}_{\text {pt }}\right)-\mathrm{TC}_{\text {is }}
$$

For ISTs directed at patients:

$$
T N B_{I S T}=T N B_{\text {cg_perfect }} *\left(\Delta a d r_{I S T} * a d r_{h p}\right)-T C_{\text {is }}
$$

With:

$\mathrm{TNB}_{\mathrm{IST}}=$ Total net benefit of the implementation strategy

$\mathrm{TNB}_{\text {cg_perfect }}=$ Total net benefit of the clinical guidance in perfect implementation 
$\Delta \operatorname{adr}_{\text {IST }}=$ Change in adherence caused by the IST

$A d r_{p t}=$ Adherence by patients

$A d r_{h p}=$ Adherence by health professionals

$\mathrm{TC}_{\text {IST }}=$ Total cost of an implementation strategy

With the TNB of the ISTS, the total net benefit of the clinical guideline plus the implementation strategy can be analysed.

$$
\mathrm{TNB}_{\text {cg_current+IST }}=\mathrm{TNB}_{\text {cg_current }}+\mathrm{TNB}_{\mathrm{IST}}
$$

With:

$\mathrm{TNB}_{\text {cg_current+IST }}=$ Total net benefit of the clinical guideline plus the implementation strategy

\subsection{Data}

The change in adherence for the ISTs is taken from the literature, specifically from Cochrane reviews, a randomized controlled trial, and a meta-analysis ${ }^{36-44}$. These included different kinds of health professionals and interventions, as data specifically for exercise and cancer survivors was not available. See Table 2.

\section{Sensitivity analyses}

In order to test the robustness of the results, sensitivity analyses are conducted. The effect on the results of changing the willingness-to-pay to $€ 20.000 / Q A L Y$ and $€ 50.000 /$ QALY is analysed, as well as that of the ISTs' costs and effect being halved or being 1.5 times as high.

\section{Results}

\section{$1 \mathrm{EVPIM}$}

The pooled difference of the health-related quality of life as measured by the EQ-5D among the studies included in the meta-analyses was 0.015 (rounded) over 12 months. Over a time horizon of five years, this accrued to an expected incremental effectiveness of PE compared to usual care of 0.077 QALYS. The average intervention costs of PE were $€ 221$ per patient. The difference in health care costs between PE and usual care was $€ 54$. The total costs over the 5 -year period were $€ 2,327$ for PE and $€ 2,160$ for usual 
care, leading to incremental costs of $€ 167$ for PE. The total net benefit of the guideline was $€ 2,155$ per patient over the 5-year time horizon. This value represents the health gain caused by the guideline when one QALY is considered worth $€ 30,000$, taking into account the costs that were made for the exercise intervention.

The average annual patient population eligible for PE from 2015 to 2020 was 49,767. This led to a total net benefit of the clinical guideline in perfect use of $€ 536 \mathrm{~m}$ over the 5 -year period. This is the value that would be achieved when every year, for five years, all 49,767 eligible patients have a health gain of 0.077 QALYS through participating in $P E$, when one QALY is worth $€ 30,000$ to society, taking into account the average incremental costs of $€ 167$ per patient.

The adherence of health professionals and patients combined to the clinical guidance in current use was 45\%, as patients can only be compliant when they were prescribed the exercise intervention in the first place. The total net benefit of the clinical guidance on PE in current use was €243 million. This equals the monetary value of the QALY-gain that is achieved when not 100\%, but only $45 \%$ adherence is achieved, with one QALY being worth $€ 30,000$ to society. The EVPIM over the 5-year period of guideline usage was $€ 293 \mathrm{~m}$. This is the monetary value of the health benefit that could be achieved by increasing the adherence from $45 \%$ to $100 \%$. See Table 1 for the results.

\section{Costs of the implementation strategies}

The development costs for the ISTs varied from €13k for printed educational material to $€ 1.8 \mathrm{~m}$ for the reminder system. The costs per professional for executing the ISTs ranged from €18 for printed educational material to $€ 2,108$ for the multifaceted strategy and from $€ 160$ for the motivational programme to $€ 481$ for financial incentives per patient. The total costs for the ISTs ranged from €34k for printed educational material to $€ 120 \mathrm{~m}$ for financial incentives. See Table 3 for the results. 
Table 3: Input parameters and results for the implementation strategies

\begin{tabular}{|c|c|c|c|c|c|c|}
\hline & $\begin{array}{l}\text { Development } \\
\text { cost of an } \\
\text { implementation } \\
\text { strategy }\end{array}$ & $\begin{array}{l}\text { Costs for executing } \\
\text { an implementation } \\
\text { strategy per health } \\
\text { professional/ } \\
\text { patient per year }\end{array}$ & $\begin{array}{l}\text { Total costs of } \\
\text { an } \\
\text { implementation } \\
\text { strategy }\end{array}$ & $\begin{array}{l}\text { Change in } \\
\text { adherence }\end{array}$ & $\begin{array}{c}\text { Total net } \\
\text { benefit of } \\
\text { implementation } \\
\text { strategy }\end{array}$ & $\begin{array}{c}\text { Total net } \\
\text { benefit of } \\
\text { clinical } \\
\text { guidance plus } \\
\text { implementa- } \\
\text { tion strategy }\end{array}$ \\
\hline \multicolumn{7}{|c|}{ Strategies directed at health professionals } \\
\hline $\begin{array}{l}\text { Continuing } \\
\text { educational } \\
\text { meeting } \\
\text { (CME) } \\
\end{array}$ & $33,654 €$ & $1,033 €$ & $705,302 €$ & 0.06 & $16,476,898 €$ & $259,891,397 €$ \\
\hline $\begin{array}{l}\text { Educational } \\
\text { outreach } \\
\text { visits (EOV) }\end{array}$ & $13,376 €$ & $916 €$ & $609,096 €$ & 0.05 & $13,709,404 €$ & $257,123,903 €$ \\
\hline $\begin{array}{l}\text { Printed } \\
\text { educational } \\
\text { materials } \\
\text { (PEM) } \\
\end{array}$ & $699,180 €$ & $18 €$ & $34,388 €$ & 0.02 & $5,693,012 €$ & $249,107,512 €$ \\
\hline $\begin{array}{l}\text { Local } \\
\text { opinion } \\
\text { leaders } \\
\text { (LOPL) } \\
\end{array}$ & $806,532 €$ & $1,238 €$ & $934,996 €$ & 0.09 & $24,838,304 €$ & $268,252,803 €$ \\
\hline $\begin{array}{l}\text { Audit and } \\
\text { feedback } \\
\text { (AF) } \\
\end{array}$ & $733,686 €$ & $1,075 €$ & $756,236 €$ & 0.03 & $7,834,864 €$ & $251,249,363 €$ \\
\hline $\begin{array}{l}\text { Reminders } \\
\text { systems } \\
\text { (RS) } \\
\end{array}$ & $1,812,176 €$ & $77 €$ & $1,185,842 €$ & 0.11 & $30,887,598 €$ & $274,302,097 €$ \\
\hline $\begin{array}{l}\text { Multifaceted } \\
\text { strategy } \\
\text { (MF) }\end{array}$ & $767,340 €$ & $2,108 €$ & $1,461,538 €$ & 0.08 & $21,448,062 €$ & $264,862,562 €$ \\
\hline \multicolumn{7}{|c|}{ Strategies directed at patients } \\
\hline $\begin{array}{l}\text { Motivational } \\
\text { programme } \\
\text { (MP) }\end{array}$ & $34,506 €$ & $160 €$ & $39,962,821 €$ & 0.31 & $100.433 .556 €$ & $343.848 .056 €$ \\
\hline $\begin{array}{l}\text { Financial } \\
\text { incentives } \\
\text { (FI) } \\
\end{array}$ & $11,502 €$ & $481 €$ & $119,778,428 €$ & 0.12 & $-67.129 .786 €$ & $176.284 .713 €$ \\
\hline
\end{tabular}

\section{Cost-effectiveness of the ISTs}

The costs of all ISTs' were well below the EVPIM of $€ 293 \mathrm{~m}$. Thus, it would be worth investing in these strategies in order to realize at least part of the potential net benefit of the ISTs. 


\section{Total net benefit of the ISTs}

The ISTs that are directed at professional added another 2\% for printed educational material up to $11 \%$ for reminder systems to the current adherence. Of the ISTs that are directed at professionals, reminder systems had the highest TNB of $€ 30.9 \mathrm{~m}$ and printed educational material had the lowest with $€ 5.7 \mathrm{~m}$. The ISTs directed at patients increased their current adherence by 31\% through the motivational programme and by $12 \%$ through financial incentives. Of these, only the motivational programme had a positive $T N B$, which was of $€ 100.4 \mathrm{~m}$. Financial incentives had a negative TNB of $€-67.1 \mathrm{~m}$.

A positive TNB indicates that the monetary value attached by society to the health gain that is created by the IST is higher than the costs of the IST. However, it cannot be spoken of a cost-saving here, as a health gain cannot be sold, does not appear on someone's balance sheets, and does not lead to actual cost-savings. It rather means that the costs of the strategy are higher than the monetary value that society places on the health gain that it produced.

The TNB of the clinical guideline plus the implementation strategy was positive for all ISTs and ranges from $€ 249.1 \mathrm{~m}$ for printed educational material to $€ 343.8 \mathrm{~m}$ for the motivational programme. All results are displayed in Table 3.

\section{Sensitivity analyses}

When the willingness-to-pay was reduced to $€ 20,000 / Q A L Y$, all ISTs that had a positive net benefit maintained this. With a willingness-to-pay of €50,000/QALY, the net benefits increased. When the total costs of the ISTs were halved, the net benefit was only influenced marginally, as the costs were very small in comparison to the net benefit. Thus, when costs were 1.5 times as high this only had a marginal effect on the results as well. Reducing the effectiveness of the ISTs by one half resulted in net benefits that were approximately half of what they were before, but all that were positive in the base case analysis maintained this. Subsequently, when the effect was 1.5 times larger, the net benefits increased even more. See Table 4. 
Table 4: The total net benefit of the ISTs as a result of the sensitivity analysis [in €]

\begin{tabular}{lcccccc}
\hline & $\begin{array}{c}\text { WTP: } \\
€ 20.000 \\
\text { /QALY }\end{array}$ & $\begin{array}{c}\text { WTP: } \\
\text { /QALY }\end{array}$ & Total costs & $\begin{array}{c}\text { Total costs } \\
\text { are halved } \\
\text { higher }\end{array}$ & $\begin{array}{c}\text { Effect is } \\
\text { halved }\end{array}$ & $\begin{array}{c}\text { Effect is 1.5 } \\
\text { times higher }\end{array}$ \\
\hline Strategies directed at professionals & & & & \\
\hline CME & $10,304,584$ & $28,821,526$ & $16,829,549$ & $16,124,247$ & $7,885,798$ & $25,067,998$ \\
\hline EOV & $8,565,809$ & $23,996,594$ & $14,013,952$ & $13,404,856$ & $6,550,154$ & $20,868,654$ \\
\hline PEM & $3,635,574$ & $9,807,888$ & $5,710,206$ & $5,675,818$ & $2,829,312$ & $8,556,712$ \\
\hline LOPL & $15,579,833$ & $43,355,245$ & $25,305,802$ & $24,370,806$ & $11,951,654$ & $37,724,954$ \\
\hline AF & $4,748,707$ & $14,007,178$ & $8,212,982$ & $7,456,746$ & $3,539,314$ & $12,130,414$ \\
\hline RS & $19,365,945$ & $53,930,903$ & $31,480,519$ & $30,294,677$ & $14,850,878$ & $46,924,318$ \\
\hline MF & $13,218,311$ & $37,907,566$ & $22,178,831$ & $20,717,293$ & $9,993,262$ & $32,902,862$ \\
\hline Strategies directed at patients & & & & \\
\hline MP & $49,999,357$ & $201,301,956$ & $120,414,967$ & $80,452,146$ & $30,235,367$ & $170,631,745$ \\
\hline FI & $-86,042,611$ & $-29,304,136$ & $-7,240,572$ & $-127,019,000$ & $-93,454,107$ & $-40,805,465$ \\
\hline
\end{tabular}

WTP = Willingness-to-pay

\section{Discussion}

This study analysed the total net benefit of ISTs for increasing the adherence of health professionals to the cancer rehabilitation guideline on exercise and of cancer survivors to their prescribed exercise interventions. The EVPIM, i.e. the value that would be created by increasing adherence to the clinical guideline on exercise of professionals and to the prescribed exercise interventions by cancer survivors from the current $45 \%$ to $100 \%$ was very high, i.e. $€ 293 \mathrm{~m}$ over the 5 -year period of guideline use. The total costs of the implementation strategies all were way below the EVPIM, and had costs between $€ 34 \mathrm{k}$ for printed educational material and $€ 120 \mathrm{~m}$ for financial incentives. The net benefits ranged from $€-67.1$ for financial incentives to $€ 100.4 \mathrm{~m}$ for the motivational programme, with financial incentives being the only strategy that had a negative net benefit.

The results showed that all but one of the implementation strategies led to high TNBs and can thus all be recommended. Based on the net benefit, the motivational 
programme for patients should be chosen. Although it has the highest costs, its effect is manifold higher than that of the remaining strategies. Of the strategies directed at professionals, reminder systems had the highest net benefit, but also very high costs. Thus, high up-front development costs are worth it when these lead to higher effectiveness in the long-run. However, high initial costs can be an issue when these cannot be covered. Therefore, although the motivational programme has by far the highest TNB it might not be the most feasible IST, due to the high costs. The same is true for reminder systems. Therefore, when resources are limited, the most feasible IST is local opinion leaders, which ranks third in the TNB, but has more acceptable costs. When time and money are scarce, even the cheapest strategy, printed educational materials, is preferable to not doing anything, as it resulted in a positive net benefit. The most critical is to conduct any of the strategies with a positive TNB at all in order to create a health benefit that otherwise would be forgone.

For strategies that are directed on increasing the adherence among patients, only two ISTs could be included ${ }^{43,44}$. Several other studies and two reviews ${ }^{46}$ were identified that measured the effect of an adherence intervention in exercise. However, of these the data was not fully suitable: The interventions were not found to be effective ${ }^{46-51}$, the study did not include a control group ${ }^{49}$, did not measure adherence ${ }^{48}$, had methodological shortcomings (not randomized, self-reported adherence, inadequate presentation of the results) ${ }^{52}$, or compared the effect of exercise plus the adherence intervention to doing-nothing, so that it was not possible to isolate the effect of the adherence intervention ${ }^{53}$.

This study has a number of limitations that require mentioning them. First, the metaanalyses we used for deducting the effectiveness of physical exercise interventions for cancer survivors included studies of all types of cancer. However, most studies included only breast cancer survivors. This limits the generalizability of the results and is a general problem in the research on physical exercise for cancer survivors ${ }^{54}$. Second, the data for the effectiveness of the intervention, as well as that of the implementation strategies, were derived from systematic reviews and meta-analysis that summarized the effect using a broad range of studies. The data thus does not represent the effectiveness of a very specific intervention or IST used, but that of the broader group this intervention or IST belongs to. Third, the literature used for the effectiveness of the ISTs shows that the effectiveness of ISTs is influenced by variables such as the intensity of the intervention, the credibility of the organisation who delivers the intervention, etc. Thus, depending on the specific intervention that is used, the effects on changing adherence differ. Finally, the literature data that was used for the effect of the ISTS on adherence is not based 
specifically on cancer patients. It therefore needs mentioning that this study provides indications of what is possible with the evaluated ISTS, rather than exact results. However, the results were very clear in that the TNBs can be huge. Moreover, the sensitivity analysis showed that the outcomes of our analysis were robust to changes in the input parameters.

Although all but one IST led to a positive TNB, they only realized a small part of the EVPIM of $€ 293 \mathrm{~m}$. Thus, there is a high potential for creating higher net benefits and more health by using more effective ISTs. Therefore, future research should concentrate on developing ISTs that more significantly improve adherence. In order to attain results that are more specific for exercise interventions for cancer survivors, more research should be conducted that analysis the effectiveness of implementation strategies for promoting adherence to cancer survivorship guidelines.

\section{Conclusion}

All but one of the evaluated implementation strategies had positive total net benefits for increasing the adherence of health professionals and patients. The greatest net benefits were achieved by a motivational programme for patients and a reminder system for health professionals. However, these also had the highest costs. The most feasible strategy is local opinion leaders, which had moderate costs and ranked third for the total net benefit. Most of the strategies directed at professionals only had a marginal contribution to achieving the highest possible value of implementation. Thus, in order to realize higher net benefits, further research into the effectiveness of the various implementation strategies for increasing compliance is needed. 


\section{References}

1. Schmitz KH, Courneya KS, Matthews C, et al. American College of Sports Medicine roundtable on exercise guidelines for cancer survivors. Medicine \& Science in Sports \& Exercise 2010; 42(7): 1409-26.

2. The Netherlands Comprehensive Cancer Organisation (IKNL). Cancer rehabilitation: nation-wide guideline. Utrecht: IKNL, 2011.

3. Harris SR, Schmitz KH, Campbell KL, McNeely ML. Clinical practice guidelines for breast cancer rehabilitation: syntheses of guideline recommendations and qualitative appraisals. Cancer 2012; 118(8 Suppl): 2312-24.

4. Hayes S, Spence R, Galvao D, Newton R. Australian Association for Exercise and Sport Science position stand: optimising cancer outcomes through exercise. Journal of Science and Medicine in Sport 2009; 12: 428-32.

5. Hellbom M, Bergelt C, Bergenmar M, et al. Cancer rehabilitation: a Nordic and European perspective. Acta Oncologica 2011; 50(2): 179-86.

6. Fenwick E, Claxton K, Sculpher M. The value of implementation and the value of information: combined and uneven development. Medical Decision Making 2008; 28: 21-32.

7. Kampshoff CS, Jansen F, van Mechelen W, et al. Determinants of exercise adherence and maintenance among cancer survivors: a systematic review. The International Journal of Behavioral Nutrition and Physical Activity 2014; 11: 80.

8. Hoomans T, Severens JL. Economic evaluation of implementation strategies in health care. Implementation Science 2014; 9(1): 168.

9. Mason J, Freemantle N, Nazareth I, Eccles MP, Haines A, Drummand M. When is it cost-effective to change the behavior of health professionals? Journal of the American Medical Association 2001; 286: 2977-92.

10. Adams R, Mosher C, Blair C, Snyder D, Sloane R, Demark-Wahnefried W. Cancer survivors' uptake and adherence in diet and exercise intervention trials: an integrative data analysis. Cancer 2015; 121(1): 77-83.

11. Husebø A, Dyrstad S, Søreide J, Bru E. Predicting exercise adherence in cancer patients and survivors: a systematic review and meta-analysis of motivational and behavioural factors. Journal of Clinical Nursing 2012; 22(1-2): 4-21.

12. Grimshaw J, Thomas R, MacLennan $G$, et al. Effectiveness and efficiency of guideline dissemination and implementation strategies. Health Technology Assessment 2004; 8(6). 
13. Hoomans T, Fenwick EA, Palmer S, Claxton K. Value of information and value of implementation: application of an analytic framework to inform resource allocation decisions in metastatic hormone-refractory prostate cancer. Value in Health 2009; 12(2): 315-24.

14. Hoomans T, Ament AJ, Evers SM, Severens JL. Implementing guidelines into clinical practice: What is the value? Journal of Evaluation in Clinical Practice 2011; 17(4): 606-14.

15. Mishra S, Scherer R, Geigle P, et al. Exercise interventions on health-related quality of life for cancer survivors. Cochrane Database of Systematic Reviews 2012; (8): 1-379.

16. Sandel S, Judge J, Landry N, Faria L, Oulette R, Majczak M. Dance and movement program improves quality-of-life measures in breast cancer survivors. Cancer Nursing 2005; 28(4): 301-9.

17. Basen-Engquist $\mathrm{K}$, Taylor CL, Rosenblum C, et al. Randomized pilot test of a lifestyle physical activity intervention for breast cancer survivors. Patient Education and Counseling 2006; 64(1-3): 225-34.

18. Speck RM, Gross CR, Hormes JM, et al. Changes in the body image and relationship scale following a one-year strength training trial for breast cancer survivors with or at risk for lymphedema. Breast Cancer Research and Treatment 2010; 121(2): 421-30.

19. Fillion L, Gognon P, Leblond $F$, et al. A brief intervention for fatigue management in breast cancer survivors. Cancer Nursing 2008; 31(2): 145-59.

20. Drummond MF, Sculpher MJ, Torrance GW, O’Brien BJ, Stoddart GL. Methods for the economic evaluation of health care programmes Oxford: Oxford University Press; 2005.

21. Briggs AH, Goeree R, Blackhouse G, O'Brien BJ. Probabilistic analysis of costeffectiveness models: choosing between treatment strategies for gastroesophageal reflux disease. Medical Decision Making 2002; 22(4): 290-308.

22. Fong D, Ho J, Hui B, et al. Physical activity for cancer survivors: meta-analysis of randomised controlled trials. British Medical Journal 2012; 344(e70): 1-14.

23. Morey M, Snyder D, Sloane R, et al. Effects of home-based diet and exercise on functional outcomes among older, overweight long-term cancer survivors. RENEW: A randomized controlled trial. Journal of the American Medical Association 2009; 301(18): 1883-91. 
24. Cadmus LA, Salovey P, Yu H, Chung G, Kasl S, Irwin ML. Exercise and quality of life during and after treatment for breast cancer: results of two randomized controlled trials. Psychooncology 2009; 18(4): 343-52.

25. Aaronson N, Muller M, Cohen $\mathrm{P}$, et al. Translation, validation, and norming of the Dutch language version of the SF-36 health survey in community and chronic disease populations. Journal of Clinical Epidemiology 1998; 52(11): 105568.

26. Ara R, Brazier J. Deriving an algorithm to convert the eight mean SF-36 dimension scores into a mean EQ-5D preference-based score from published studies (where patient level data are not available). Value in Health 2008; 11(7): 1131-43.

27. Trinh L, Mutrie N, Campbell AM, Crawford JJ, Courneya KS. Effects of supervised exercise on motivational outcomes in breast cancer survivors at 5 year follow-up. European Journal of Oncology Nursing 2014; 18(6): 557-63.

28. Haas B, Kimmel G, Hermanns M, Deal B. Community-based FitSTEPS for Life exercise program for persons with cancer: 5-year evaluation. Journal of Oncology Practice 2012; 8(6): 320-4.

29. Ottenbacher AJ, Day RS, Taylor WC, et al. Long-term physical activity outcomes of home-based lifestyle interventions among breast and prostate cancer survivors. Supportive Care in Cancer 2012; 20(10): 2483-9.

30. Mewes J, Steuten LD, SFA, Duijts, SFA, et al. Cost-effectiveness of cognitive behavioral therapy and physical exercise for alleviating treatment-induced menopausal symptoms in breast cancer patients. Journal of Cancer Surviorship 2014; 9(1): 126-35.

31. Boersma C, Broere A, Postma M. Quantification of the potential impact of costeffectiveness thresholds on Dutch drug expenditures using retrospective analysis. Value in Health 2010; 13(6): 853-6.

32. Signaleringscommissie Kanker van KWF Kankerbestrijding. Kanker in Nederland tot 2020 - trends en prognoses. Amsterdam: Dutch Cancer Society, 2011.

33. Cijfersoverkanker.nl. Incidence according to age. 2013. cijfersoverkanker.nl (accessed 13 May 2013).

34. Dutch Oncology Association. Nederlandse Vereniging voor Oncologie. 2015. nvvoncologie.nl/ (accessed 12 July 2015).

35. Mansouri M, Lockyer J. A meta-analysis of continuing medical education effectiveness. Journal of Continuing Education in the Health Professions 2007; 27(1): 6-15. 
36. Forsetlund L, Bjørndal A, Rashidian A, et al. Continuing education meetings and workshops: effects on professional practice and health care outcomes. Cochrane Database of Systematic Reviews 2009; (2).

37. Squires JE, Sullivan K, Eccles MP, Worswick J, Grimshaw JM. Are multifaceted interventions more effective than single-component interventions in changing health-care professionals' behaviours? An overview of systematic reviews. Implementation Science 2014; 9: 152.

38. O'Brien M, Rogers S, Jamtvedt $G$, et al. Educational outreach visits: effects on professional practice and health care outcomes. Cochrane Database of Systematic Reviews 2007; (4).

39. Giguère A, Légaré F, Grimshaw J, et al. Printed educational materials: effects on professional practice and healthcare outcomes. Cochrane Database of Systematic Reviews 2012; (10): 1-197.

40. Flodgren G, Parmelli E, Doumit G, et al. Local opinion leaders: effects on professional practice and health care outcomes. Cochrane Database of Systematic Reviews 2011; (8).

41. Ivers N, Jamtvedt G, Flottorp S, et al. Audit and feedback: effects on professional practice and healthcare outcomes. Cochrane Database of Systematic Reviews 2012; (6).

42. Arditi C, Rège-Walther $M$, Wyatt J, Durieux P, Burnand B. Computer-generated reminders delivered on paper to healthcare professionals; effects on professional practice and health care outcomes Cochrane Database of Systematic Reviews 2012; (12): 1-121.

43. Friedrich $M$, Gittler $G$, Halberstadt Y, Cermak T, Heiller I. Combined exercise and motivation program: effect on the compliance and level of disability of patients with chronic low back pain: a randomized controlled trial. Archives of Physical Medicine and Rehabilitation 1998; 79: 475-87.

44. Mitchell MS, Goodman JM, Alter DA, et al. Financial incentives for exercise adherence in adults: systematic review and meta-analysis. American Journal of Preventive Medicine 2013; 45(5): 658-67.

45. Hakkaart-Van Roijen L, Tan SS, Bouwmans CAM. Manual for cost research: methods and standard cost prices for economic evaluations in health care. Diemen: Health Care Insurance Board, 2010.

46. McGrane N, Galvin R, Cusack T, Stokes E. Addition of motivational interventions to exercise and traditional physiotherapy: a review and meta-analysis. Physiotherapy 2015; 101: 1-12. 
47. van Weert E, May AM, Korstjens I, et al. Cancer-related fatigue and rehabilitation: a randomized controlled multicenter trial comparing physical training combined with cognitive-behavioral therapy with physical training only and with no intervention. Physical Therapy 2010; 90(10): 1413-25.

48. Benett J, Lyons K, Winters-Stone K, Nail L, Scherer J. Motivational interviewing to increase physical activity in long-term cancer survivors. Nursing Research 2007; 56(18-27).

49. Damush TM, Perkins A, Miller K. The implementation of an oncologist referred, exercise self-management program for older breast cancer survivors. Psychooncology 2006; 15(10): 884-90.

50. Lusczcynska A, Gregajtys A, Abraham C. Effects of a self-efficacy intervention on initiation of recommended exercises in patients with spondylosis. Journal of Aging and Physical Activity 2006; 15: 26-40.

51. Basler HB, H, Quint S, Wilke A, Wolf U. TTM-based counselling in physiotherapy does not contribute to an increase of adherence to activity recommendations in older adults with chronic low back pain-a randomised controlled trial. European Journal of Pain 2007; 11(1): 31-7.

52. Martinus R, Corban R, Wackerhage H, Atkins S, Singh J. Effect of psychological intervention on exercise adherence in type 2 diabetes patients. Annals of the New York Academy of Sciences 2006; 1084: 350-60.

53. Hughes S, Seymour R, Campbell R, Pollak N, Huber G, Sharma L. Impact of the fit and strong interventionon older adults with osteoarthritis. The Gerontologist 2004; 44(2): 217-28.

54. Rowland JH, Kent EF, LP, Havard Loge J, et al. Cancer survivorship research in Europe and the United States: Where have we been, where are we going, and what can we learn from each other? Cancer 2013; 19(S11): 2094-108. 
Value-of-implementation analysis 


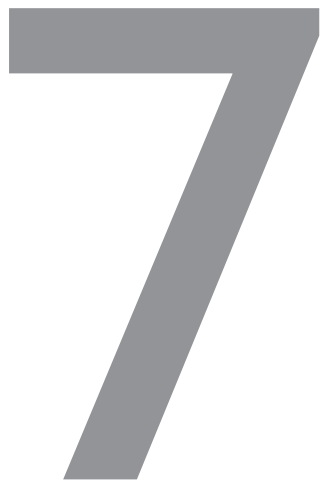

Discussion 



\section{Discussion}

To date, many eligible cancer survivors do not have access to cancer rehabilitation interventions. One explanation of this insufficient response to unmet needs is the lacking reimbursement for the largest group of cancer survivors by health insurance. Therefore, the aim of this thesis was to expand the evidence base on the cost-effectiveness and budget impact of cancer rehabilitation interventions and to advance the methodology for evaluating multicomponent interventions on their cost-effectiveness. The following section presents the main findings of this thesis after which the implications for policy and practice, the methodological considerations, and the suggestions for future research are discussed.

\section{Main findings}

In chapter two, the literature on the cost-effectiveness of rehabilitation for cancer survivors and on the effectiveness of multidimensional cancer rehabilitation was systematically reviewed. The results showed that the evidence base on the costeffectiveness of cancer rehabilitation for patients and survivors was rather small. When the interventions were found to be effective, they were also considered cost-effective or even cost-saving. The identified multidimensional rehabilitation interventions were effective, however, those studies that evaluated the effect of the multidimensional intervention compared to the single intervention found no additional benefit for the multidimensional interventions.

In chapter three, two interventions for alleviating treatment-induced menopausal symptoms in breast cancer patients, cognitive behavioural therapy and physical exercise, were evaluated on their cost-effectiveness. The interventions were compared to usual care and evaluated over a time horizon of five years. The ICER was $€ 22,500$ per QALY for cognitive behavioural therapy and $€ 28,000$ per QALY for physical exercise. Thus, both interventions were considered cost-effective at a prevailing threshold of $€ 30,000$ per QALY?. The choice of the intervention can therefore be based on the individual preferences of the survivor.

Multicomponent interventions ( $\mathrm{MCl})$ are common in cancer rehabilitation, but a method

to estimate their cost-effectiveness in comparison to the single components, when head-to-head studies do not exist, is lacking. Therefore, such an approach was 
developed in chapter four. The approach explicitly is a pragmatic approach for use when a decision needs to be taken while full evidence is not (yet) available. It consists of six steps of which the first four lead to identifying the minimum effect that the $\mathrm{MCl}$ needs to attain in order to be considered cost-effective, given its costs and the willingness-to-pay for an additional unit of effectiveness. In step five, a qualitative but systematic assessment is made of how likely the $\mathrm{MCl}$ is to attain this effect size. Finally, the expected cost-effectiveness of the $\mathrm{MCl}$ can be compared to that of the single interventions. It can then be concluded which one should be adopted.

Chapter five presented the budget impact analysis of a multidisciplinary return-to-work intervention consisting of counselling sessions with an occupational physician and a supervised exercise programme. From the Dutch societal perspective, the intervention was cost-saving, as the productivity gains were much higher than the costs of the intervention. From the perspective of a hypothetical large cancer centre the budget impact was very high as most costs for the interventions are not reimbursed by health insurance. It was also analysed how the costs and financial rewards of providing returnto-work interventions were distributed among the involved stakeholders in several EUcountries. In most of them, the stakeholders paying for return-to-work interventions did not receive the financial benefits, which dis-incentivized their reimbursement.

In chapter six, an expected value of perfect implementation-analysis of strategies to further increase the adherence of professionals and patients to (the guideline on) physical exercise was conducted. Examples of such implementation strategies include audit and feedback, local opinion leaders, financial incentives provided to patients, or printed educational material. The expected value of perfect implementation, i.e. the health gains that are forgone by not increasing the adherence expressed in monetary terms, was $€ 293 \mathrm{~m}$. All but one of the nine strategies had a positive net benefit and could therefore be recommended. The motivational programme for patients had the highest net benefit, followed by electronic reminders systems for professionals. The latter also had the largest development costs. Because currently only a small part of the full potential of exercise interventions is realised due to low adherence rates, further implementation and research efforts should concentrate on developing strategies that are more effective in increasing adherence. 


\section{Implications for policy \& practice}

\section{Cost-effectiveness of cancer rehabilitation}

The systematic review on the cost-effectiveness of cancer rehabilitation in chapter two found that effective interventions typically are cost-effective. Two interventions that were not evaluated on cost-effectiveness previously, cognitive behavioural therapy and physical exercise for alleviating treatment-induced menopausal symptoms in breast cancer patients, were analysed in this thesis with the result that these also provide value for money. The same was found for eight of the nine implementation strategies that aim at increasing the adherence of patients and professionals to exercise interventions.

From these results it can be concluded that cancer rehabilitation generally, when the interventions are effective and do not have unusually high costs, is cost-effective. Thus, the criterion of being cost-effective can be considered fulfilled and is an argument for providing access to cancer rehabilitation for all cancer survivors who have a need for it and to include it into the package of reimbursed care.

\section{Implement comprehensive rehabilitation as stepped care}

In this thesis, the separate rehabilitation interventions for cancer survivors were found to be cost-effective. However, what is required in order to provide suitable rehabilitation is not a fragmented implementation of separate interventions, but a thorough assessment of the individual patient's need and a tailored rehabilitation programme that is available for all cancer survivors, irrespective of the location in which they are treated ${ }^{2,3}$. As cancer survivors mostly suffer from several symptoms, many would benefit from a multicomponent programme ${ }^{4,5}$. These may consist of various combinations of interventions, yet not all of these combinations have been evaluated on their costeffectiveness. This especially seems important because it was found in chapter two that multicomponent interventions not always have an added benefit compared to a single intervention. However, evaluating all possible combinations of interventions on their cost-effectiveness neither is efficient nor necessary, as an incredible and unrealistic amount of research would need to be conducted in order to establish the required evidence. Moreover, this information would be of very limited benefit for decisionmakers. The decision that needs to be taken is whether cancer rehabilitation should be provided as reimbursed care to survivors. This requires that individual treatment plans would generally be acknowledged.

Therefore, it is advised that cancer rehabilitation is implemented and reimbursed, but multicomponent interventions should be provided to cancer survivors as stepped care. 
This way, first, only one intervention is provided, which is targeted at the individual's primary need and proven (cost-)effective. Afterwards, it is assessed whether the need for the second additional intervention is still existent and if so an additional intervention may be prescribed, and so on ${ }^{6-8}$. By doing so, it is ensured that interventions are only used when patients have an indicated need, in which case it is likely that the intervention is effective and cost-effective for that patient. In cases where e.g. a hospital wishes to offer a certain intervention standardly as a multicomponent programme of which the cost-effectiveness is unknown, the approach developed in chapter four should be used. It can then be analysed if the intervention has the potential to be at least as costeffective as the single intervention.

\section{Affordability}

For cancer rehabilitation, affordability might be an issue, due to the high number of survivors, which will continue to grow in the years to come ${ }^{9}$. In chapter five, the budget impact of a multidisciplinary return-to-work intervention was analysed. It was found that the financial benefits in terms of productivity gains from survivors who are enabled to resume work earlier are so high, that the intervention has a negative budget impact, i.e. is cost-saving, from the societal point of view. As yet this is the only formally conducted budget impact analysis in cancer rehabilitation; no evidence exists on other interventions. However, it can be expected that other interventions are cost-saving as well: In chapter five, a more expensive intervention with average patient costs of $€ 1,500$ was evaluated. Other interventions evaluated in this thesis, such as physical exercise and cognitive behavioural therapy, have much lower average patient costs of less than $€ 200$. Thus, when these achieve the very small effect of enabling patients to resume work 6.7 hours earlier (i.e. €200 divided by productivity costs of $€ 30$ an hour ${ }^{10}$ ), they already are cost-saving from a societal perspective. Next to productivity benefits, savings in terms of reduced future health care costs would be realised. For example, a physical exercise intervention improves health in general and reduces the risk for a cancer recurrence or a second cancer $^{11}$ in addition to its primary effect of alleviating the symptoms for which it was prescribed. Considering the amount of costs that could be prevented (for example, one inpatient day in the hospital of $€ 460$ or in intensive care of $€ 2,200$, a visit to the GP of $€ 30$ or to the physiotherapist of $€ 40$, or an $E C$ visit of $€ 150^{10}$ ), it is very likely that other rehabilitation interventions are cost-saving as well.

The problematic part of the affordability of cancer rehabilitation thus does not lie in the size of the budget impact on societal level, as the interventions might result in large cost-savings, but in the distribution of the costs and financial benefits, as was shown in 
chapter five. Although cancer rehabilitation is assumed to be cost-saving from the societal perspective, this is not the case from the perspective of the stakeholders who pay for these interventions, such as hospitals. Therefore, the distribution of costs and financial benefits of the interventions should be adapted in order to make the financing of cancer rehabilitation more viable.

\section{Reimbursing cancer rehabilitation}

Based on the paragraphs above, it is recommended to implement guidelinerecommended cancer rehabilitation, as it is cost-effective and is expected to be costsaving from a societal perspective. In the long-run, implementing guideline-based cancer rehabilitation would lead to savings for the health insurances through better health of the survivors. From these savings, the costs for rehabilitation measures could be covered. However, the additional expenses occurring in the short-run need to be financed. Two possibilities exist; increasing the money that is coming in by raising the insurance premiums, or decreasing the money that is going out elsewhere. The latter option should be chosen as in the field of cancer care, possibilities for costs savings exist that would not lead to a lower quality of care. One example is introducing value based pricing, a payment mechanism in which drugs receive reimbursement based on their added benefit. Here, the benefit is defined much broader than in cost-effectiveness analysis. The drug is then priced accordingly ${ }^{12}$ 13. In addition, oncology is a field where overtreatment can be observed, especially for care at the end of life ${ }^{14-16}$.

In cancer, it can be seen very clearly that the focus of where the money goes is misaligned. What is happening at the moment is that first, many resources are spent on detecting if people have cancer and subsequently on cancer treatment and cancer drugs that often are not cost-effective. In the following, cancer survivors have finished treatment and could go back to their previous lives. However, many of them experience symptoms that prevent that they can pick up their daily life again and resume work, although cost-effective interventions are available. Thus, after a huge amount has been spent on detecting and curing cancer, insufficient reimbursement limits access of survivors to effective and cost-effective care for their late and long-term symptoms, because these are considered too expensive. This calls for a major rethinking of where the available resources are spent on. 


\section{Methodological considerations}

Throughout the chapters of this thesis, it was not always possible to take the heterogeneity among cancer survivors into account. Cancer survivors differ considerably in terms of cancer type, treatment received, treatment outcome, the phase of survivorship they are in, their age, their preferences for certain (forms) of interventions, etc. $^{17}$. It is thus important that this heterogeneity is taken into account. This is especially relevant for the cost-effectiveness, as the more an intervention matches the patient's needs, the more effective and therefore the more cost-effective it would be. Rather than finding "one-size-fits-all-approaches", solutions for the specific subgroups need to be found.

In the systematic review in chapter two it was found that the trials evaluating the multidimensional interventions often include all types of cancer survivors, as long as they were suffering from at least any two symptoms of a list. Moreover, most studies had included a majority of breast cancer patients. The explanation probably is that breast cancer has a high incidence and that the patients are in a relatively good condition compared to other cancer types, which enables them more often to be physically able to take part in interventions ${ }^{18}$. Therefore, the results of chapter two tell us which intervention on average has an effect in a broad patient group. But it does neither tell us if there were differences regarding the (cost-) effectiveness of the interventions depending on the subgroup, nor whether the patients' needs were met. For the models that were built in chapter five and six, data from the literature was used. This was the case in chapter five, for the effectiveness of the intervention. This again originates from a study which included a large majority of female and breast cancer patients ${ }^{19}$. In chapter six, several studies from two meta-analyses were used for analysing the QALY-gain of exercise interventions. All but one of these included only breast cancer patients $^{20,21}$. Therefore, it was not possible to draw conclusions specifically for certain subgroups of patients.

\section{Suggestions for future research}

\section{Evaluate cancer rehabilitation as a whole}

This thesis has provided evidence on the value for money of cancer rehabilitation, on the basis of which it is considered safe to conclude that it is cost-effective in most cases. 
This is especially the case when the interventions are effective, when patients have a need for the specific intervention, and when the interventions are inexpensive, e.g. when they are provided as a group intervention. If the current evidence still would be considered insufficient for assuming that cancer rehabilitation in general is costeffective, an economic evaluation of implementing the guideline as a whole, rather than of specific interventions, should be conducted. This would require a large research project in which the cost-effectiveness of the current situation in which only very few cancer survivors receive rehabilitation is compared to that in which all cancer patients are treated according to the guideline. This would be much more valuable than evaluating the separate interventions, as the decision that needs to be taken is whether to reimburse cancer rehabilitation in general. The intention of the Dutch guideline is that for every patient the rehabilitation need is assessed. If the patient requires rehabilitation, a tailored programme is prescribed ${ }^{3}$. This, however, is only possible when all kinds of interventions are available. Otherwise, the ability of the physician to prescribe the most suitable programme for the patient, taking into account the patient's preferences, would be limited. Moreover, the differences in the costs and cost-effectiveness of the various interventions in cancer rehabilitation are so small that it is inefficient to conduct thorough research projects and take reimbursement decisions for every single one of them.

\section{Explore the possibilities of e-health interventions}

A new form in which cancer rehabilitation can be provided is e-health. It could make cancer rehabilitation accessible for patients who live far away from treatment facilities or have limited transportation means. Also, many cancer survivors would prefer to not visit the hospital again for rehabilitation. Within the A-Care2-Move project, of which this research is part of, three IT-interventions were developed; (1) an interactive internet portal that aims to empower cancer survivors by improving their skills to cope with the disease, by providing knowledge on lifestyle changes that can positively influence the patient's health status, and by increasing their motivation ${ }^{22,23}$, (2) a telemonitoring device that supports patient in spreading their energy for activities throughout the day, and (3) a web-based exercise programme which patients can follow from home. Providing interventions as e-health might also reduce costs. However, previous research has shown that it is unclear if cost-savings are realised or if e-health adds costs by forming an addition to current health services rather than a replacement ${ }^{24-26}$. It therefore needs to be carefully analysed which e-health solutions in cancer rehabilitation can improve the provided care and are at least as cost-effective as the standard 
interventions. In the interpretation of the results of a cost-effectiveness analysis of the telemonitoring device and the web-based exercise programme it should be taken into account that for patients who are not mobile or live far away from a hospital that offers such an intervention, these might be the only possibilities to follow rehabilitation interventions.

\section{Implementation of cancer rehabilitation}

The analysis of the net benefit of implementation strategies for exercise interventions in chapter six showed that their effect on improving the adherence of health professionals was very small, between two and eleven per cent, which leaves a large potential for improvement. Thus, even when investing in these implementation strategies, only a small part of the potential health gains would be realized. It is therefore crucial to investigate and develop more effective implementation strategies. During the last years, many articles were published that analysed the association between patient characteristics and exercise adherence ${ }^{27,28}$. From these, interventions should be developed and evaluated on their effectiveness, in order to identify more effective implementation strategies. These also have the potential to further increase the costeffectiveness of exercise interventions, as these are most beneficial for those patients not contemplating exercise as yet, and when the cancer survivors participate in as many sessions as possible.

\section{Conclusion}

This thesis has set out to analyse the cost-effectiveness and budget impact of cancer rehabilitation interventions and strategies to implement these. From the results it can be concluded that cancer rehabilitation is very likely to be cost-effective from a societal perspective. As multicomponent interventions are not expected to always be costeffective, these should be implemented as stepped care or be evaluated on their estimated cost-effectiveness using the approach that was developed in this thesis. Based on this thesis' results, cancer rehabilitation can also be considered affordable, and most interventions are expected to even be cost-saving. Therefore, it is highly recommended to include cancer rehabilitation into the package of reimbursed care. However, the costsavings that would be realised in the long-run still would need to be financed in the short-run. 


\section{References}

1. Raad voor de Volksgezondheid en Zorg. Zinnige en duurzame zorg. Zoetermeer, 2006.

2. Schmitz KH, DiSipio T, Gordon LG, Hayes SC. Adverse breast cancer treatment effects: the economic case for making rehabilitative programs standard of care. Supportive Care in Cancer 2015; 23(6): 1807-17.

3. The Netherlands Comprehensive Cancer Organisation. Cancer rehabilitation nation-wide guideline. Utrecht: IKNL, 2011.

4. Cheng KKF, Thompson DR, Ling WM, Chan CWH. Measuring symptom prevalence, severity and distress of cancer survivors. Clinical Effectiveness in Nursing 2005; 9(3-4): 154-60.

5. Schmitz KH, Speck RM, Rye S, DiSipio T, Hayes S. Prevalence of breast cancer sequelae over 6 years of follow-up. The pulling through study. Cancer 2012; 118(8 Suppl): 2217-25.

6. Bower P. Stepped care in psychological therapies: access, effectiveness and efficiency: narrative literature review. The British Journal of Psychiatry 2005; 186(1): 11-7.

7. Broten LA, Naugle AE, Kalata AH, Gaynor ST. Depression and a stepped care model. In: O'Donohue WT, Draper C, eds. Stepped care and e-health, practical applications to behavioral disorders. New York: Springer; 2011: 1-328.

8. Von Korff M, Tiemens B. Individualized stepped care of chronic illness. The Western Journal of Medicine 2000; 172: 133-7.

9. Signaleringscommissie Kanker van KWF Kankerbestrijding. Kanker in Nederland tot 2020 - trends en prognoses. Amsterdam: Dutch Cancer Society, 2011.

10. Hakkaart-Van Roijen L, Tan SS, Bouwmans CAM. Manual for cost research: methods and standard cost prices for economic evaluations in health care. Diemen: Health Care Insurance Board, 2010.

11. Lahart I, Metsios G, Nevill A, Carmichael A. Physical activity, risk of death and recurrence in breast cancer survivors: a systematic review and meta-analysis of epidemiological studies. Acta Oncologica 2015; 54: 635-54.

12. Linley WG, Hughes DA. Societal views on NICE, cancer drugs fund and valuebased pricing criteria for prioritising medicines: a cross-sectional survey of 4118 adults in Great Britain. Health Economics 2013; 22(8): 948-64.

13. Sussex J, Towse A, Devlin N. Operationalizing value-based pricing of medicines: a taxonomy of approaches. PharmacoEconomics 2013; 31(1): 1-10. 
14. Earle C, Landrum M, Souza J, Neville B, Weeks J, Ayanian J. Aggressiveness of cancer care near the end of life: Is it a quality-of-care issue? Journal of Clinical Oncology 2008; 26(23): 3860-6.

15. Wedding U, Meran JG, Höffken K. Übertherapie in der Onkologie: Wann ist weniger mehr? Der Onkologe 2008; 14(7): 691-700.

16. Buiting HM, Rurup ML, Wijsbek H, van Zuylen L, den Hartogh G. Understanding provision of chemotherapy to patients with end stage cancer: qualitative interview study. BMJ Supportive \& Palliative Care 2011; 1(1): 33-41.

17. Hewitt M, Greenfield S, Stovall EE. From cancer patient to cancer survivor: lost in transition. Washington, DC: The National Academies Press; 2005.

18. Rowland JH, Kent EF, LP, Havard Loge J, et al. Cancer survivorship research in Europe and the United States: Where have we been, where are we going, and what can we learn from each other? Cancer 2013; 19(S11): 2094-108.

19. Thijs KM, de Boer AG, Vreugdenhil G, van de Wouw AJ, Houterman S, Schep G. Rehabilitation using high-intensity physical training and long-term return-towork in cancer survivors. Journal of Occupational Rehabilitation 2012; 22(2): 220-9.

20. Fong D, Ho J, Hui B, et al. Physical activity for cancer survivors: meta-analysis of randomised controlled trials. British Medical Journal 2012; 344(e70): 1-14.

21. Mishra S, Scherer R, Geigle P, et al. Exercise interventions on health-related quality of life for cancer survivors. Cochrane Database of Systematic Reviews 2012; (8): 1-379.

22. Kuijpers W, Groen WG, Loos R, et al. An interactive portal to empower cancer survivors: a qualitative study on user expectations. Supportive Care in Cancer 2015; 23(9): 2535-42.

23. Kuijpers W, Groen WG, Oldenburg HS, Wouters MW, Aaronson NK, van Harten $\mathrm{WH}$. Development of MijnAVL, an interactive portal to empower breast and lung cancer survivors: an iterative, multi-stakeholder approach. JMIR Research Protocols 2015; 4(1): e14.

24. Elbert NJ, van Os-Medendorp H, van Renselaar W, et al. Effectiveness and costeffectiveness of ehealth interventions in somatic diseases: a systematic review of systematic reviews and meta-analyses. Journal of Medical Internet Research 2014; 16(4): e110.

25. Black AD, Car J, Pagliari $C$, et al. The impact of eHealth on the quality and safety of health care: a systematic overview. PLoS Medicine 2011; 8(1): e1000387. 
26. Henderson C, Knapp M, Fernandez $J \mathrm{~L}$, et al. Cost-effectiveness of telehealth for patients with long term conditions (whole systems demonstrator telehealth questionnaire study): nested economic evaluation in a pragmatic, cluster randomised controlled trial. British Medical Journal 2013; 346: f1035.

27. Husebø A, Dyrstad S, Søreide J, Bru E. Predicting exercise adherence in cancer patients and survivors: a systematic review and meta-analysis of motivational and behavioural factors. Journal of Clinical Nursing 2012; 22(1-2): 4-21.

28. Kampshoff CS, Jansen F, van Mechelen W, et al. Determinants of exercise adherence and maintenance among cancer survivors: a systematic review. The International Journal of Behavioral Nutrition and Physical Activity 2014; 11: 80. 
Discussion 


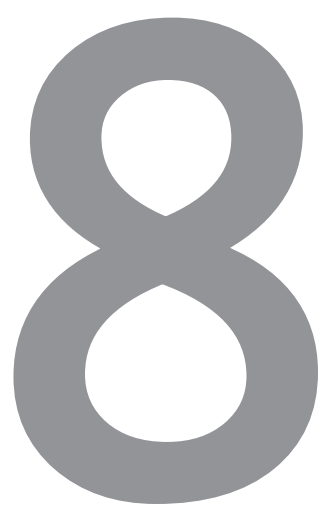

Summary 



\section{Summary}

\section{Introduction}

As the incidence of cancer is rising and more patients survive their disease, the number of people within the population who have a history of cancer is rising. The expected number for the Netherlands was 690,000 for 2015 and is supposed to have doubled since the year 2000. Unfortunately, most cancer survivors experience bothersome late and long-term symptoms, such as fatigue, low physical functioning, low quality of life, depression, anxiety, cognitive limitations, and pain. These prevent many of them from returning to their previous daily lives and often from returning to work. In order to alleviate the symptoms, survivors can follow a rehabilitation programme. However, these are not implemented widely. A major obstacle in the further implementation of cancer rehabilitation is the limited reimbursement by health insurance.

As the pressure on the health care budget is high, health services that are added to the Dutch health insurance scheme are assessed on their cost-effectiveness and affordability, next to the criteria of being necessary and effective. At the start of this research, the evidence base on the cost-effectiveness of cancer rehabilitation was very small. Therefore, the aim of this thesis was to increase the evidence base on the costeffectiveness and budget impact of cancer rehabilitation.

\section{Chapter 2: Systematic literature review}

In order to analyse what is already known and what the gaps in the evidence-base are, a systematic literature review was conducted on two topics; the effectiveness of multidimensional rehabilitation interventions for cancer survivors, consisting of at least two interventions, and the cost-effectiveness of rehabilitation interventions for cancer survivors and patients. On the effectiveness of multidimensional interventions, 16 articles could be included. Except for one study, significant improvements were found in the intervention groups, mostly for the outcomes fatigue, physical functioning, muscle strength, and energy levels. Interestingly, the articles that compared the effect of a multidimensional programme to one of the included single interventions did not find an additional effect for the multidimensional programme. On the cost-effectiveness of rehabilitation interventions six studies were included. The interventions were inexpensive, as the average costs per patient ranged from $€ 19$ to $€ 793$. All interventions

that were effective had favourable ICERs of $€-17,000$ (indicating cost-savings) to $€ 11,000$ 
per QALY. It was concluded that in the evaluation of multidimensional interventions it is important to compare these against doing-nothing and to the included single interventions, in order to identify if adding more components also results in higher effectiveness. This is especially important as adding more components in the majority of cases results in higher costs. When mono-disciplinary cancer rehabilitation interventions are effective, they have a great potential for being cost-effective.

\section{Chapter 3: Cost-effectiveness analysis of interventions to alleviate treatment-induced menopausal symptoms}

Many breast cancer patients experience early, treatment-induced menopausal symptoms caused by cancer treatment. Two promising non-pharmacologic treatment options for this patient-group are cognitive behavioural therapy (CBT) and physical exercise (PE). The aim of chapter four was to evaluate these on their cost-effectiveness. The cost-effectiveness was evaluated from the Dutch health care perspective over a 5year time horizon, comparing both interventions against usual care using a Markov model. The main outcomes were incremental treatment costs per significant reduction in endocrine symptoms and incremental treatment costs per QALY. The interventions were inexpensive, with costs of $€ 190$ for CBT and $€ 197$ for PE. The incremental costs for achieving a significant improvement in endocrine symptoms were $€ 1,100$ for CBT. PE was less effective than usual care. The ICER for CBT was $€ 22,000$ per QALY for CBT and $€ 28,100$ per QALY for PE. Thus, both interventions were cost-effective at a commonly accepted threshold of $€ 30,000$ per QALY. The conclusion of the analysis was that CBT is likely to be the most cost-effective intervention of the two. However, as CBT as well as PE are effective and cost-effective at the $€ 30,000 /$ QALY-threshold, both can be recommended. Thus, the choice for an intervention should be taken together with the patient and take into account his or her preferences.

\section{Chapter 4: An approach for estimating if multicomponent interventions are cost- effective}

For multicomponent interventions (MCls), evidence of their added effectiveness over one of the included single interventions often is not available, which prohibits an economic evaluation with the standard methods. Therefore, the aim of chapter four was to develop a pragmatic approach that allows estimating if a multicomponent intervention is more cost-effective than the included single interventions in the absence of full data on costs and effects. First, the literature was reviewed for methods that aim at solving similar methodological problems. Second, the requirements that the 
approach had to fulfil were identified by analysing the Dutch cancer rehabilitation guideline. Third, it was analysed which of the identified methods from the literature fulfilled the criteria. This applied to one approach, which subsequently was developed further into a fully suitable approach.

In the literature that was reviewed, six methods could be identified. These had to fulfil the following criteria: being able to estimate the cost-effectiveness of the single interventions vs. that of the $\mathrm{MCl}$ within a reasonable time frame, being able to estimate (cost-) effectiveness in the absence of full data, and being able to take into account carry-over and interaction effects. The only method that fulfilled all three criteria was headroom analysis, which was developed further into a fully suitable approach. The final approach starts by analysing the costs of all interventions, setting the willingness-to-pay, and choosing a common outcome measure for which the analysis is conducted. Subsequently, the minimum required effect for the $\mathrm{MCl}$ in order to be cost-effective, given its costs and the willingness-to-pay, is determined by headroom analysis. In the following, a qualitative but systematic assessment is conducted of how likely the $\mathrm{MCl}$ is to attain the minimum required effect. Finally, the MCl's likelihood for being costeffective is compared to the cost-effectiveness of the single interventions, which allows choosing which intervention is estimated to be the most cost-effective.

The approach was explicitly designed for use by decision-makers and hospitals for conducting a pragmatic and practical assessment that can be conducted within a short time frame and without advanced health economic expertise.

\section{Chapter 5: Budget impact analysis of a multidisciplinary return-to-work intervention}

As resuming work often is a very difficult process for cancer survivors, return-to-work interventions are designed to support them in this step. However, it is not clear whether these are affordable. Therefore, the first aim of chapter five was to analyse the budget impact of multidisciplinary return-to-work interventions. The second aim was to analyse the distribution of the costs and financial benefits of the intervention for several EUcountries, as this was expected to be an obstacle towards the implementation.

In the budget impact analysis the situation in which return to work is gradually implemented over 5 years from 2015 to 2020 was compared to the current situation. The analysis was conducted from the Dutch societal perspective and from that of a hypothetical large cancer centre. It is assumed that the intervention enables the participants to work 5.8 hours more per week than in usual care and that $12 \%$ of all cancer patients who are diagnosed per year are eligible for the intervention. For analysing the distribution of the costs and financial benefits of the multidisciplinary 
return-to-work intervention among the stakeholders, a survey was conducted among the members of the Organisation of European Cancer Institutes.

The average costs of the intervention were $€ 1,500$ per patient. From the Dutch societal perspective, the budget impact in 2020 would be $€-71.1 \mathrm{~m}$. This indicated that the intervention is highly cost-saving, as the productivity benefits outweighed the costs. For a hypothetical cancer centre, the budget impact would be $€ 1.1 \mathrm{~m}$ in 2020, since for most participants the costs are not reimbursed. The results from the questionnaire showed that in most countries, a disincentive to provide reimbursement for return-to-work interventions existed. In order to make the implementation more viable, the misalignment of costs and financial benefits needs to be solved.

\section{Chapter 6: Value of implementation analysis}

As not all professionals are adherent to diagnosing and prescribing physical exercise as recommended by the Dutch cancer rehabilitation guideline, and as survivors who are prescribed an exercise intervention often only have an average compliance, implementation strategies (ISTs) to further increase adherence are needed. The aim of chapter six was to evaluate several ISTs on their total net benefit.

In four steps, seven ISTs directed at health professionals and two directed on patients were evaluated by (1) analysing the expected value of perfect implementation (EVPIM) that represents the maximum cost an IST may have in order to be considered costeffective, (2) assessing the costs of the ISTS, (3) comparing the ISTs' costs to that of the EVPIM in order to determine if these are cost-effective, and (4) evaluating the ISTs on their total net benefit (TNB) to identify which of them has the greatest value.

The EVPIM, the value that would be realised by increasing the adherence from the current level of $45 \%$ to $100 \%$ was high, with $€ 293 \mathrm{~m}$ over the 5 -year period of guideline use. The costs of the ISTs ranged from €34k for printed educational materials to $€ 120 \mathrm{~m}$ for financial incentives for patients. Thus, all strategies could be considered costeffective. The TNB of the strategies was lowest for printed educational materials with $€ 5.7 \mathrm{~m}$ and highest for a motivational programme for patients with €100.4m and a reminder system for professionals with $€ 30.9 \mathrm{~m}$. Only financial incentives for patients had a negative TNB.

Based on the results, all ISTS, apart from financial incentives for patients, can unrestrictedly be recommended. The ISTs with the highest net benefits, the motivational programme and the electronic reminder system, also had the highest costs, which showed that large initial investments are worth their costs. 


\section{Discussion and conclusion}

The results of this thesis showed that rehabilitation for cancer survivors in general can be assumed to be cost-effective. The interventions are relatively inexpensive with average per patient costs ranging from €190 to €1,500 for the typical interventions. Thus, when they are effective the chances are high that they also are cost-effective. When survivors are prescribed more than one intervention, in the absence of evidence of that multicomponent intervention's cost-effectiveness, the intervention should be provided in the form of stepped cared. The reason here fore is that multicomponent interventions were found to not always be more effective than a single intervention. However, costs often do increase, which leads to lower cost-effectiveness overall. Another option is to conduct a comparison of the multicomponent intervention's cost-effectiveness against that of the single intervention using the approach that was developed in this thesis. Considering the affordability of cancer rehabilitation, a multidisciplinary return-to-work intervention was found to be highly cost-saving in this thesis. Thus, rather than adding costs, the intervention saves costs from a societal point of view. As it is expected that other interventions, such as exercise, lead to savings in terms of productivity gains and reduced future health care costs as well, it can be expected that these also are highly affordable to society. Thus, the criteria of being cost-effective and affordable that are required for reimbursed health services can be considered fulfilled.

Still, an issue in the financing and further implementation of cancer rehabilitation interventions is the misalignment of their costs and financial benefits among the stakeholders. Financing interventions, especially return-to-work programmes, would become much more feasible when employers and pension funds would take a share of the costs, as these benefit the most when their employees/clients resume work faster. Although being expected to be cost-saving in the long-term, adding cancer rehabilitation into the insurance scheme would result in increased expenses in the shortrun. Rather than increasing health insurance fees, cost-savings elsewhere in the field of cancer can be realised. Possibilities lie, for example, in the policy for reimbursing expensive cancer drugs. A re-thinking and societal and political debate about where the available resources should be spent on would need to take place in order to maximize the health gain that can be achieved with the available resources. 


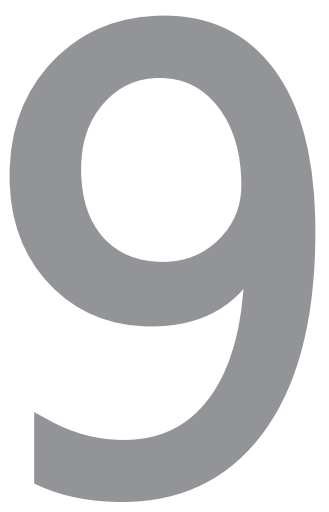

Samenvatting 



\section{Nederlandse samenvatting}

Doordat de incidentie van kanker stijgt en steeds meer kankerpatiënten hun ziekte overleven neemt hat aantal ex-kankerpatiënten binnen de bevolking toe. Naar schatting zijn dit 690.000 mensen in 2015, wat een verdubbeling sinds het jaar 2000 betekent. Helaas ervaren veel ex-kankerpatiënten na afloop van de behandeling late en langetermijn symptomen die door de ziekte zelf of door de behandeling zijn veroorzaakt, zoals vermoeidheid, slecht fysiek functioneren, lage kwaliteit van leven, depressie, angststoornissen, cognitieve problemen en pijn. Hierdoor kunnen veel patiënten niet terugkeren naar hun dagelijks leven van voor de ziekte en lukt het hen vaak niet om het werk weer op te pakken. De symptomen kunnen goed verholpen worden door revalidatie, alleen zijn revalidatieprogramma's voor ex-kankerpatiënten nog weinig beschikbaar. Omdat deze maar zelden door de zorgverzekeringen vergoedt worden verloopt de implementatie ervan moeizaam. Doordat de zorgkosten de laatste jaren snel gestegen zijn, moet zorg die in Nederland vanuit het basispakket vergoed wordt aan vier criteria voldoen. De zorg moet (1) nodig en (2) effectief zijn, maar ook (3) kosteneffectief en (4) betaalbaar zijn. Over de kosteneffectiviteit en betaalbaarheid van kankerrevalidatie was weinig bekend. Daarom was het doel van dit proefschrift om de kosteneffectiviteit en de budget impact van kankerrevalidatie te onderzoeken.

\section{Hoofdstuk 2: Systematische litertuurreview}

In dit hoofdstuk werd een systematische literaturreview uitgevoerd waarin het bestaande onderzoek over twee onderwerpen samengevat en geanalyseerd is; de effectiviteit van multidisciplinaire revalidatie-interventies voor ex-kankerpatiënten en de kosteneffectiviteit van kankerrevalidatieinterventies voor (ex-)kankerpatiënten. Met betrekking tot de effectiviteit van multidisciplinaire interventies werden 16 geschikte studies gevonden. Afgezien van één studie lieten alle onderzoeken significante verbeteringen in de interventiegroep zien, in het bijzonder voor vermoeidheid, fysiek functioneren, spierkracht, en energielevels. Interessant is dat in de weinige studies waarin multidisciplinaire interventies vergeleken werden met monodisciplinaire interventies, er voor eerstgenoemde geen toegevoegde waarde gevonden werd. In het tweede gedeelte over de kosteneffectiviteit van kankerrevalidatie werden zes geschikte studies geïncludeerd. De kosten per interventie waren met €19 tot €793 redelijk laag. Alle effectieve interventies hadden een acceptabele incrementele kosteneffectiviteitsratio (ICER) tussen $€-17.000$ (wat een kostenbesparing betekent) en $€ 11.000$ per quality- 
adjusted life year (QALY). Uit de review kwam naar voren dat het erg belangrijk is dat multidisciplinaire interventies met de aparte interventies waaruit ze bestaan vergeleken worden, om er op die manier achter te komen of de multidisciplinaire interventie daadwerkelijk een toegevoegde waarde heeft. Dit is bijzonder belangrijk omdat het toevoegen van een interventie aan al bestaande interventies in de meeste gevallen ook hogere kosten met zich meebrengt. Vanwege de lage interventiekosten is de kans groot dat, wanneer kankerrevalidatie effectief is, de interventie ook kosteneffectief is.

\section{Hoofdstuk 3: Kosteneffectiviteitsanalyse van cognitieve gedragstherapie en beweging}

Veel borstkankerpatiënten komen door hun behandeling vervroegd in de overgang en ervaren de daarmee gepaard gaande klachten, zoals hitteaanvallen en nachtzweten. Twee veelbelovende interventies voor deze patiëntengroep zijn cognitieve gedragstherapie (CGT) en beweging. Het doel van dit hoofdstuk was om deze twee interventies op hun kosteneffectiviteit te evalueren. Dit werd gedaan vanuit het perspectief van de Nederlandse gezondheidszorg over een tijdshorizon van vijf jaar, in vergelijking met een wachtlijstcontrolegroep. De uitkomstmaten waren onder andere incrementele zorgkosten per significante reductie in endokriene symptomen en incrementele kosten per QALY. De interventies hadden gemiddelde kosten per deelenemer van €190 voor CGT en €197 voor beweging. De incrementele kosten voor een significante reductie in de endokriene klachten waren $€ 1.100$ voor CGT. Voor deze klachten was beweging minder effectief dan de controlegroep. De ICER voor CGT en beweging bedroeg respectievelijk €22.000 en €28.100 per QALY. Beide interventies werden daarom kosteneffectief geacht bij een gebruikelijke drempelwaarde van €30.000 per QALY. Het is aan te bevelen de interventiekeuze ook op de preferenties van de patiënt te baseren.

\section{Hoofdstuk 4: Ontwikkeling van een benadering om multidisciplinaire interventies op} kosteneffectiviteit te onderzoeken

De toegevoegde waarde van een multicomponenteninterventie $(\mathrm{MCl})$ ten opzichte van een mono-disciplinaire interventie is vaak onbekend, waardoor de standaardmethoden voor economische evaluatie niet gebruikt kunnen worden. In hoofdstuk 4 werd een methode ontwikkeld waarmee de kosteneffectiviteit van een $\mathrm{MCl}$ in vergelijking met een monodisciplinaire interventie op een pragmatische manier geschat kan worden.

In een eerste stap werd de literatuur doorzocht naar methoden die soortgelijke beslisproblemen proberen op te lossen. Dit leverde zes methoden op. Om de criteria waaraan de methode moest voldoen vast te stellen werd de richtlijn voor oncologische 
revalidatie geanalyseerd. Deze criteria waren: (1) in staat zijn om de kosteneffectiviteit binnen een redelijke tijdsperiode te schatten, (2) in staat zijn om de kosteneffectiviteit te schatten wanneer niet alle data beschikbaar is, en (3) in staat zijn om met carry-over en interactie-effecten rekening te houden. Vervolgens werd gekeken welke van de gevonden methoden aan deze criteria voldeden. Dit was het geval voor één methodeheadroom analysis-die verder werd ontwikkeld, totdat ze helemaal geschikt was om het beslisprobleem op te lossen.

In de uiteindelijke methode worden als eerste de kosten van alle interventies in kaart gebracht. De betalings-bereidheid moet worden gekozen, alsmede één uitkomstmaat die voor alle interventies gebruikt wordt. Middels headroom analysis wordt het minimaal nodige effect dat de $\mathrm{MCl}$ moet halen om kosteneffectief te zijn vastgesteld, gegeven de kosten en de betalingsbereidheid. Vervolgens wordt een systematische, qualitatieve inschatting gemaakt van de waarschijnlijkheid dat de $\mathrm{MCl}$ dit effect bereikt. Aan het eind wordt deze waarschijnlijkheid vergeleken met de kosteneffectiviteit van de aparte interventies en kan geconcludeerd worden welke interventie volgens de schatting het meest kosteneffectief geacht wordt.

Deze methode is expliciet ontwikkeld voor het gebruik door beleidsmaker en ziekenhuizen. Deze kunnen hiermee op een pragmatische een praktische manier, binnen een korte tijdsperiode, een analyse uitvoeren die geen hele specifieke gezondheidseconomische expertkennis vereist.

\section{Hoofdstuk 5: Budget impact-analyse van een muldidisciplinaire werkhervattings- interventie}

Omdat het veel ex-kankerpatiënten niet lukt om naar het werk terug te keren zijn er werkhervattings(RTW)-interventies ontwikkeld die patiënten hierin ondersteunen. Helaas is het onduidelijkin in hoeverre deze betaalbaar zijn. Daarom was het eerste doel van dit hoofdstuk om dit middels een budgetimpactanalyse te onderzoeken. Omdat verwacht werd dat de verdeling van de kosten en financiële baten van de interventies tussen de betrokkene stakeholders ongelijk is, was het tweede doel om dit voor een aantal Europese landen in kaart te brengen.

De multidisciplinaire RTW-interventie bestond uit counseling met een bedrijfsarts en beweging. De situatie waarin de interventie gradueel werd ingevoerd over vijf jaar (2015-2020) werd vergeleken met de huidige zorg. De analyse werd uitgevoerd vanuit het perspectief van de Nederlandse maatschappij en een groot fictief kankercentrum. Om de verdeling van de kosten en financiële baten van de interventie tussen de 
stakeholders in kaart te brengen werd een enquete gehouden onder de leden van de Europese Organisatie van Kankercentra.

De gemiddelde interventiekosten waren $€ 1.500$ per deelnemer. Vanuit het Nederlands maatschappelijk perspectief zou dit leiden tot een budget impact van $€-71,1 \mathrm{~m}$. Dit betekent dat kosten bespaard worden omdat de toename in productiviteit meer dan opweegt tegen de interventiekosten. Omdat de kosten voor een groot gedeelte van de deelnemers niet vergoed worden, ontstaan er voor een fictief groot kankercentrum in 2020 kosten van $€ 1,1 \mathrm{~m}$. De uitkomsten van de enquete lieten zien dat in de meeste landen een negatieve prikkel bestaat voor het uitbreiden van de interventie. Om de implementatie en vergoeding haalbaarder te maken is het daarom aan te raden de kostenverdeling te veranderen.

\section{Hoofdstuk 6: Value of implementation-analyse}

Het feit dat in Nederland een richtlijn voor o.a. beweging in het kader van oncologische revalidatie gepubliceerd werd betekent niet automatisch dat ex-kankerpatiënten die ervoor in aanmerking komen ook een beweeginterventie voorgeschreven krijgen of dat de deelnemers volgzaam zijn aan de interventie. Het doel van hoofdstuk zes was om een aantal implementatie-strategieën (ISTS) die ervoor moeten zorgen dat de volgzaamheid van artsen en ex-kankerpatiënten omhoog gaat te onderzoeken op hun net benefit.

Dit werd gedaan in vier stappen: (1) een analyse van de expected value of perfect implementation (EVPIM) die de waarde uitdrukt die behaald zou worden bij 100\% volgzaamheid van professionals en patiënten, (2) het vaststellen van de kosten van de ISTS, (3) het vaststellen of de ISTs kosteneffectief zijn, en (4) het evalueren van de ISTS op hun total net benefit (TNB) om vast te stellen welke strategie het meest waardevol is. De TNB is de waarde die gecreëerd wordt door de IST door middel van het verhogen van de volgzaamheid.

De EVPIM was hoog; €293m over de 5-jaarsperiode die in de rijchtlijn gebruikt wordt voor een jaarlijks aantal van 50.000 patiënten. De kosten voor de ISTs lagen tussen €34k voor geprint educatiemateriaal en $€ 120 \mathrm{~m}$ voor financiële prikkels voor patiënten. Daarom konden alle strategieën als kosteneffectief worden beschouwd. De TNB van de ISTs was het laagsts voor het geprint educatiemateriaal en het hoogst voor een motivatieprogramma voor patiënten met $€ 100,4 \mathrm{~m}$, gevolgd door een softwareherinneringssysteem voor professionals met $€ 30,9 \mathrm{~m}$. De ISTs met de hoogste waardes, het motivatieprogramme en het herinneringssysteem, hadden tegelijkertijd ook de hoogste kosten. Dit laat zien dat de duurdere ISTs hun geld waard zijn. 


\section{Discussie en conclusie}

Op basis van de resultaten uit dit proefschrift kan ervan uitgegaan worden dat kankerrevalidatie kosteneffectief is. Met gemiddelde kosten per persoon van €190 to $€ 1.500$ voor de typische interventies zijn deze relatief goedkoop. Er kan geconcludeerd worden dat wanneer een interventie effectief is, deze met hoge waarschijnlijkheid ook kosteneffectief is. Voor multidisciplinaire interventies geldt dit niet, omdat deze niet altijd effectiever zijn dan monodisciplinaire interventies, maar meestal wel hogere kosten hebben. Daarom wordt aangeraden om multidisciplinaire interventies in de vorm van stepped care aan te bieden of deze voor de invoering op kosteneffectiviteit te onderzoeken door middel van de methode die in dit proefschrift zijn ontwikkeld. Wat betreft de betaalbaarheid van kankerrevalidatie kan gesteld worden dat in ieder geval de hier geëvalueerde interventie, multidisciplinaire werkhervatting, zichzelf meer dan terugverdient vanuit het maatschappelijk perspectief. Dit wordt ook voor andere interventies verwacht, zoals beweegprogramma's, omdat deze ook kunnen leiden tot een snellere terugkeer naar werk en tot het voorkomen van toekomstige zorguitgaven. Daarom kan geconcludeerd worden dat in het geval van revalidatie voor exkankerpatiënten aan de criteria van kosteneffectiviteit en betaalbaarheid voldaan is. Wat betreft de implementatie ervan bestaan er negatieve prikkels voor de betrokken stakeholders in het financieren van de interventies, wat een obstakel vormt voor verdere implementatie. Daarom is het nodig om de financieringsstructuur zodanig aan te passen dat ook werkgevers en pensioenfondsen meebetalen, wat zou leiden tot een evenredigere kosten- en batenverdeling. Ook al wordt verwacht dat de brede invoering van kankerrevalidatie leidt tot kostenbesparingen op de lange termijn, onstaan er op korte termijn kosten bij het volwaardig implementeren van kankerrevalidatie die toch betaald moeten worden. Bij voorkeur kunnen kostenbesparingen elders in de zorg voor kanker gerealiseerd worden, die geen afbreuk aan de kwaliteit hoeven doen. Mogelijkheden liggen hier bijvoorbeeld in het vergoedingsbeleid van dure medicijnen. Er moet goed nagedacht worden over waaraan het geld dat ter beschikking staat voor de zorg wordt uitgegeven om een zo groot mogelijke gezondheidswinst te realiseren. Een maatschappelijke en politieke discussie is hiervoor onontbeerlijk. 
Nederlandse samenvatting 
is

x"

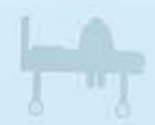

s

(x)

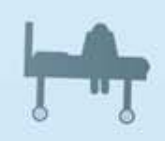

